\title{
1 Evolutionary analysis of LP3 gene family in conifers: an ASR homolog
}

2 Lecoy Jonathan ${ }^{1} \&$ García-Gil MR ${ }^{1}$

$3{ }^{1}$ Department of Forest Genetics and Plant Physiology, Umeå Plant Science Center, SLU,

4 Umeå, Sweden.

5 Corresponding author: Maria Rosario García-Gil, m.rosario.garcia@slu.se

6

7 


\section{Abstract}

Drought has long been established as a major environmental stress for plants which have in turn developed several coping strategies, ranging from physiological to molecular mechanisms. LP3; a homolog of the Abscisic Acid, Stress and Ripening (ASR) gene was first detected in tomato; and has been shown to be present in four different isoforms in loblolly pine called LP30, LP3-1, LP3-2 and LP3-3. While ASR has already been extensively studied notably in tomato, the same cannot be said of $L P 3$. Like ASR, the different $L P 3$ isoforms have been shown to be upregulated in response to water deficit stress and to also act as transcription factors for genes likely involved in hexose transport. In this study we have investigated the evolutionary history of $L P 3$ gene family, with the aim of relating it to that of $A S R$ from a phylogenetic perspective and comparing the differences in selective pressure and codon usage. Phylogenetic analyses of different $L P 3$ homologs compared to ASR show that $L P 3$ is less divergent across species than $A S R$ and that even when comparing the different sub-sections of the gene the divergence rate of $L P 3$ is lower than that of ASR. Analysis of different gene parameters showed that there were differences in $\mathrm{GC} 1 \%$ and $\mathrm{GC} 2 \%$ but not in total or GC3\% content. All genes had a relatively high CAI value associated with a low to moderate ENC value, which is indicative of high translation efficiency found in highly expressed genes. Analysis of codon usage also showed that $L P 3$ preferentially uses different codons than $A S R$. Selective pressure analysis across most of the LP3 and ASR genes used in this study showed that these genes were principally undergoing purifying selection, with the exception of LP3-3 which seems to be undergoing diversifying selection most probably due to the fact that it likely recently diverged from LP30 . This study thus provides insight in how ASR and LP3 have diverged from each other while remaining homologous.

Keywords: ASR, ABA/WDS, LP3, drought resistance, pine, selective pressures, codon usage, GC-content. 


\section{Introduction}

Land colonisation by plants during the Paleozoic has forced these to adopt several adaptive strategies to survive desiccation (Edwards and Selden, 1992). These strategies led to the development of organs such as roots for taking up water and the implementation of water stress management tactics like the closure of stomata and the modulation of osmotic pressures within the plant cell in an effort to maintain the plants' water potential (Chaves et al., 2003). Today, many plants species have adapted to be able to cope with drought through millennia of evolution, yet anthropogenic climate change is expected to dramatically affect the growth conditions of most plant species, notably through increased drought occurrence and aridity around the world.

Drought is a major hazard to the survival and development of commercially important plants, from both crops to forest tree species. In recent years, there has been an observed increase in drought occurrences notably in southern Europe, sub-Saharan Africa and many other areas around the world and this trend will only increase with time as climate change continues to progress (Gudmundsson and Seneviratne, 2016; Ruosteenoja et al., 2018). In this context, it is more important than ever to understand more about the mechanisms by which plants adapt and overcome water deficit stress in an effort to potentially produce more drought resistant varieties.

Water deficiency as a major stress for plant species is detected in many ways, with the signalling component being mediated largely through the phytohormone Abscisic acid (ABA) which is involved in stress response in plants, notably via its' effects on gene expression and osmotic pressure adjustment within the plant cell (Bray, 1993). ABA is also implicated in the plant response to cold stress and the ripening process. The ABA dependent pathway has been the focus of extensive studies in a multitude of species, notably Arabidopsis thaliana L. and

\section{Populus tremula L.}


Since the 1990s several research projects have focused on a drought responsive gene called Arabidopsis thaliana (Iusem et al., 1993). This research has led to the discovery of many different $A S R$ orthologues and paralogs, with tomato having five different $A S R$ genes, and rice up to six to date (Dominguez and Carrari, 2015; Frankel et al., 2006) .ASR1 in tomato has by far been the most studied ASR gene in tomato. Transgenic expression of the ASR gene in Arabidopsis produced a phenotype similar to what is observed in abi4 mutants in addition to an increased tolerance to salt, cold and other stresses (González and Iusem, 2014; Yang et al., 2005).

The ASR gene family contains a highly conserved midsection gene domain called the ABA/WDS domain is also expressed in mushrooms of the Fomitopsis genus, a membrane protein of Pseudomonas and angiomotin found in fern (Wang et al., 2002; Padmanabhan et al., 1997; González and Iusem, 2014). ASR in its native state is a disorganised, highly hydrophilic protein that requires two zinc ions to bind to lysine located in its $\mathrm{N}$-terminal region to adopt its functional conformation, which leads to a protein dimerization and in turn bind to the plants' DNA sequence (Goldgur et al., 2007; González and Iusem, 2014). ASR proteins act as transcription factors that induce the expression of aquaporines, cellulose synthases (CESA) and glucanases. $A S R 1$, the most studied of the $A S R$ genes, is for example involved in sugar metabolism in response to drought (Dominguez and Carrari, 2015). 
(González and Iusem, 2014; Padmanabhan et al., 1997; Wang et al., 2002). For the purposes of this study, while both genes are homologous, the terms $L P 3$ and ASR will be used to describe the gymnosperm and angiosperm sequences, respectively. $L P 3$ differs from $A S R$ in that it contains a consequent insertion of 35 amino acids between its N-terminal and ABA/WDS regions and is present as a gene family (each individual gene isoform is called $L P 3-0, L P 3-1$, $L P 3-2$ and $L P 3-3 ; L P 3-2$ and $L P 3-3$ have only been partially sequenced therefore only partial sequences are available) within pines and other gymnosperms (Chang et al., 1996; Padmanabhan et al., 1997). LP3 transport into the nucleus is mediated by the putative Cterminal Nuclear Localisation Signal (NLS) of sequence KKESKEEEKEAEGKKHHH (Padmanabhan et al., 1997; Wang et al., 2002). Alternatively, this NLS sequence might not be necessary due to the short size of the $L P 3$ protein which should allow it to diffuse through the nuclear envelope. Indeed research into ASR has shown that the NLS sequence to the one described above is not necessary for the ASR protein to diffuse into the nucleus (Ricardi et al., 2012). LP3 has not been as extensively studied as $A S R$, probably due to the difficulty of genetic studies within gymnosperms. This lack of study is the motivation for this study.

The objective of this research work is to investigate and compare the rate and mode of evolution of two orthologous genes $L P 3$ and ASR genes. To achieve our objective we have conducted the following actions: We have (i) retraced the phylogeny of $L P 3$ as a member of the ABA/WDS family and relate it to the ASR genes, (ii) estimated the GC content and Codon Usage Bias (CUB), and (iii) determined the mode of evolution of different subsections of the $A S R / L P 3$ genes. 


\section{Materials and Methods}

\subsection{Identification of LP3 and ASR genes}

110 Loblolly pine LP3-0, LP3-1, LP3-2 and LP3-3 CDSs were downloaded from NCBI

111 (Padmanabhan et al., 1997). Homologous angiosperm ASR and where possible gymnosperm

112 LP3 whole gene CDSs were then extracted from NCBI using these sequences as queries via

113 BLASTN in the NCBI database (Boratyn et al., 2013) with an e-value of $1^{\mathrm{e}-10}$ as a threshold.

114 More complete gymnosperm homologous sequences were also extracted via BLASTN in the

115 Gymno Plaza database(v1.0) (Altschul, 1997). For naming sequences in the instances where the

116 gymnosperm sequences were uncharacterized, comparison with loblolly pine LP3 sequences

117 via the NEEDLE alignment tool were done and whichever alignment had the highest score was

118 used to determine to which isoform the uncharacterized sequence was most likely to be

119 orthologous. Those sequences were then number as LP3-0-1, LP3-0-2, LP3-0-3 etc. according

120 to the species. Since LP3 and ASR are members of the ABA/WDS induced protein superfamily

121 (Chang et al., 1996; González and Iusem, 2014; Padmanabhan et al., 1997) care was taken to

122 ensure that all sequences retrieved contained the ABA/WDS domain using PFAM v.31

123 (Bateman and Finn, 2007; Mistry et al., 2007; Schaeffer et al., 2017). Sequence names and

124 accession numbers used in phylogenetic tree reconstruction according to species is shown in

125 the Supplementary Table 1. Supplementary Table 2 represents majorly represented species in

126 which three or more ABA/WDS genes are present and its use if further detailed in section 2.3.

\subsection{Phylogenetic analysis}

129 The phylogenetic history of LP3 and ASR was determined using MEGA X (Kumar et al., 2018).

130 Firstly, this was done by looking at the whole nucleotide sequences, then by looking only at the

131 conserved ABA/WDS region of the sequences, the conserved $\mathrm{N}$-terminal zinc binding region

132 before the gymnosperm insertion, and then finally by looking only at the variable C-terminal

133 NLS/DNA binding region of the sequences, producing a total of four different trees called 
134 FullSeq-tree, ABA/WDS-tree, N-tree and C-tree, respectively. The taxonomic phylogenetic

135 tree was constructed using the Timetree software (Kumar et al., 2017).

137 For FullSeq-tree, sequences were aligned using the MUSCLE algorithm (Edgar, 2004), checked

138 for errors and the multiple sequence alignment was exported for further analysis. The Maximum

139 Likelihood (ML) Phylogenetic best fit model was determined in MEGA X by log-likelihood

140 analysis of each model and the one with the highest AICc score was used. The resulting best fit

141 model for the sequences used in tree FullSeq-tree was the Kimura 2 parameter model. The

142 phylogenetic tree was created using the Maximum likelihood method combined with the

143 Kimura 2 parameter model with a gamma parameter of 1, 30 with 1000 permutations.

145 ABA/WDS-tree was constructed by isolating the highly conserved ABA/WDS nucleotide 146 domains from the MSA of $L P 3$ and ASR and exporting those for phylogenetic analysis. The ML

147 phylogenetic model was determined in the same manner as previously described, with the 148 resulting best model by log-likelihood analysis being the Kimura 2 parameter model. The tree 149 was constructed using the ML method with the Kimura 2 parameter with a Gamma parameter 150 equal to 1,0846 with 1000 permutations.

152 Tree N-tree was constructed by extracting the N-terminal nucleotide region of LP3 and ASR.

153 Due to the presence of incomplete sequences that did not cover this section of the gene, the

154 following sequences were excluded from the phylogenetic analysis: LP3-0 Cupressus

155 sempervirens; LP3-1 Pinus sylvestris; LP3-1 Pinus hwangshenensis; LP3-O Pinus

156 masssoniana; LP3-2 Pinus taeda; LP3-2 Pinus sylvestris and all LP3-3 sequences. The ML

157 phylogenetic model was determined in the same manner as previously described, with the 158 resulting best model by log-likelihood analysis result being the Kimura 2 parameter model. The 
tree was therefore constructed using the ML method with the Kimura 2 parameter model with a gamma parameter equal to 1,27 with 1000 permutations.

Tree C-tree was constructed by focusing on the C-terminal NLS/DNA binding regions of the sequences. The ML phylogenetic model was determined in the same manner as previously described, with the resulting best model by log-likelihood analysis result being the Kimura 2 parameter model. The following partial sequences were excluded from the phylogenetic analysis due to too short C-terminal sequences: LP3-O Cupressus sempervirens, LP3-0 Pinus masssoniana; LP3-2 Pinus taeda; LP3-2 Pinus sylvestris and all LP3-3 sequences. The tree was therefore constructed using the ML method with the Kimura 2 parameter model with a gamma parameter equal to 1, 5588 with 1000 permutations. Analysis of gene duplication events and construction of the corresponding gene duplication tree was also carried out in MEGA X, using FullSeq-tree as a template on which to perform the analysis.

\subsection{GC\% and RCSU analyses}

174 Sequence names and accession numbers for determining GC and RCSU content according to species are shown in the Supplementary Table 2

The Relative Synonymous Codon Usage (RSCU) is a measure of the codon usage bias for a

178 particular amino acid. As such codon bias is can be a measure of how efficient and accurate a 179 given gene translation is. The RSCU of the ABA/WDS genes found in majorly represented species (species in which at least three different ABA/WDS genes are present) was extracted using MEGA X. The average RSCU values per amino acid were then calculated and used to

182 determine which codon was on average the most used in a particular gene. Codons with RSCU 183 values above 1 are abundant, whilst codons with RSCU values below 1 are less abundant. 184 Codons for Methionine and Tryptophane were not included since these amino acids are encoded 
by only one codon. Stop codons were not included either as they are only involved in transcription termination and therefore not in transcription efficiency. computed using CAICal (http://genomes.urv.cat/CAIcal/). The CAI is derived from the codon usage of highly expressed genes in organisms and is positively correlated with transcription levels. As such the CAI is often used as a proxy for expression levels (Sharp and Li, 1987). The

ENC is a number corresponding to the overall codon bias in a given gene, with 20 symbolising

194 a complete bias of only one codon per amino acid whereas a value of 61 symbolises a completely unbiased codon usage, with each available codon being used equally for a given amino acid (Wright, 1990). Statistical analyses were done in $\mathrm{R}$ using $\mathrm{p}=0,05$ as the significance threshold. Gene parameters were first compared using a Levene test to ensure variance equality performed in the case of ANOVA and a pairwise Wilcoxon test in the case of a Kruskal-Wallis.

201 Pearson correlations between the different gene parameters were also done. For this the different ASR and LP3 genes were grouped together.

\subsection{Mode of evolution of different subsections of the ASR/LP3 gene}

205 A codon-by-codon selective pressure analysis provides insights into which amino acids in a 206 protein are undergoing selective constraints or not. This in turn allows one to suggest which amino acids are likely to change over time. Visualisation of codon selective pressure as defined

208 by the ratio of synonymous to non-synonymous codons $\omega=d N / d S$ on the LP3-O gene was 209 done using the complete CDS of all LP3-O homologous sequences were uploaded to the 210 Selecton server for selective pressure analysis using the M8 model that allows for positive 
211 selection (Stern et al., 2007). The sequences were aligned in the server using the MUSCLE

212 algorithm (Edgar, 2004) and the Pinus taeda LP3-O CDS was set as the reference query.

213 Statistical analysis of the calculated selective pressure was also performed using Selecton with

214 default settings by calculating the log likelihood ratio between M8 and the null model M8a.

215 The same procedure was repeated for LP3-1, LP3-3, ASR1, ASR2, ASR3 and ASR4. P.taeda

216 LP3 and S. lycopersicum ASR sequences were set as references on which to visualise sites of

217 selective pressure. There were not enough $L P 3-2$ orthologous sequences for this analysis to be 218 performed on it.

\section{Results}

\subsection{Phylogenetic analysis of LP3 and ASR}

222 On a broad level, it can be seen that $L P 3-1$ is the most ancestral form of $L P 3$, from which $L P 3$ -

2 diverged, followed by LP3-O and LP3-3. The ASR gene phylogeny show that ASR4 is the

224 ancestral sequence in tomato, followed by $A S R 3$, being $A S R 2$ and $A S R 1$ the result of are more recent diverge event (Figure 1). The clear distinction between the ASR and LP3 seems to 


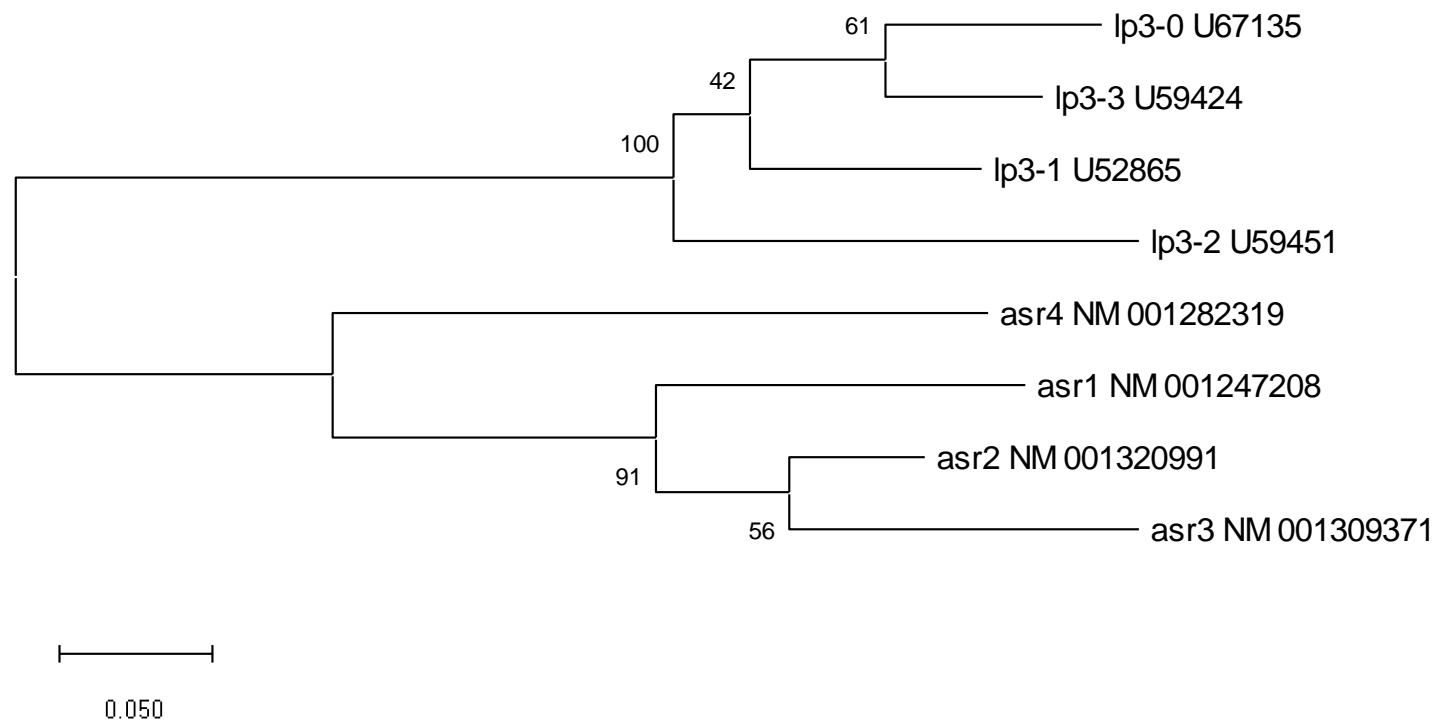

Figure 1: Phylogenetic tree of Pinus taeda LP3 and Solanum lycopersicum ASR sequences.

230 FullSeq-tree (Figure 2) shows that there is a clear divergence between the angiosperm ASR and

231 the gymnosperm LP3 sequences. This could be to certain extent be attributed to the sequence

232 insertion present between the N-terminal zinc binding domain and ABA/WDS regions in

233 gymnosperm. Low bootstrap values within the gymnosperm nodes could be explained by the

234 general high similitude between sequences which would result in them easily swapping 235 positions during different bootstrap analyses. It can be observed that the $L P 3$ sequences cluster 236 together according to genus and isoform. There is also perfect clustering of $L P 3-1$ and $L P 3-2$ 237 sequences within the Pinus cluster, however this is not the case when observing the LP3-3 238 cluster. In that instance, clustering of LP3-3 occurs with LP3-0-2 and LP3-0-3 of Pinus 239 sylvestris. This might be indicative of orthology between LP3-3 and the Pinus sylvestris 240 sequences shown. The grouping together of Pinus taeda LP3-3 and Pinus taeda LP3-0-2 with 241 a very high bootstrap score could suggest that LP3-0-2 (PITA_00002958) might be actually a 242 complete sequence of LP3-3. In Picea most of the sequences were annotated as LP3-0, except 
243 one sequence that was annotated as LP3-1 (MA45729). No LP3-2 and LP3-3 were available.

244 The ASR sequences also show clear clustering together of ASR1, ASR2 and ASR3 sequences.

245 The ASR1 of Oryza sativa, ASR3 of Zea mays, ASR2 of Vitis vinifera and ASR3 of Populus

246 trichocarpa show signs of divergence from the other ASR sequences. There are big genetic

247 distances between the different ASR clusters, indicative of substantial divergence between the

$248 \quad A S R$ genes in the angiosperms. 
bioRxiv preprint doi: https://doi.org/10.1101/2020.03.27.011197; this version posted March 29, 2020. The copyright holder for this preprint (which was not certified by peer review) is the author/funder, who has granted bioRxiv a license to display the preprint in perpetuity. It is made available under aCC-BY-NC-ND 4.0 International license.

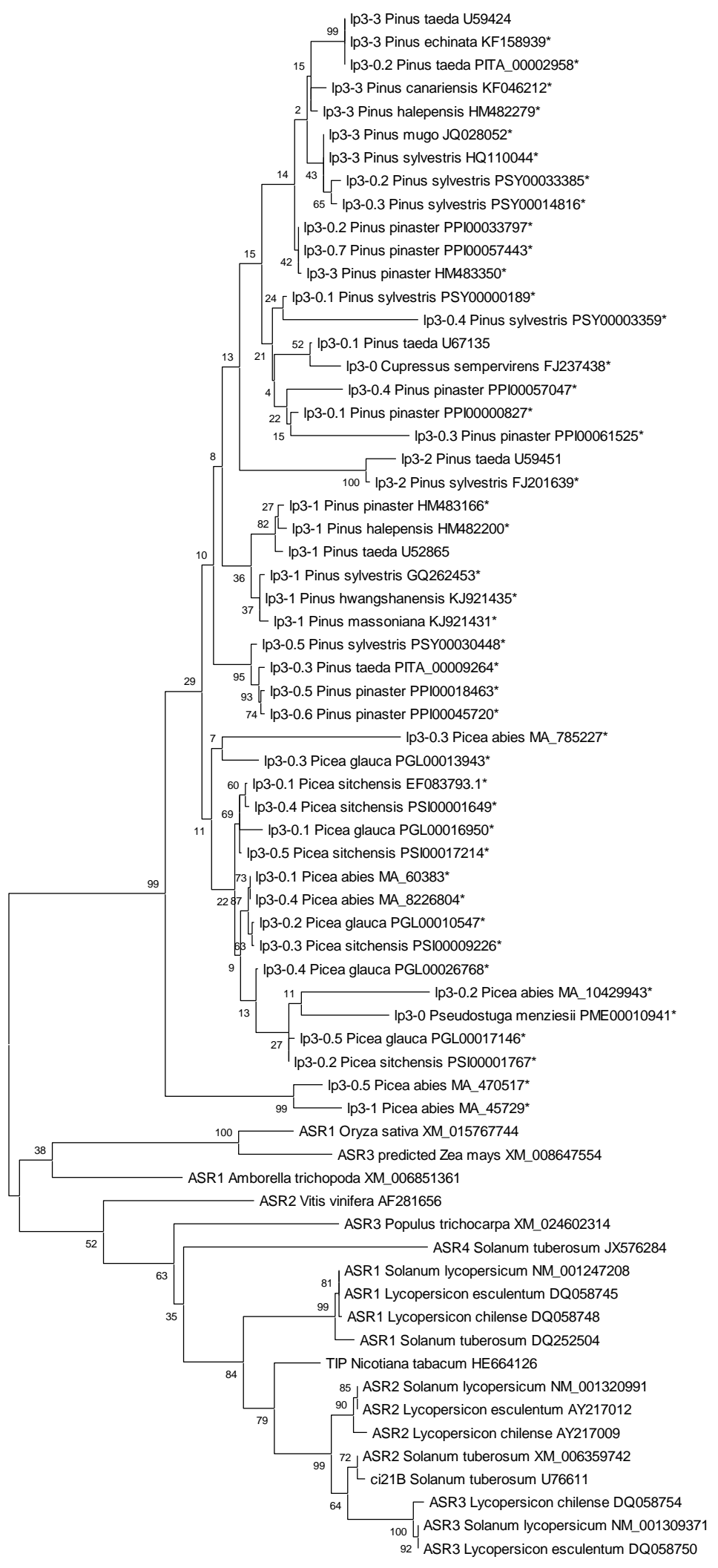


Figure 2: FullSeq-tree corresponding to the entirety of available CDS of ASR/LP3 sequences. Constructed in MEGAX using the ML method and the K2 model + gamma $=1,2882$. Genetic distance is given in number of substitutions per site. Bootstrap values are

253

254 Looking at ABA/WDS-tree (Figure 3) which focuses on the central ABA/WDS domain, there

255 is yet again another clear grouping of angiosperm and gymnosperm sequences together. Within

256 the gymnosperm grouping one can observe the sub-grouping of LP3-1 and LP3-2 together,

257 while similarly to FullSeq-tree, the LP3-3 sequences are again broadly grouped together with

258 some $L P 3-0$ sequences grouped alongside them. The angiosperm sequences also show clear 259 clustering of ASR1, ASR2 and ASR3 sequences with the Oriza sativa ASR1 and Zea mays ASR3

260 seeming to diverge from the other $A S R$ sequences. As in FullSeq-tree, there is also a clear 261 clustering according to genus, with Picea and Pinus sequences clustering together, respectively. 
bioRxiv preprint doi: https://doi.org/10.1101/2020.03.27.011197; this version posted March 29, 2020. The copyright holder for this preprint (which was not certified by peer review) is the author/funder, who has granted bioRxiv a license to display the preprint in perpetuity. It is made available under aCC-BY-NC-ND 4.0 International license.

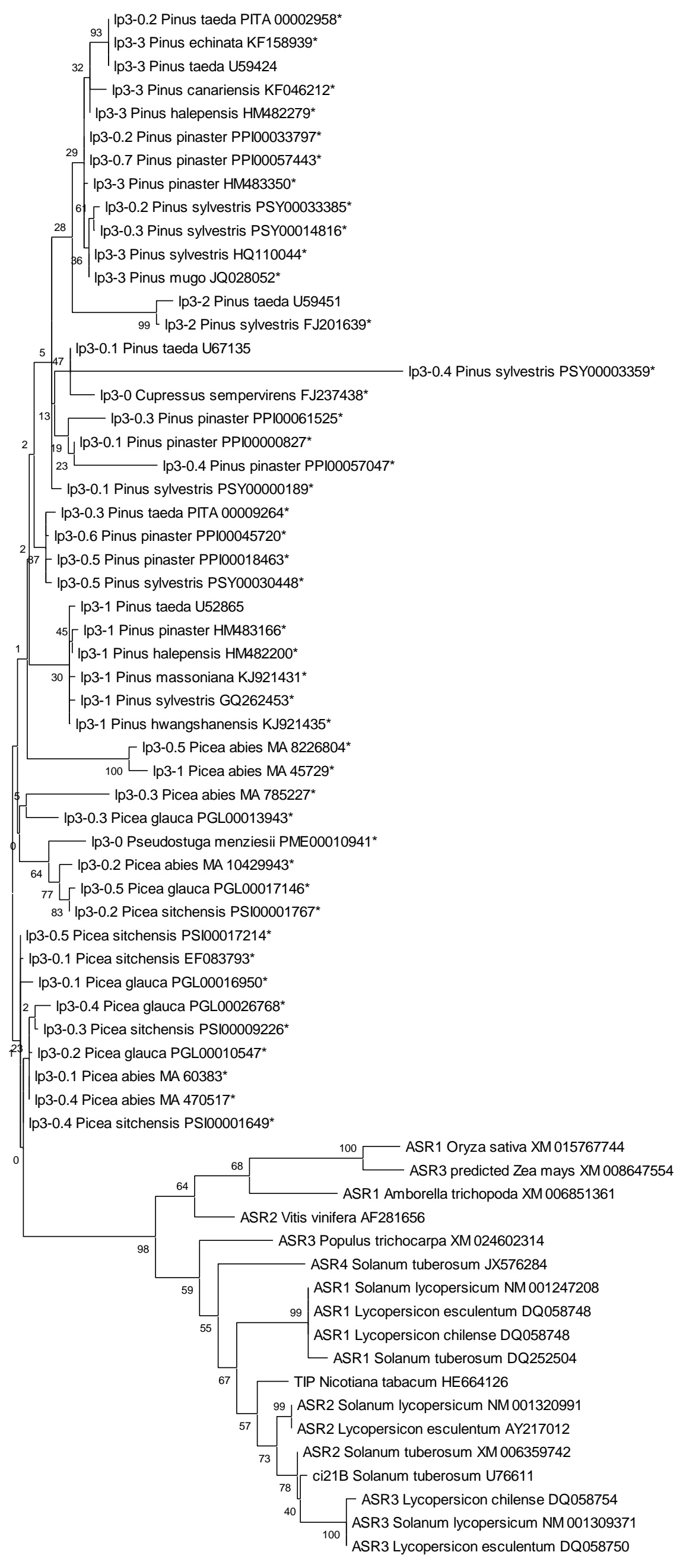


Figure 3: ABA/WDS-tree focusing on the conserved ABA/WDS domain within each gene. Constructed in MEGAX using the ML method and the K2 model with gamma=1,0846. Genetic distances are in number of substitutions per site. Bootstrap values are shown next to each node

$267 \mathrm{~N}$-tree focuses on the $\mathrm{N}$-terminal region of ASR and LP3, to which zinc ions are theorised to 268 bind (Figure 4), here it can be observed that there is not a definite separation between 269 angiosperm and gymnosperm sequences, with ASR2 from Vitis vinifera and ASR4 from 270 Solanum tuberosum being the most divergent sequences when focusing on the N-terminal 271 region. LP3-1 sequences in Pinus formed a different cluster although with low support. After 272 this node, ASR and LP3 sequences mostly segregate according to their order. Like the trees 273 previously analysed, the $A S R$ sequences cluster according to $A S R 1, A S R 2$ and $A S R 3$, with the Oriza sativa ASR1 and Zea mays ASR3 diverging together. In contrast to previous trees, there

275 is a less clear clustering of $L P 3$ sequences according to genus. There remains however a very 276 short genetic distance between each of the LP3 sequences, indicative yet again of a high level 277 of conservation between the sequences. 
bioRxiv preprint doi: https://doi.org/10.1101/2020.03.27.011197; this version posted March 29, 2020. The copyright holder for this preprint (which was not certified by peer review) is the author/funder, who has granted bioRxiv a license to display the preprint in perpetuity. It is made available under aCC-BY-NC-ND 4.0 International license.

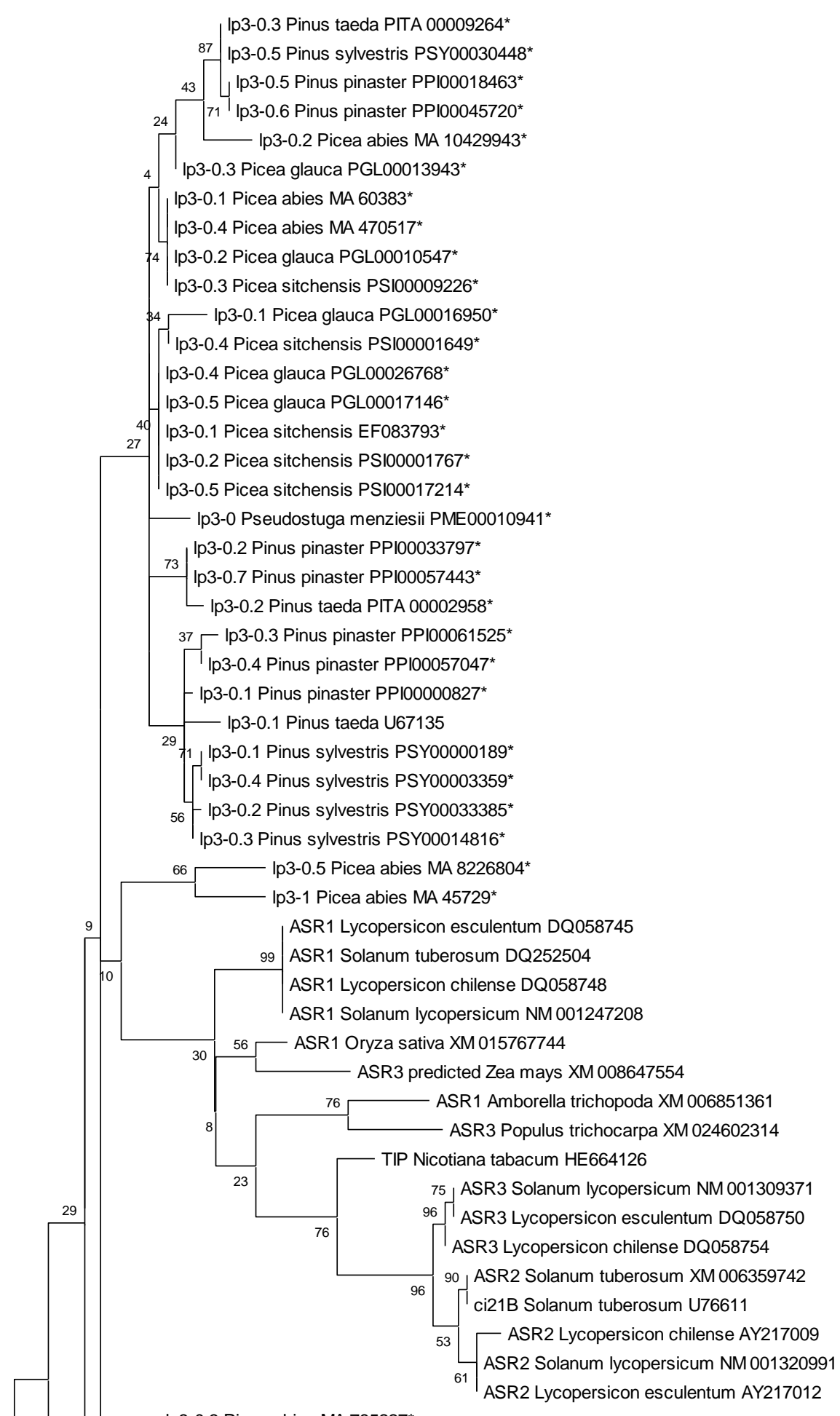

Ip3-0.3 Picea abies MA $785227^{*}$

Ip3-1 Pinus taeda U52865

- Ip3-1 Pinus halepensis HM482200*

Ip3-1 Pinus pinaster HM483166*

ASR2 Vitis vinifera AF281656

ASR4 Solanum tuberosum JX576284

0.20 
Figure 4: N-tree focusing on N-terminal of ASR and LP3 genes. Constructed with MEGAX and using the ML methodand K2 model with gamma =1,3701. Genetic distances are in number of substitutions per site. Bootstrap values are shown next to each node.

283 C-tree, which focuses on the variable C-terminal regions of $A S R$ and $L P 3$ which contains the

284 NLS/DNA binding domain (Figure 5), again shows partial segregation of $A S R$ and LP3 sequences. Here the tree is rooted by the ASR4 of Solanum tuberosum, LP3-0-3 Pinus pinaster and Picea abies LP3-0-2 and LP3-0-3 sequences, indicative that these sequences are the most divergent in the C-terminal NLS region. Subsequently, the ASR and LP3 sequences do segregate according to their order (similar to what can be observed for the other trees). Within the ASR

289 cluster the ASR1, ASR2 and ASR3 groups show low genetic distances, which suggests that the 290 C-terminal region of those sequences are well conserved. The LP3 C-terminal sequences also 291 do not show much divergence between them as seen by the small genetic distances between the 292 sequences. The exception are LP3-0-3, LP3-0-4 and LP3-0-2 sequences of Picea abies, which 293 show a high level of divergence from the other $L P 3$ sequences. The segregation within the $L P 3$ 294 sequences showed a similar clustering mostly according to the genus. 


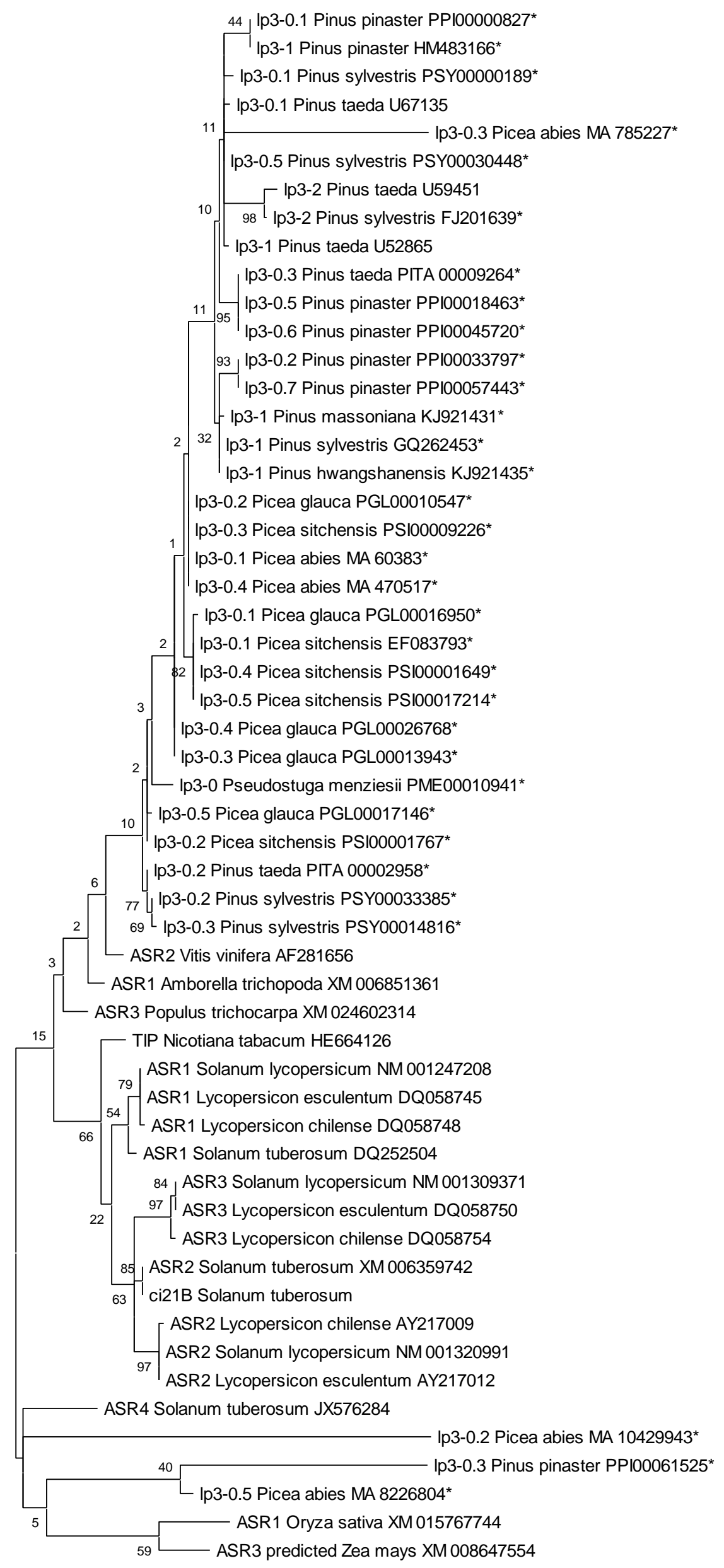


Figure 5: C-tree focusing on the C-terminal region of ASR and LP3 genes. Constructed with MEGA X and using the ML method with K2 model and gamma =1,5588. Genetic distances are in number of substitutions per site. Bootstrap values are shown next to each node

\subsection{Gene parameters and RSCU analyses}

301 There appear to be differences in average preferential codon usage between the different

302 ABA/WDS genes (Table 1, Figure 6). Both LP3_0 and LP3_3 have the same most highly used

303 codon AGG, encoding arginine, at RSCU values 3,71 and 6 respectively. LP3-2 and ASR2 both

304 preferentially use CCA, encoding proline, at RSCU values 4 and 2,77 respectively.

305 Furthermore, ASR2 has a second codon AGC, encoding serine, at RSCU 2,77. LP3_1, ASR3

306 and ASR4 have all got codons encoding for serine as their most used codons with codons UGC,

307 AGC and AGU at RSCU values 3,86, 3,27 and 2,8 respectively. There were similarities in

308 least used codons, such as the arginine encoding CGG and leucine encoding CUA.

\begin{tabular}{|l|l|l|r|}
\hline Gene & AA & Codon & RSCU \\
\hline ASR1 & Leucine & CUC & 2,63 \\
\hline ASR2 & $\begin{array}{l}\text { Proline, } \\
\text { Serine }\end{array}$ & $\begin{array}{l}\text { CCA, } \\
\text { AGC }\end{array}$ & 2,77 \\
\hline ASR3 & Serine & AGC & 3,27 \\
\hline ASR4 & Serine & AGU & 2,8 \\
\hline LP3_0 & Arginine & AGG & 3,71 \\
\hline LP3_1 & Serine & UCG & 3,86 \\
\hline LP3_2 & Proline & CCA & 4 \\
\hline LP3_3 & Arginine & AGG & 6 \\
\hline
\end{tabular}

Table 1: Average most used codon in ABA/WDS genes. 


\section{Average RSCU values} of ABA/WDS genes
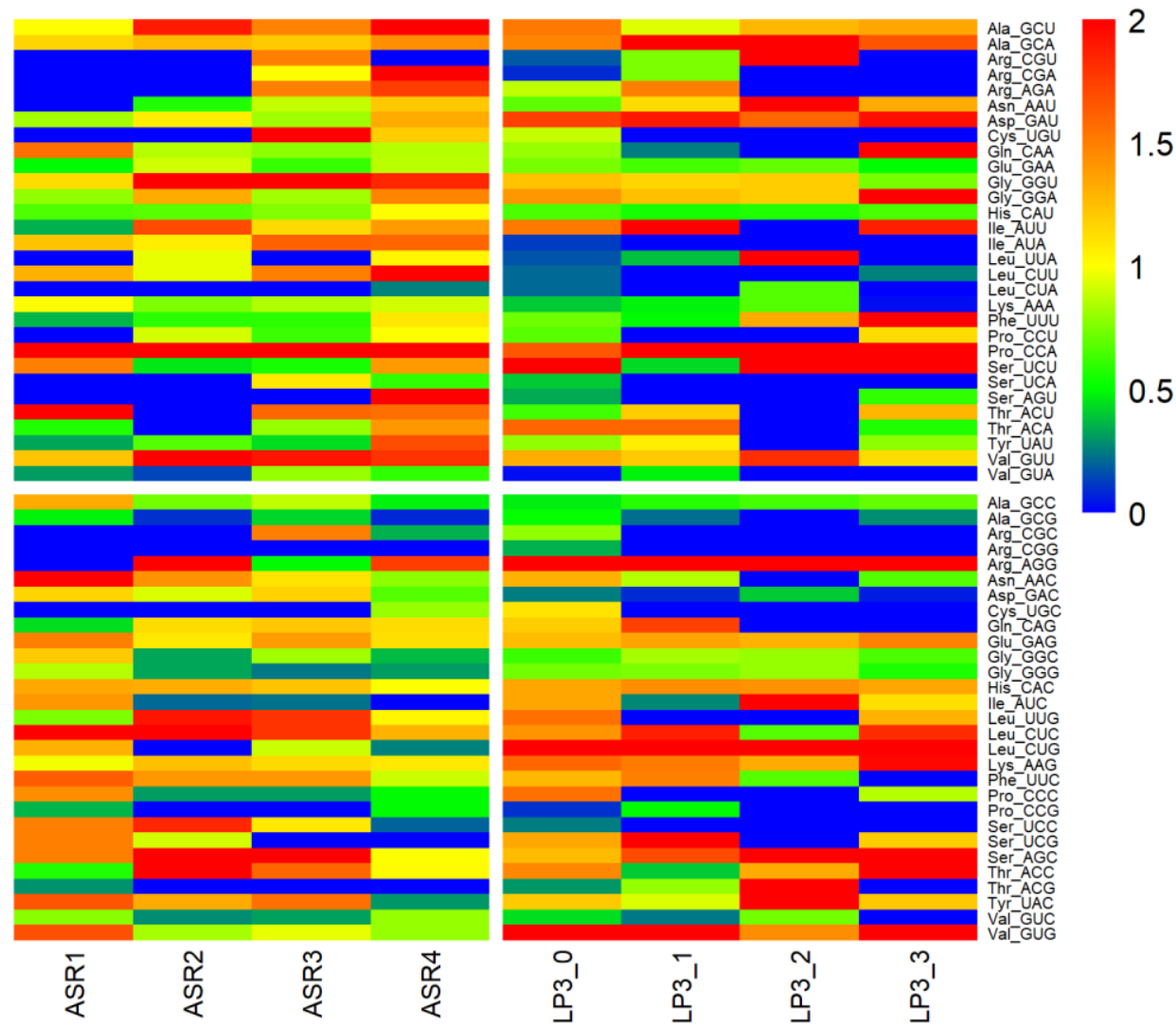

\section{.5}

$$
\text { (1) }
$$

\section{5}

Figure 6: Heatmap of average codon usage per ABA/WDS genes. Codons separated according to whether they are $A U$ or GC ended. Average codon usage above 1,5 are indicated in red while codon usage lower than 0,5 are indicated in blue. Produced in $R$.

314 In all cases, the average GC2\% of the ABA/WDS genes was lower than both average GC1\% 315 and GC3\%. With the exception of ASR1, all ABA/WDS genes had on average higher GC1\%

316 than GC3\% (Table 2). Levene test results showed that only GC1 and GC2 respected the equal

317 variance among groups assumption for ANOVA ( $\mathrm{p}>0,05)$. Total GC, GC3, ENC and CAI were

318 thus tested using a Kruskal-Wallis test. GC1, GC2 and CAI had significant differences between

319 the ABA/WDS genes $(\mathrm{p}<0,05)$ whereas total GC, GC3 and ENC showed no significant

320 difference between the ABA/WDS genes $(p>0,05)$. 


\begin{tabular}{|l|r|r|r|r|r|r|r|}
\hline Gene & Length(bp) & CAl & \multicolumn{1}{l|}{ GC\%tot } & GC1\% & GC2\% & GC3\% & ENC \\
\hline ASR1 & 323,25 & 0,8428 & 56,825 & 71,25 & 27,2 & 72,05 & 44,775 \\
ASR2 & 336 & 0,852 & 55,9 & 69,125 & 31,8 & 66,7 & 37,725 \\
ASR3 & 337,5 & 0,866 & 56,425 & 69,05 & 33,1 & 67,175 & 41,9 \\
ASR4 & 629 & 0,8217 & 43,46666667 & 56,5 & 36,6 & 37,33333333 & 50,03333333 \\
LP3_0 & 435,7 & 0,8472 & 50,69333333 & 64,76333333 & 30,43666667 & 56,89 & 51,02333333 \\
LP3_1 & 300,75 & 0,8528 & 51,25 & 68,975 & 27,875 & 56,975 & 42,4 \\
LP3_2 & 306 & 0,8435 & 51,6 & 71,95 & 29,35 & 53,5 & 53,9 \\
LP3_3 & 272 & 0,9073 & 52,83333333 & 67,73333333 & 35,43333333 & 55,43333333 & 37,33333333 \\
\hline
\end{tabular}

326 Analysis of GC1 (Figure 7) suggests that on average ASR1 and LP3_2 have a higher GC1\%

327 than LP3_0, which itself has a higher GC1\% than ASR4. ASR2, ASR3, LP3_1 and LP3_3 do

328 not have significantly different GC1\% from ASR1, LP3_2 and LP3_0.

\section{Average GC1\% content of ABA/WDS genes}

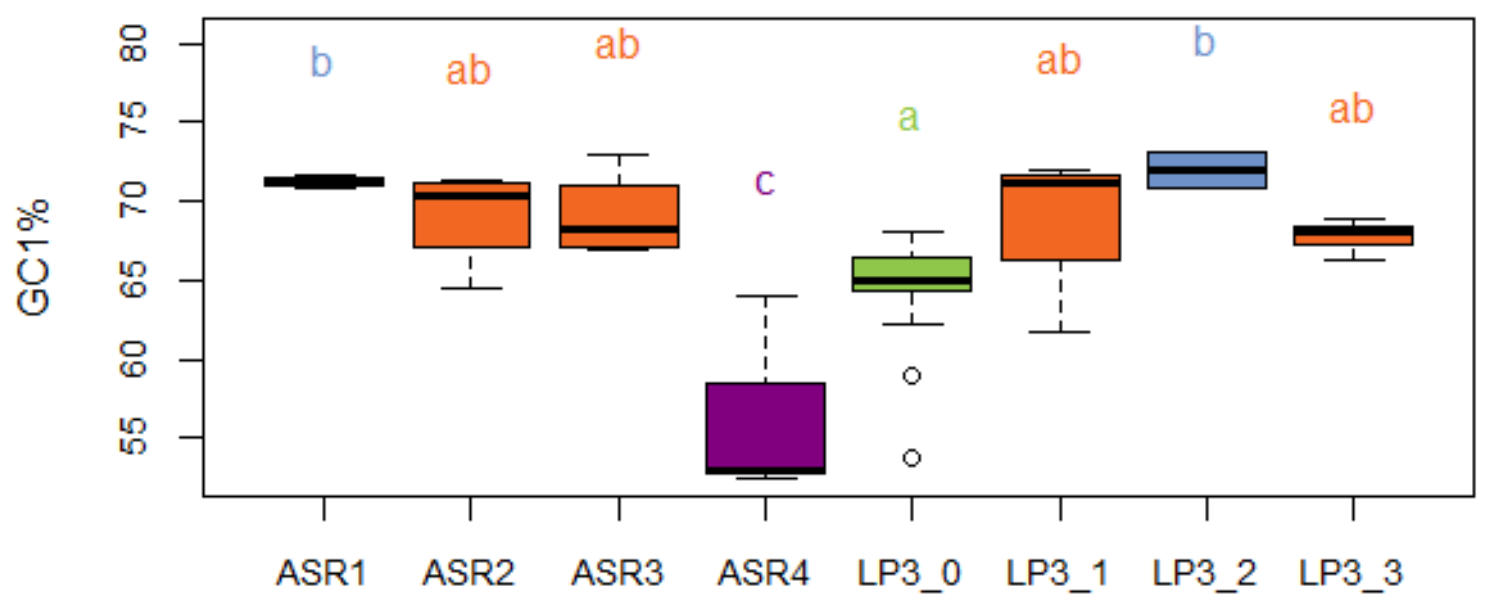

Genes

$330 \quad$ Figure 7: Comparison of the average GC1\% per ABA/WDS gene, done in R, using a one-way ANOVA followed 331 by Tukey HSD test.

332 Analysis of GC2\% (Figure 8) suggests that ASR4 has on average a significantly higher GC2\%

333 than ASR1, LP3_0, LP3_1 and LP3_2. In turn, this analysis suggests that on average LP3_3

334 has a significantly higher GC2\% than LP3_0. By contrast, ASR2, ASR3 and LP3_2 do not 335 appear to have significantly different GC2\% from each other. 


\section{Average GC2\% content of ABA/WDS genes}

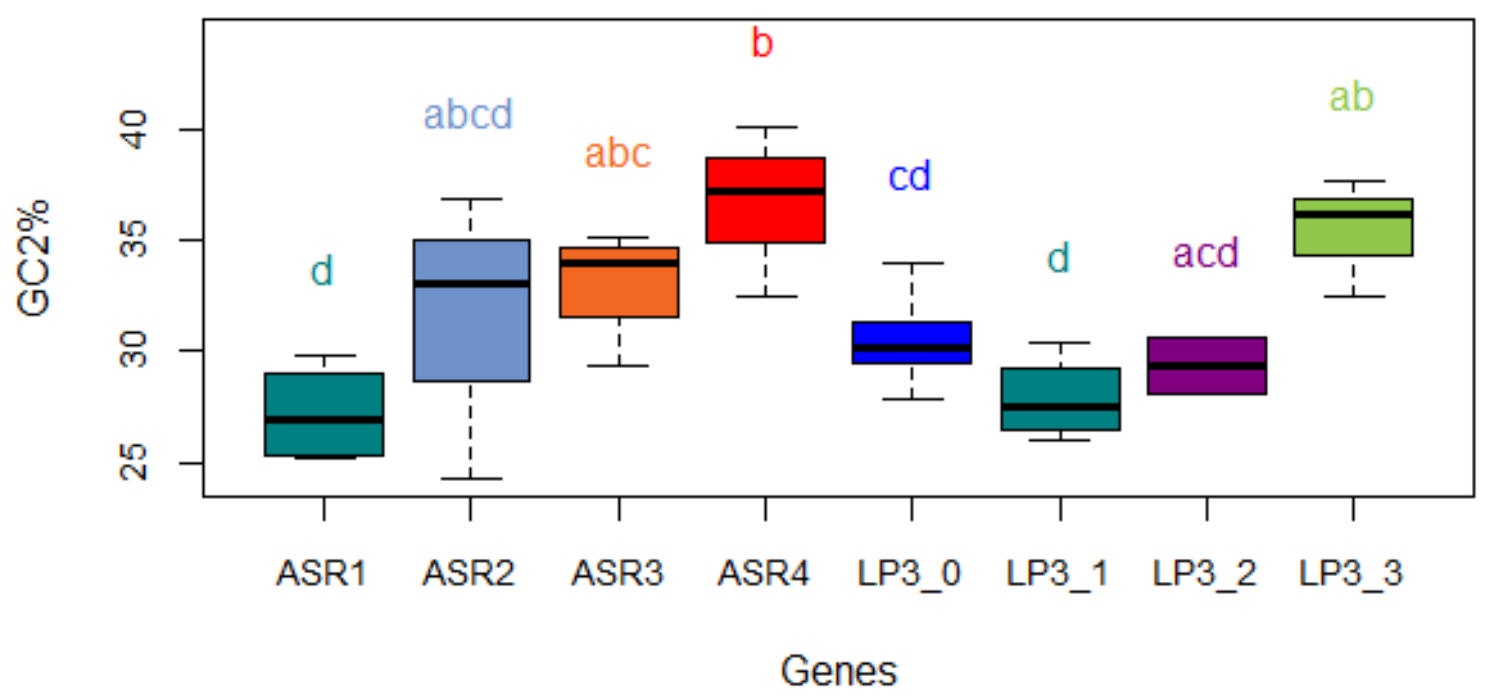

337 Figure 8: Comparison of the average GC2\% per ABA/WDS gene, done in R, using a one-way ANOVA followed 338 by Tukey HSD test.

339 There is also variation in the average CAI of ABA/WDS genes between the different majorly

340 represented species (Figure 9). Picea abies, Picea glauca, Populus trichocarpa, Solanum

341 lycopersicum and Solanum tuberosum have similar CAI levels to each other and are

342 significantly lower than Oryza sativa, Picea sitcchensis, Pinus pinaster, Pinus sylvestris, Pinus

343 taeda and Zea mays. Oryza sativa appears to have a significantly higher CAI than all other

344 species apart from Picea sitchensis, Pinus pinaster and Zea mays. Finally, Pinus sylvestris

345 appears to have a significantly lower average CAI than Pinus pinaster, Zea mays and Oryza

346 sativa, but is significantly higher on average than Picea abies, Picea glauca, Populus

347 trichocarpa, Solanum lycopersicum and Solanum tuberosum yet is not significantly different

348 from Picea sitchensis and Pinus taeda. 


\section{Average Codon Adaptive Index \\ of ABAWDS genes per Species}

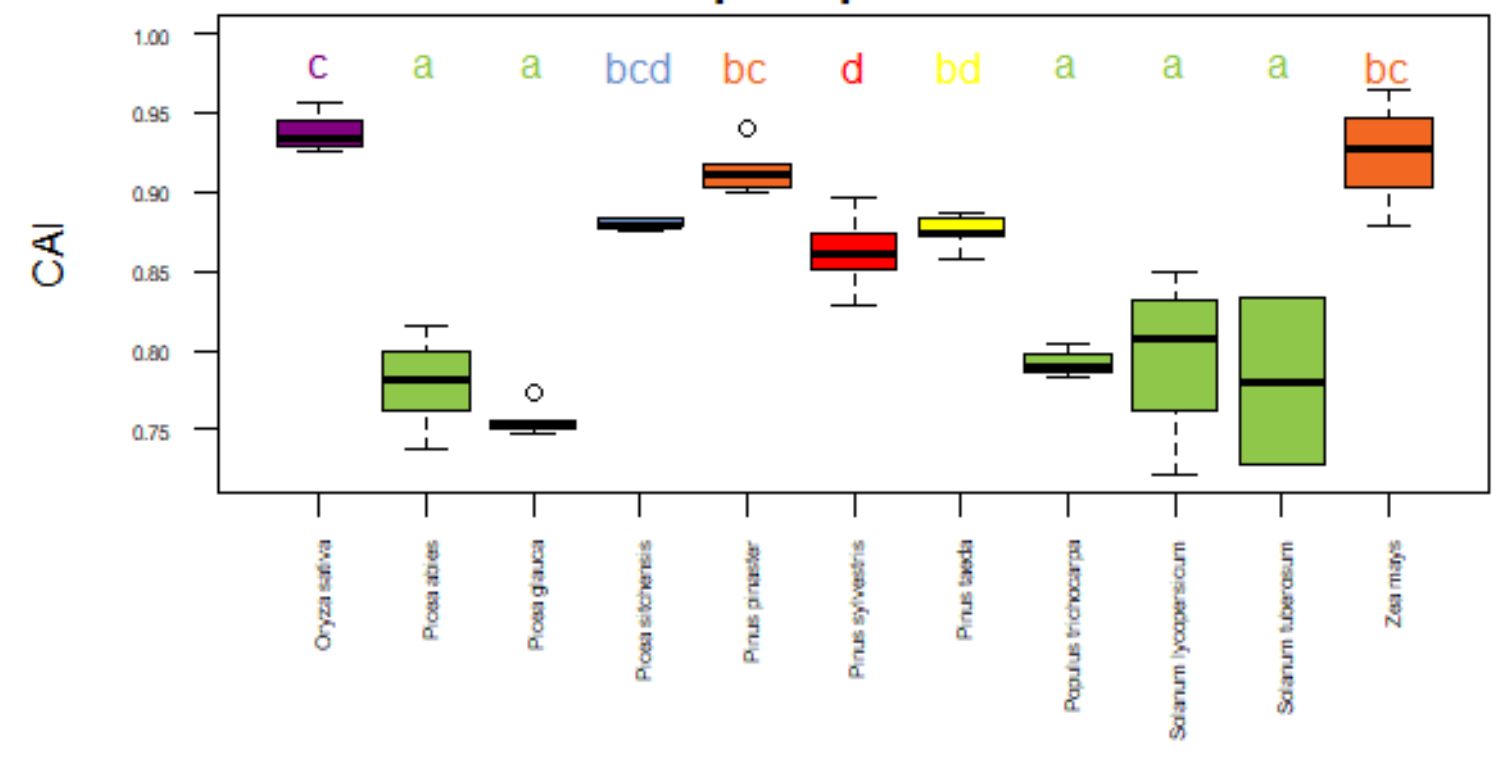

350 Figure 9: CAI per species of the ABA/WDS genes obtained from the values of majorly represented species, done in $R$, using a Kruskal-Wallis test followed by a pairwise Wilcoxon test.

353 Significant correlations were found between the different gene parameters in ASR and LP3

354 (Table 3; Table 4). In both ASR and LP3, gene length was negatively correlated with total $355 \mathrm{GC} \%, \mathrm{GC} 1 \%$ and positively correlated with ENC. CAI was positively correlated with total $356 \mathrm{GC} \%$ and GC3\% in ASR and was positively correlated with GC1\%. CAI was also negatively 357 correlated with ENC in both cases. Total GC\% was in turn positively correlated with GC1\% 358 and GC3\% in both ASR and LP3 genes however total GC\% was correlated with ENC in ASR 359 only. GC1\% was negatively correlated with GC2\% in both ASR and LP3 and positively 360 correlated with GC3\% in ASR only. GC3\% was negatively correlated with ENC in ASR but 361 displayed no significant correlation with ENC in LP3.

\begin{tabular}{l|lllllll} 
& Length & CAI & GC_tot & GC_one & GC_two & GC_three & ENC \\
\hline Length & & 0.5806 & 0.0413 & 0.0000 & 0.0294 & 0.0602 & 0.5827 \\
CAI & -0.14 & & 0.0001 & 0.4982 & 0.1384 & 0.0000 & 0.0000 \\
GC_tot & $\mathbf{- 0 . 5 0}$ & $\mathbf{0 . 8 0}$ & & 0.0182 & 0.5516 & 0.0000 & 0.0000 \\
GC_one & $\mathbf{- 0 . 8 9}$ & 0.18 & $\mathbf{0 . 5 6}$ & & 0.0048 & 0.0263 & 0.4806 \\
GC_two & $\mathbf{0 . 5 3}$ & 0.37 & 0.16 & $\mathbf{- 0 . 6 5}$ & & 0.5729 & 0.0572 \\
GC_three & -0.46 & $\mathbf{0 . 8 1}$ & $\mathbf{1 . 0 0}$ & $\mathbf{0 . 5 4}$ & 0.15 & & 0.0000
\end{tabular}


\begin{tabular}{l|llllll} 
ENC & 0.14 & $\mathbf{- 0 . 9 0}$ & $\mathbf{- 0 . 8 4}$ & -0.18 & -0.47 & $\mathbf{- 0 . 8 4}$
\end{tabular}

362 Table 3: Pearson correlation matrix of ASR genes. Correlation values indicated below diagonal and p-values

363 indicated above diagonal. Significant correlations shown in bold.

\begin{tabular}{l|lllllll} 
& Length & CAI & GC_tot & GC_one & GC_two & GC_three & ENC \\
\hline Length & & 0.5357 & 0.0284 & 0.0020 & 0.7432 & 0.6149 & 0.0018 \\
CAI & -0.10 & & 0.1385 & 0.0431 & 0.7252 & 0.6568 & 0.0004 \\
GC_tot & $\mathbf{- 0 . 3 5}$ & 0.24 & & 0.0000 & 0.8198 & 0.0000 & 0.3053 \\
GC_one & $\mathbf{- 0 . 4 8}$ & $\mathbf{0 . 3 3}$ & $\mathbf{0 . 5 8}$ & & 0.0110 & 0.9112 & 0.1220 \\
GC_two & -0.05 & 0.06 & 0.04 & $-\mathbf{0 . 4 0}$ & & 0.1903 & 0.5746 \\
GC_three & 0.08 & -0.07 & $\mathbf{0 . 6 5}$ & -0.02 & -0.21 & & 0.5214 \\
ENC & $\mathbf{0 . 4 8}$ & $\mathbf{- 0 . 5 4}$ & -0.17 & -0.25 & -0.09 & 0.11 &
\end{tabular}

364 Table 4 Pearson correlation matrix of LP3 genes. Correlation values indicated below diagonal and p-values

365 indicated above diagonal. Significant correlations shown in bold.

366

367

368

369

370

371

372

373

374

375

\subsection{Mode of evolution of different subsections of the ASR/LP3 gene}

The reference sequences of LP3-0, LP3-1, ASR1, ASR2, ASR3 and ASR4 show signs of purifying selection, mainly focused on $\mathrm{K}, \mathrm{H}$ and $\mathrm{E}$ residues, and no sites of positive selection (Figure 10, Figure 11, Figure 13, Figure 14, Figure 15, Figure 16; Supplementary Table $3,4,6,7,8,9)$. In contrast, $L P 3-3$ presents signs of positive selection on residues $\mathrm{N}, \mathrm{S}$ and $\mathrm{T}$ at positions 34, 37 and 61, respectively (Figure 12, ). These residues tend to turn into E, T and A, respectively $\left(\mathrm{w}\right.$-values $=2,8 ; 2,9 ; 2,9 ; \mathrm{p}$-values $=2,1 \times 10^{-14} ; 1,2 \times 10^{-19} ; 1,4 \times 10^{-19}$, Supplementary Table 5). On average, the ABA/WDS genes investigated here are all undergoing purifying selection, and all tend to similar amino acid sequences and codon usage as shown by the low $\mathrm{Ka} / \mathrm{Ks}$ values between gene pairs (Table 5).

\begin{tabular}{ll|llll}
\multicolumn{1}{l}{} & \multicolumn{1}{c}{ LP3-0 } & LP3-1 & LP3-2 & LP3-3 \\
\cline { 3 - 6 } U67135 & LP3-0 & & & & \\
U52865 & LP3-1 & 0.21 & & & \\
U59451 & LP3-2 & 0.74 & 0.53 & & \\
U59424 & LP3-3 & 0.35 & 0.28 & 0.74 &
\end{tabular}

\begin{tabular}{ll|llll}
\multicolumn{1}{c}{} & \multicolumn{1}{c}{ ASR1 } & ASR2 & ASR3 & ASR4 \\
\cline { 3 - 6 } NM001247208 & ASR1 & & & & \\
NM001320991 & ASR2 & 0.15 & & & \\
NM001309371 & ASR3 & 0.25 & 0.06 & & \\
NM001282319 & ASR4 & 0.16 & 0.10 & 0.21 &
\end{tabular}

377 Table 5: $1 \mathrm{Ka} / \mathrm{Ks}$ estimates between (a) LP3 genes in Pinus taeda, and (b) ASR genes in tomato. 


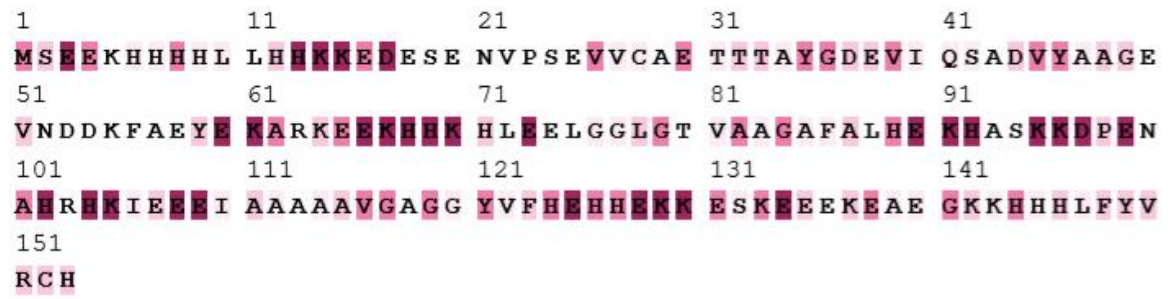

Figure 10: Selective pressures on LP3-0. Yellow colours indicate sites of positiveldiversifying selection; purple 380 colours indicate sites of purifying selection. Figure produced using Selecton.

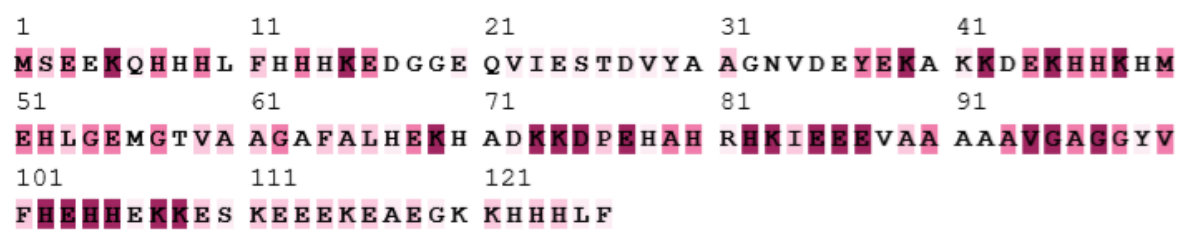

382 Figure 11: Selective pressures on LP3-1. Yellow colours indicate sites of positive/diversifying selection; purple



Figure 12: Selective pressures on LP3-3. Yellow colours indicate sites of positive/diversifying selection; purple 


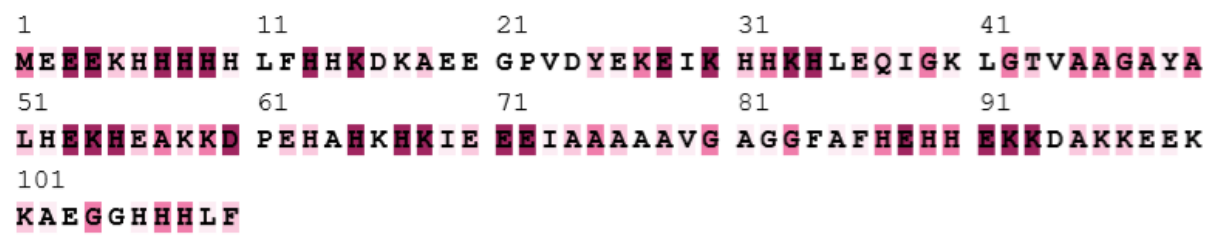

Legend:

The selection scale:

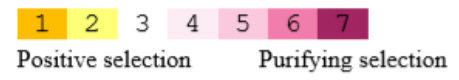

388 Figure 13: Selective pressures on ASR1. Yellow colours indicate sites of positive/diversifying selection; purple colours indicate sites of purifying selection. Figure produced using Selecton.

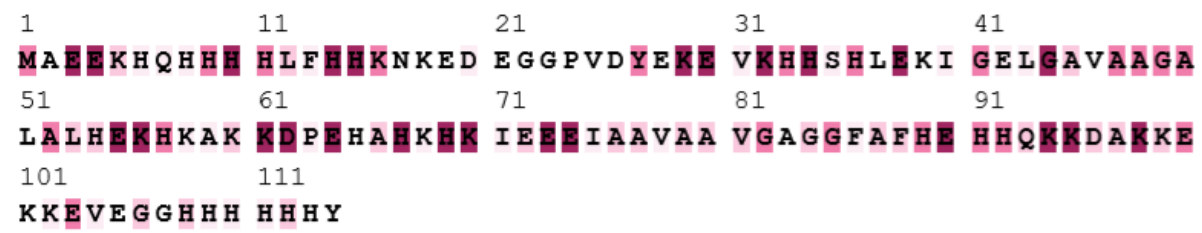

Figure 14: Selective pressures on ASR2. Yellow colours indicate sites of positiveldiversifying selection; purple 392 colours indicate sites of purifying selection. Figure produced using Selecton.

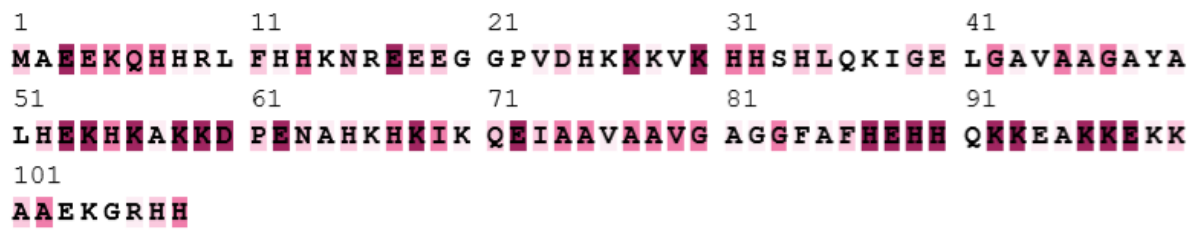

394 Figure 15: Selective pressures on ASR3. Yellow colours indicate sites of positive/diversifying selection; purple 395 colours indicate sites of purifying selection. Figure produced using Selecton. 


\begin{tabular}{|c|c|c|c|c|}
\hline$\perp$ & 11 & 21 & 31 & 41 \\
\hline MAEEKKH F & G L F N H KN KE & EDT P I EKTTY & EETTYEDSEK & TS TYGDNTYG \\
\hline 51 & 61 & 71 & 81 & 91 \\
\hline EKTSYGDDTY & GKKTTTYGDD & NKYSEKTSYG & DDTYEKTNT & YGDENKYGEK \\
\hline 101 & 111 & 121 & 131 & 141 \\
\hline TSYSEGDDN & YGEKTSYGGD & TYGEKPTSYG & GDNTYGEKTS & Y G G GDENKYG \\
\hline 151 & 161 & 171 & 181 & 191 \\
\hline EKT S GEKAS & $\overline{Y G G G D D N}$ & EKTSYGNEGG & GYGGGVGAYS & SETTTNYEN \\
\hline 201 & $\begin{array}{l}211 \\
\mathbf{Y}\end{array}$ & 221 & 231 & 241 \\
\hline 51 & 261 & 271 & 281 & 291 \\
\hline
\end{tabular}

397 Figure 16: Selective pressures on ASR4. Yellow colours indicate sites of positive/diversifying selection; purple

Legend:

The selection scale:

\begin{tabular}{llllll|l|l}
1 & 2 & 3 & 4 & 5 & 6 & 7
\end{tabular}

Positive selection Purifying selection

\section{Discussion}

\subsection{LP3 genes are less divergent than ASR genes}

402 While there is ample evidence that ASR and LP3 belong to the same gene family (González and

like the ABA/WDS domain. The separation between LP3 and ASR sequences are consistent

2015; Kumar et al., 2017).

410 The FullSeq-tree is corroborated by a previous study on ASR genes (Frankel et al., 2006). The

411 phylogenetic analyses of different sub-sections of the $A S R / L P 3$ genes provide insight into the

412 different divergence rates occurring within each of them. The ABA/WDS-tree, which focuses

413 on the ABA/WDS subsection, shows that there is very little divergence between the $L P 3$

414 sequences, unlike the $A S R$ sequences. This is indicative of a high level of similarity of the 
ABA/WDS domain within $L P 3$ that is not seen in ASR. This can be explained by the action of negative selection acting on the LP3 sequences, or that the rate of substitutions in gymnosperms is lower than in angiosperms (Palmé et al 2009; Buschiazzo et al 2012; De La Torre et al., 2017).

This low level of phylogenetic divergence within $L P 3$ can also generally be observed in the other two domain-based trees ( $\mathrm{N}$-terminal tree and $\mathrm{C}$-terminal tree). The $\mathrm{N}$-terminal tree focused on the putative zinc binding domains in the N-terminal region of ASR/LP3 genes, therefore it would make sense that there is a low level of divergence occurring since ASR/LP3 requires Zinc ions to adopt their functional conformation (Dominguez and Carrari, 2015; González and Iusem, 2014). A lack of clear segregation between ASR and LP3 can also be indicative of high purifying selective pressures thereby favouring a conserved nucleotide sequence. The lack of a definite separation between angiosperm and gymnosperm sequences is another argument in support of the essential and possibly similar role of the $\mathrm{N}$-terminal domain in both clades.

C-tree, which focused on the putative NLS/DNA binding region of ASR/LP3, reveals similar topological properties as the $\mathrm{N}$-tree but with a lower support to the branches discerning the different ASR gene family members. Both ASR and $L P 3$ encode relatively small proteins and in the case ASR1 it has been previously shown that it does not require its putative NLS to enter

433 the nucleus (Ricardi et al., 2012; Rom et al., 2006). This low level of divergence might indicate 434 that the selective pressures focusing on these parts of the genes stem mostly from their role as 435 transcription factors. Following this reasoning, it could be suggested that the sequence 436 corresponding to lp3-0-3 Picea abies targets a different gene somewhere along the genome 437 other than the LP3 gene family.

438 In all cases, it was observed that the LP3 genes had much lower divergence between them than the ASR genes. This is in line with previous research that found that coniferous genes have a 
440 low divergence rate among themselves when compared with angiosperm (Buschiazzo et al.,

441 2012). In addition to all the individual reasons listed previously, previous transcriptomic

442 analyses of homologous genes have shown that angiosperm genes tend to diverge much more

443 strongly than coniferous genes (Li et al., 2010). Our phylogenetic analyses are therefore in line

444 with previous known research.

ABA/WDS genes, there were differences in the GC1 and GC2 contents between genes. In all cases the GC2 was lower than both GC1 and GC3, a pattern which has been observed in other gene analyses (Song et al., 2017, 2018). In all the major species investigated, CAI was on average highest in Oryza sativa, which in turn can be used to predict that ABA/WDS expression levels are highest within Oryza sativa (Sharp and Li, 1987). Previous research on ASR expression in rice has shown that it responds strongly to drought stress (Pérez-Díaz et al., 2014),

so this high CAI is further indicative of high expression, which in turn lends credence to the other average CAI of ABA/WDS of the other investigated species being indicative of gene expression. It was interesting to see variations in CAI levels between the coniferous species, especially between the Picea and Pinus genuses, with Pinus species exhibiting higher CAI than Picea (except for Picea sitchensis). This in turn may be indicative that the ABA/WDS expression is higher in Pinus than in Picea, although a more thorough gene expression analysis within more species of each genus is required to confirm this hypothesis.

461 Previous gene studies have focused on the correlations of CAI with various other factors such 462 as gene length, GC content and ENC (Gun et al., 2018; Song et al., 2017, 2018; Zhou and Li, 463 2009). Our study however showed no significant correlation between sequence length and CAI.

464 CAI is often correlated with GC3\% yet this correlation was only significant when concerning 465 ASR genes and not the LP3 genes. Instead CAI was positively correlated with GC1\% in LP3, 
which contrasts with previous gene studies (Gun et al., 2018; Song et al., 2017, 2018). Our

study does reflect significant correlations between CAI and ENC within the ABA/WDS genes,

\subsection{ASR has a different codon usage than LP3}

471 Another factor that contributes to differentiate $A S R$ and LP3 gene families is the RSCU.

472 Differences in codon usage were observed for several amino acids. Yet it was interesting to see that the amino acid with the highest codon bias was serine, although the individual codon with

474 the highest bias was different among different genes. It has already been established that 475 monocots and dicots differ in their codon usage for the homologous genes (Campbell and 476 Gowri, 1990), therefore it is not improbable that gymnosperms would have different codon 477 usages than angiosperms for homologous genes. Highly expressed genes have been shown to have both a more pronounced codon bias and higher overall GC content compared to lowly expressed genes (De La Torre et al., 2015; Song et al., 2017; Kuzniar et al., 2008), however no

480 significant differences in overall average GC content between the ABA/WDS genes were observed in this study.

482 After gene duplication the original and new copies can go down multiple evolutionary paths 483 (Innan, Kondrachov, 2011). While LP3-3 and LP3-0 genes have seemingly diverged recently 484 they are affected by different modes of gene-duplication evolution. LP3-3 presents signs of 485 positive selection on three residues and the rest are evolving either under neutral or purifying 486 selection, whereas $L P 3-0$ is only affected by purifying selection.

487 In LP3-3 those three residues (mutation) may have introduced new beneficial functional aspects to the original $L P 3$ copy resulting in their fixation and maintenance through positive selection. This mode of gene-duplication evolution would suggest the acquisition of a novel 490 function for LP3-3 gene. Notably purifying selection is acting on Lysine (K), Histidine $(\mathrm{H})$ and 491 Glutamate (E). LP3 and ASR, both belonging to the ABA/WDS gene family, are both highly 
hydrophilic protein groups therefore the presence of charged, polar amino acids is important in attaining their functional conformations(González and Iusem, 2014; Rom et al., 2006).

494 It has also been suggested that Zinc ions bind to lysine residues in the N-terminal region of both conformation, thereby further explaining why mutations affecting Lysine are purified. Evidence of purifying selection can also be observed in both the ABA/WDS domain and C-terminal containing a putative NLS/DNA binding amino acid sequence, implying that both are important for the overall functioning of the genes. This is logical when considering that expressions of both $L P 3$ and ASR are upregulated in presence of ABA and that both act as transcription factors in response to water-deficit stress (Padmanabhan et al., 1997; Wang et al., 2002).

\subsection{Conclusion and future perspectives}

504 Overall, this study highly suggests that while ASR and LP3 may have originated from the same 505 common ancestor, they have undergone significant shifts in codon usage, maybe due to 506 different evolutionary constraints. Different ASR genes have already been studied in depth, with 507 ASRl being the most substantially studied of them. This is not the case for $L P 3$ for which more research opportunities are available. Further studies into LP3 mutants could produce similar phenotypes as observed in ASR mutants. Precise functions and genomic targets of LP3 could be hypothesized by homology with genes targeted by ASR. Precise mapping of the $L P 3$ genes onto the Pinus taeda genome should also be done. Further research could establish the presence of paralogous genes of $L P 3$ within Pinus taeda and their precise role in drought response. Since the responses of plants to cold stress are similar to their responses to drought stress, research

514 into how ASR and LP3 are affected in terms of expression and cellular function in conditions 515 of cold stress would also be an interesting research objective. Finally, a precise expression 516 network between ASR/LP3 and downstream targets should be established since these have not 517 yet been determined. 


\section{Conflict of interest}

519 No conflicts of interest during the making of this study.

520

\section{Acknowledgments}

522 We would like to thank Nicolas Delhomme and Sonali Ranade for bioinformatic support. We

523 would like to acknowledge the UPSC Vinnova Center for Forest Biotechnology. 


\section{References}

Altschul, S., 1997. Gapped BLAST and PSI-BLAST: a new generation of protein database search programs. Nucleic Acids Res. 25, 3389-3402. https://doi.org/10.1093/nar/25.17.3389

Bateman, A., Finn, R.D., 2007. SCOOP: a simple method for identification of novel protein superfamily relationships. Bioinforma. Oxf. Engl. 23, 809-814. https://doi.org/10.1093/bioinformatics/btm034

Boratyn, G.M., Camacho, C., Cooper, P.S., Coulouris, G., Fong, A., Ma, N., Madden, T.L., Matten, W.T., McGinnis, S.D., Merezhuk, Y., Raytselis, Y., Sayers, E.W., Tao, T., Ye, J., Zaretskaya, I., 2013. BLAST: a more efficient report with usability improvements. Nucleic Acids Res. 41, W29-W33. https://doi.org/10.1093/nar/gkt282

Bray, E.A., 1993. Molecular Responses to Water Deficit. Plant Physiol. 103, 1035-1040.

Buschiazzo, E., Ritland, C., Bohlmann, J., Ritland, K., 2012. Slow but not low: genomic comparisons reveal slower evolutionary rate and higher $\mathrm{dN} / \mathrm{dS}$ in conifers compared to angiosperms. BMC Evol. Biol. 12, 8. https://doi.org/10.1186/1471-2148-12-8

Campbell, W.H., Gowri, G., 1990. Codon Usage in Higher Plants, Green Algae, and Cyanobacteria. PLANT Physiol. 92, 1-11. https://doi.org/10.1104/pp.92.1.1

Chang, S., Puryear, J.D., Dias, M.A.D.L., Funkhouser, E.A., Newton, R.J., Cairney, J., 1996. Gene expression under water deficit in loblolly pine (Pinus taeda): Isolation and characterization of cDNA clones. Physiol. Plant. 97, 139-148. https://doi.org/10.1111/j.1399-3054.1996.tb00490.x

Chaves, M.M., Maroco, J.P., Pereira, J.S., 2003. Understanding plant responses to drought from genes to the whole plant. Funct. Plant Biol. 30, 239-264. https://doi.org/10.1071/fp02076

De La Torre, A.R., Li, Z., Van de Peer, Y., Ingvarsson, P.K., 2017. Contrasting Rates of Molecular Evolution and Patterns of Selection among Gymnosperms and Flowering Plants. Mol. Biol. Evol. 34, 1363-1377. https://doi.org/10.1093/molbev/msx069

Dominguez, P.G., Carrari, F., 2015. ASR1 transcription factor and its role in metabolism. Plant Signal. Behav. 10, e992751. https://doi.org/10.4161/15592324.2014.992751

Edgar, R.C., 2004. MUSCLE: multiple sequence alignment with high accuracy and high throughput. Nucleic Acids Res. 32, 1792-1797. https://doi.org/10.1093/nar/gkh340

Edwards, D., Selden, P.A., 1992. The development of early terrestrial ecosystems. Bot. J. Scotl. 46, 337-366. https://doi.org/10.1080/03746600508684794

Frankel, N., Carrari, F., Hasson, E., Iusem, N.D., 2006. Evolutionary history of the Asr gene family. Gene 378, 74-83. https://doi.org/10.1016/j.gene.2006.05.010

Goldgur, Y., Rom, S., Ghirlando, R., Shkolnik, D., Shadrin, N., Konrad, Z., Bar-Zvi, D., 2007. Desiccation and Zinc Binding Induce Transition of Tomato Abscisic Acid Stress Ripening 1, a Water Stress- and Salt Stress-Regulated Plant-Specific Protein, from Unfolded to Folded State. Plant Physiol. 143, 617. https://doi.org/10.1104/pp.106.092965

González, R.M., Iusem, N.D., 2014. Twenty years of research on Asr (ABA-stress-ripening) genes and proteins. Planta 239, 941-949. https://doi.org/10.1007/s00425-014-2039-9

Gudmundsson, L., Seneviratne, S.I., 2016. Anthropogenic climate change affects meteorological drought risk in Europe. Environ. Res. Lett. 11, 044005. https://doi.org/10.1088/1748-9326/11/4/044005

Gun, L., Yumiao, R., Haixian, P., Liang, Z., 2018. Comprehensive Analysis and Comparison on the Codon Usage Pattern of Whole Mycobacterium tuberculosis Coding Genome from Different Area. BioMed Res. Int. 2018. https://doi.org/10.1155/2018/3574976 
Hedges, S.B., Marin, J., Suleski, M., Paymer, M., Kumar, S., 2015. Tree of Life Reveals Clock-Like Speciation and Diversification. Mol. Biol. Evol. 32, 835-845. https://doi.org/10.1093/molbev/msv037

Iusem, N.D., Bartholomew, D.M., Hitz, W.D., Scolnik, P.A., 1993. Tomato (Lycopersicon esculentum) transcript induced by water deficit and ripening. Plant Physiol. 102, 1353-1354.

Kumar, S., Stecher, G., Li, M., Knyaz, C., Tamura, K., 2018. MEGA X: Molecular Evolutionary Genetics Analysis across Computing Platforms. Mol. Biol. Evol. 35, 1547-1549. https://doi.org/10.1093/molbev/msy096

Kumar, S., Stecher, G., Suleski, M., Hedges, S.B., 2017. TimeTree: A Resource for Timelines, Timetrees, and Divergence Times. Mol. Biol. Evol. 34, 1812-1819. https://doi.org/10.1093/molbev/msx 116

Li, X., Wu, H.X., Southerton, S.G., 2010. Comparative genomics reveals conservative evolution of the xylem transcriptome in vascular plants. BMC Evol. Biol. 10, 190. https://doi.org/10.1186/1471-2148-10-190

Mistry, J., Bateman, A., Finn, R.D., 2007. Predicting active site residue annotations in the Pfam database. BMC Bioinformatics 8, 298. https://doi.org/10.1186/1471-2105-8-298

Padmanabhan, V., Dias, D.M.A.L., Newton, R.J., 1997. Expression analysis of a gene family in loblolly pine (Pinus taeda L.) induced by water deficit stress. Plant Mol. Biol. 35, 801-807. https://doi.org/10.1023/A:1005897921567

Pérez-Díaz, J., Wu, T.-M., Pérez-Díaz, R., Ruíz-Lara, S., Hong, C.-Y., Casaretto, J.A., 2014. Organ- and stress-specific expression of the ASR genes in rice. Plant Cell Rep. 33, 61-73. https://doi.org/10.1007/s00299-013-1512-4

Ricardi, M.M., Guaimas, F.F., González, R.M., Burrieza, H.P., López-Fernández, M.P., JaresErijman, E.A., Estévez, J.M., Iusem, N.D., 2012. Nuclear Import and Dimerization of Tomato ASR1, a Water Stress-Inducible Protein Exclusive to Plants. PLoS ONE 7, e41008. https://doi.org/10.1371/journal.pone.0041008

Rom, S., Gilad, A., Kalifa, Y., Konrad, Z., Karpasas, M.M., Goldgur, Y., Bar-Zvi, D., 2006. Mapping the DNA- and zinc-binding domains of ASR1 (abscisic acid stress ripening), an abiotic-stress regulated plant specific protein. Biochimie 88, 621-628. https://doi.org/10.1016/j.biochi.2005.11.008

Ruosteenoja, K., Markkanen, T., Venäläinen, A., Räisänen, P., Peltola, H., 2018. Seasonal soil moisture and drought occurrence in Europe in CMIP5 projections for the 21st century. Clim. Dyn. 50, 1177-1192. https://doi.org/10.1007/s00382-017-3671-4

Schaeffer, R.D., Liao, Y., Cheng, H., Grishin, N.V., 2017. ECOD: new developments in the evolutionary classification of domains. Nucleic Acids Res. 45, D296-D302. https://doi.org/10.1093/nar/gkw1137

Sharp, P.M., Li, W.H., 1987. The codon Adaptation Index--a measure of directional synonymous codon usage bias, and its potential applications. Nucleic Acids Res. 15, 1281-1295.

Song, H., Gao, H., Liu, J., Tian, P., Nan, Z., 2017. Comprehensive analysis of correlations among codon usage bias, gene expression, and substitution rate in Arachis duranensis and Arachis ipaënsis orthologs. Sci. Rep. 7. https://doi.org/10.1038/s41598-01713981-1

Song, X., Ma, X., Li, C., Hu, J., Yang, Q., Wang, T., Wang, Li, Wang, J., Guo, D., Ge, W., Wang, Z., Li, M., Wang, Q., Ren, T., Feng, S., Wang, Lixia, Zhang, W., Wang, X., 2018. Comprehensive analyses of the BES1 gene family in Brassica napus and examination of their evolutionary pattern in representative species. BMC Genomics 19. https://doi.org/10.1186/s12864-018-4744-4 
621 Stern, A., Doron-Faigenboim, A., Erez, E., Martz, E., Bacharach, E., Pupko, T., 2007.

622

623

624

625

626

627

628

629

630

631

632

633

634

635

636

637 Selecton 2007: advanced models for detecting positive and purifying selection using a Bayesian inference approach. Nucleic Acids Res. 35, W506-W511. https://doi.org/10.1093/nar/gkm382

Wang, J.-T., Gould, J.H., Padmanabhan, V., Newton, R.J., 2002. Analysis And Localization of the Water-Deficit Stress-Induced Gene (lp3). J. Plant Growth Regul. 21, 469-478. https://doi.org/10.1007/s00344-002-0128-7

Wright, F., 1990. The "effective number of codons" used in a gene. Gene 87, 23-29. https://doi.org/10.1016/0378-1119(90)90491-9

Yang, C.-Y., Chen, Y.-C., Jauh, G.Y., Wang, C.-S., 2005. A Lily ASR Protein Involves Abscisic Acid Signaling and Confers Drought and Salt Resistance in Arabidopsis. Plant Physiol. 139, 836-846. https://doi.org/10.1104/pp.105.065458

Zhou, M., Li, X., 2009. Analysis of synonymous codon usage patterns in different plant mitochondrial genomes. Mol. Biol. Rep. 36, 2039-2046.

https://doi.org/10.1007/s11033-008-9414-1 


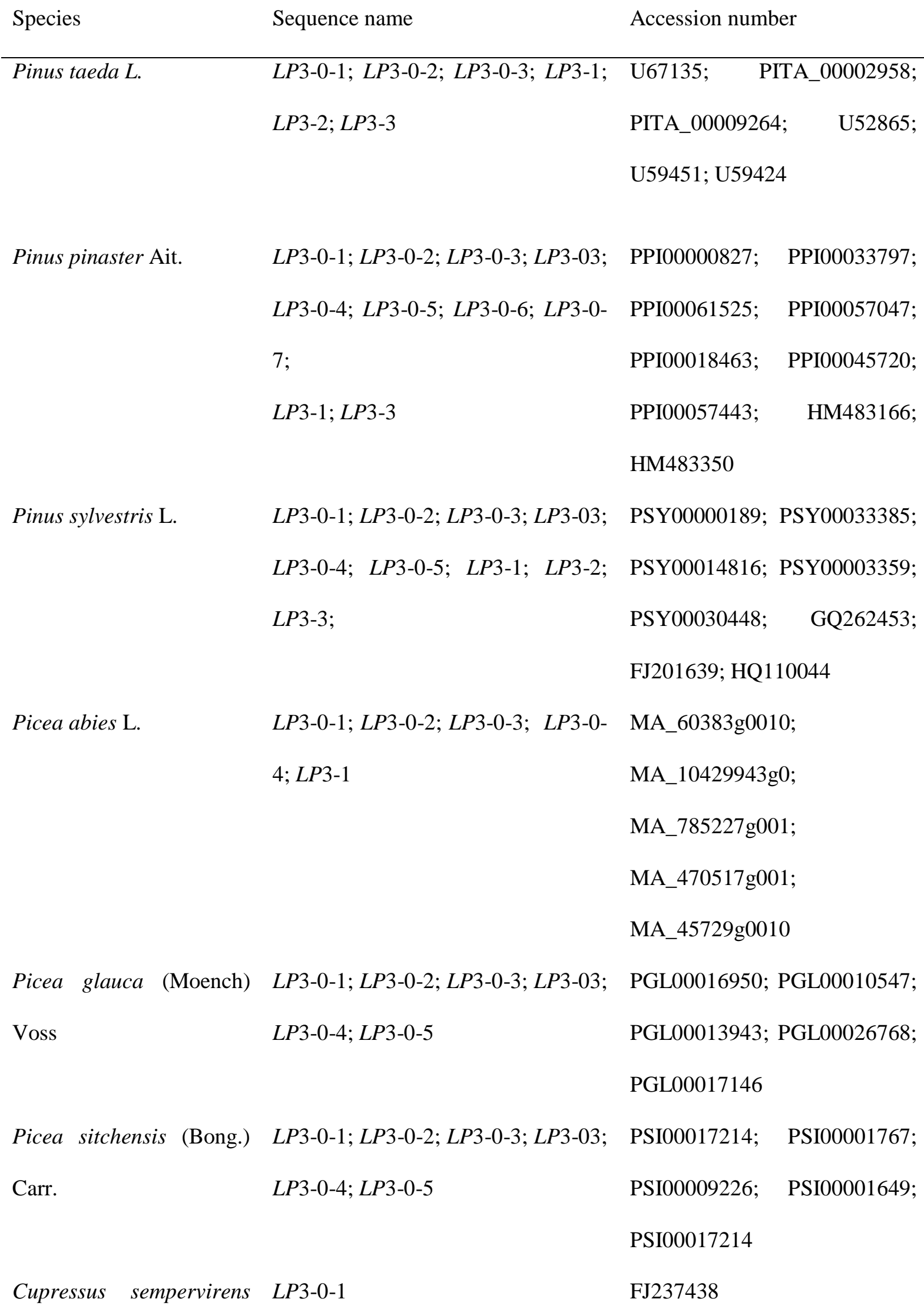


Pseudostuga menziesii LP3-0-1

(Mirb.) Franco

Pinus halepensis Miller $\quad$ LP3-1; LP3-3

Pinus $\quad$ hwangshanensis LP3-1

W.Y.Hsia

Pinus massoniana Lamb. LP3-1

Pinus echinata Miller LP3-3

Pinus canariensis C.Sm. LP3-3

Pinus mugo Turra LP3-3

Solanum lycopersicum L. ASR1, ASR2, ASR3

Lycopersicon chilense ASR1, ASR2, ASR 3

(Dunal) Reiche

Lycopersicon esculentum ASR1, ASR2, ASR3

Mill.

Solanum tuberosum L.

ASR1, ASR2, ASR4, ci21B

Oryza sativa $\mathrm{L}$.

ASR1

Amborella $\quad$ trichopoda ASR 1

Baill.

Vitis vinifera L.

ASR2

Populus trichocarpa Torr ASR3

\& A.Gray ex.Hook
PME00010941

HM482200; HM482279

KJ921435

KJ921431

KF158939

KF046212

JQ028052

NM_001247208;

NM_001320991;

NM_001309371

DQ058748; $\quad$ AY217009;

DQ058754

DQ058745; $\quad$ AY217012;

DQ058750

DQ252504; XM_006359742;

JX576284; U76611

XM_015767744;

XM_006851361

AF281656

XM_024602314 
Zea mays L.

ASR3

Nicotiana tabacum L.
TIP
XM_008647554

HE664126

Supplementary Table 1: Sequence names and accession numbers used in phylogenetic tree reconstruction according to species.

Species Gene name Accession numbers

Pinus taeda L.

LP3-0-1; LP3-0-2; LP3-0-3; U67135; $\quad$ PITA_00002958;

LP3-1; LP3-2; LP3-3

PITA_00009264; U52865;

U59451;

U59424

Pinus pinaster Ait.

LP3-0-1; LP3-0-2; LP3-0-3; PPI00000827; $\quad$ PPI00033797;

LP3-03; LP3-0-4; LP3-0-5; PPI00061525; PPI00057047;

LP3-0-6; LP3-0-7; $\quad$ PPI00018463; $\quad$ PPI00045720;

LP3-1; LP3-3 PPI00057443; HM483166;

HM483350

Pinus sylvestris $\mathrm{L}$.

LP3-0-1; LP3-0-2; LP3-0-3; PSY00000189; PSY00033385;

LP3-03; LP3-0-4; LP3-0-5; PSY00014816; PSY00003359;

LP3-1; LP3-2; LP3-3;

PSY00030448; GQ262453;

FJ201639; HQ110044

Picea abies L.

LP3-0-1; LP3-0-2; LP3-0-3; MA_60383g0010;

LP3-0-4; LP3-1

MA_10429943g0;

MA_785227g001;

MA_470517g001;

MA_45729g0010

Picea glauca (Moench) Voss

LP3-0-1; LP3-0-2; LP3-0-3; PGL00016950; PGL00010547;

LP3-03; LP3-0-4; LP3-0-5 PGL00013943; PGL00026768; 
PGL00017146

Picea sitchensis (Bong.) Carr. $\quad$ LP3-0-1; LP3-0-2; LP3-0-3; PSI00017214; PSI00001767;

LP3-03; LP3-0-4; LP3-0-5 PSI00009226; PSI00001649;

PSI00017214

Solanum lycopersicum L. $\quad$ ASR1, ASR2, ASR3, ASR4 NM_001247208;

NM_001320991;

NM_001309371;

NM_001282319

Solanum tuberosum L. ASR1，ASR2，ASR4， ci21A， DQ252504； XM_006359742;

ci21B JX576284; U76610; U76611

Populus trichocarpa Torr \& ASR3,ASR2, ASR4 XM_024602314;

$\begin{array}{ll}\text { A.Gray ex.Hook } & \text { Potri.005G193800; }\end{array}$

Potri.005G193900

Zea mays L. $\quad$ ASR1, ASR2, ASR3

EU963502; XM_008677645;

XM_008647554

Oryza sativa L. ASR1, ASR2, ASR3 XM_015767744;

XM_015779843;

XM_015794522

Supplementary Table 2: Sequence names and accession numbers from majorly represented species (i.e. species in which three or more ABA/WDS were found) for determining CAI, GC content, ENC and RSCU according to species.

\begin{tabular}{l|lrlrlrlr}
\hline AA & Codon & RSCU & Codon & RSCU & Codon & RSCU & Codon & RSCU \\
\hline \multirow{4}{*}{ Ala } & ASR1 & & ASR2 & & ASR3 & & ASR4 & \\
& Ala_GCU & 1,01 & Ala_GCU & 1,9 & Ala_GCU & $\mathbf{1 , 4 9}$ & Ala_GCU & $\mathbf{2}$ \\
& Ala_GCA & 1,17 & Ala_GCA & $\mathbf{1 , 2 7}$ & Ala_GCA & 1,21 & Ala_GCA & 1,44 \\
& Ala_GCC & $\mathbf{1 , 3 3}$ & Ala_GCC & 0,73 & Ala_GCC & 0,88 & Ala_GCC & 0,48
\end{tabular}




\begin{tabular}{|c|c|c|c|c|c|c|c|c|}
\hline & Ala_GCG & 0,48 & Ala_GCG & 0,1 & Ala_GCG & 0,42 & Ala_GCG & 0,08 \\
\hline \multirow[t]{6}{*}{ Arg } & Arg_CGU & 0 & Arg_CGU & 0 & Arg_CGU & 1,5 & Arg_CGU & 0 \\
\hline & Arg_CGA & 0 & Arg_CGA & 0 & Arg_CGA & 1 & Arg_CGA & 2,12 \\
\hline & Arg_AGA & 0 & Arg_AGA & 0 & Arg_AGA & 1,5 & Arg_AGA & 1,76 \\
\hline & Arg_CGC & 0 & Arg_CGC & 0 & Arg_CGC & 1,5 & Arg_CGC & 0,35 \\
\hline & Arg_CGG & 0 & Arg_CGG & 0 & Arg_CGG & 0 & Arg_CGG & 0 \\
\hline & Arg_AGG & 0 & Arg_AGG & 6 & Arg_AGG & 0,5 & Arg_AGG & 1,76 \\
\hline \multirow[t]{2}{*}{ Asn } & Asn_AAU & 0 & Asn_AAU & 0,57 & Asn_AAU & 0,89 & Asn_AAU & 1,22 \\
\hline & Asn_AAC & 2 & Asn_AAC & 1,43 & Asn_AAC & 1,11 & Asn_AAC & 0,78 \\
\hline \multirow[t]{2}{*}{ Asp } & Asp_GAU & 0,83 & Asp_GAU & 1,07 & Asp_GAU & 0,82 & Asp_GAU & 1,33 \\
\hline & Asp_GAC & 1,17 & Asp_GAC & 0,93 & Asp_GAC & 1,18 & Asp_GAC & 0,67 \\
\hline \multirow[t]{2}{*}{ Cys } & Cys_UGU & 0 & Cys_UGU & 0 & Cys_UGU & 2 & Cys_UGU & 1,2 \\
\hline & Cys_UGC & 0 & Cys_UGC & 0 & Cys_UGC & 0 & Cys_UGC & 0,8 \\
\hline \multirow[t]{2}{*}{ Gln } & GIn_CAA & 1,56 & GIn_CAA & 0,86 & Gln_CAA & 0,78 & GIn_CAA & 0,86 \\
\hline & Gln_CAG & 0,44 & Gln_CAG & 1,14 & Gln_CAG & 1,22 & GIn_CAG & 1,14 \\
\hline \multirow[t]{2}{*}{ Glu } & Glu_GAA & 0,5 & Glu_GAA & 0,91 & Glu_GAA & 0,61 & Glu_GAA & 0,87 \\
\hline & Glu_GAG & 1,5 & Glu_GAG & 1,09 & Glu_GAG & 1,39 & Glu_GAG & 1,13 \\
\hline \multirow[t]{4}{*}{ Gly } & Gly_GGU & 1,14 & Gly_GGU & 2 & Gly_GGU & 2,12 & Gly_GGU & 1,85 \\
\hline & Gly_GGA & 0,79 & Gly_GGA & 1,33 & Gly_GGA & 0,82 & Gly_GGA & 1,48 \\
\hline & Gly_GGC & 1,21 & Gly_GGC & 0,33 & Gly_GGC & 0,82 & Gly_GGC & 0,37 \\
\hline & Gly_GGG & 0,86 & Gly_GGG & 0,33 & Gly_GGG & 0,24 & Gly_GGG & 0,31 \\
\hline \multirow[t]{2}{*}{ His } & His_CAU & 0,66 & His_CAU & 0,68 & His_CAU & 0,76 & His_CAU & 1 \\
\hline & His_CAC & 1,34 & His_CAC & 1,32 & His_CAC & 1,24 & His_CAC & 1 \\
\hline \multirow[t]{3}{*}{ Ile } & Ile_AUU & 0,35 & Ile_AUU & 1,71 & Ile_AUU & 1,15 & Ile_AUU & 1,4 \\
\hline & Ile_AUA & 1,24 & Ile_AUA & 1,07 & Ile_AUA & 1,62 & Ile_AUA & 1,6 \\
\hline & Ile_AUC & 1,41 & Ile_AUC & 0,21 & Ile_AUC & 0,23 & Ile_AUC & 0 \\
\hline \multirow[t]{6}{*}{ Leu } & Leu_UUA & 0 & Leu_UUA & 0,96 & Leu_UUA & 0 & Leu_UUA & 1,04 \\
\hline & Leu_CUU & 1,31 & Leu_CUU & 0,96 & Leu_CUU & 1,5 & Leu_CUU & 2,09 \\
\hline & Leu_CUA & 0 & Leu_CUA & 0 & Leu_CUA & 0 & Leu_CUA & 0,26 \\
\hline & Leu_UUG & 0,75 & Leu_UUG & 1,92 & Leu_UUG & 1,8 & Leu_UUG & 1,04 \\
\hline & Leu_CUC & 2,63 & Leu_CUC & 2,16 & Leu_CUC & 1,8 & Leu_CUC & 1,3 \\
\hline & Leu_CUG & 1,31 & Leu_CUG & 0 & Leu_CUG & 0,9 & Leu_CUG & 0,26 \\
\hline \multirow[t]{2}{*}{ Lys } & Lys_AAA & 1,02 & Lys_AAA & 0,75 & Lys_AAA & 0,85 & Lys_AAA & 0,91 \\
\hline & Lys_AAG & 0,98 & Lys_AAG & 1,25 & Lys_AAG & 1,15 & Lys_AAG & 1,09 \\
\hline \multirow[t]{2}{*}{ Phe } & Phe_UUU & 0,36 & Phe_UUU & 0,59 & Phe_UUU & 0,59 & Phe_UUU & 1,1 \\
\hline & Phe_UUC & 1,64 & Phe_UUC & 1,41 & Phe_UUC & 1,41 & Phe_UUC & 0,9 \\
\hline \multirow[t]{4}{*}{ Pro } & Pro_CCU & 0 & Pro_CCU & 0,92 & Pro_CCU & 0,62 & Pro_CCU & 1 \\
\hline & Pro_CCA & 2,18 & Pro_CCA & 2,77 & Pro_CCA & 3,08 & Pro_CCA & 2 \\
\hline & Pro_CCC & 1,45 & Pro_CCC & 0,31 & Pro_CCC & 0,31 & Pro_CCC & 0,5 \\
\hline & Pro_CCG & 0,36 & Pro_CCG & 0 & Pro_CCG & 0 & Pro_CCG & 0,5 \\
\hline \multirow[t]{3}{*}{ Ser } & Ser_UCU & 1,5 & Ser_UCU & 0,46 & Ser_UCU & 0,55 & Ser_UCU & 1,4 \\
\hline & Ser_UCA & 0 & Ser_UCA & 0 & Ser_UCA & 1,09 & Ser_UCA & 0,6 \\
\hline & Ser_AGU & 0 & Ser_AGU & 0 & Ser_AGU & 0 & Ser_AGU & 2,8 \\
\hline
\end{tabular}




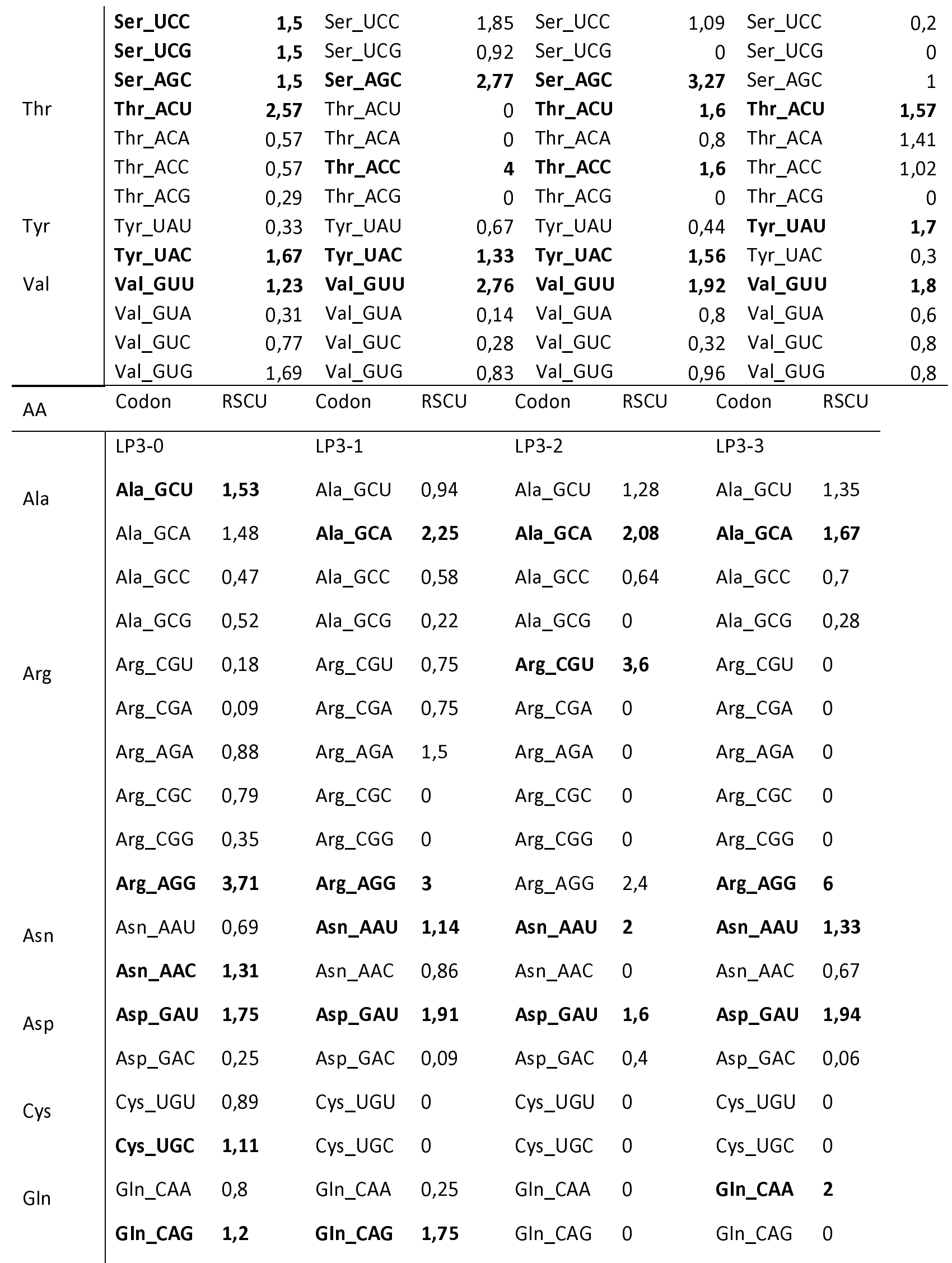




\begin{tabular}{|c|c|c|c|c|c|c|c|c|}
\hline \multirow[t]{2}{*}{ Glu } & Glu_GAA & 0,74 & Glu_GAA & 0,64 & Glu_GAA & 0,7 & Glu_GAA & 0,51 \\
\hline & Glu_GAG & 1,26 & Glu_GAG & 1,36 & Glu_GAG & 1,3 & Glu_GAG & 1,49 \\
\hline \multirow[t]{4}{*}{ Gly } & Gly_GGU & 1,24 & Gly_GGU & 1,17 & Gly_GGU & 1,2 & Gly_GGU & 0,74 \\
\hline & Gly_GGA & 1,41 & Gly_GGA & 1,25 & Gly_GGA & 1,2 & Gly_GGA & 2,05 \\
\hline & Gly_GGC & 0,62 & Gly_GGC & 0,83 & Gly_GGC & 0,8 & Gly_GGC & 0,65 \\
\hline & Gly_GGG & 0,73 & Gly_GGG & 0,75 & Gly_GGG & 0,8 & Gly_GGG & 0,56 \\
\hline \multirow[t]{2}{*}{ His } & His_CAU & 0,65 & His_CAU & 0,55 & His_CAU & 0,57 & His_CAU & 0,65 \\
\hline & His_CAC & 1,35 & His_CAC & 1,45 & His_CAC & 1,43 & His_CAC & 1,35 \\
\hline \multirow[t]{3}{*}{ Ile } & Ile_AUU & 1,53 & Ile_AUU & 2,73 & Ile_AUU & 0 & Ile_AUU & 1,88 \\
\hline & Ile_AUA & 0,12 & Ile_AUA & 0 & Ile_AUA & 0 & Ile_AUA & 0 \\
\hline & Ile_AUC & 1,35 & Ile_AUC & 0,27 & Ile_AUC & 3 & Ile_AUC & 1,13 \\
\hline \multirow{6}{*}{ Leu } & Leu_UUA & 0,17 & Leu_UUA & 0,38 & Leu_UUA & 2,67 & Leu_UUA & 0 \\
\hline & Leu_CUU & 0,21 & Leu_CUU & 0 & Leu_CUU & 0 & Leu_CUU & 0,26 \\
\hline & Leu_CUA & 0,21 & Leu_CUA & 0 & Leu_CUA & 0,67 & Leu_CUA & 0 \\
\hline & Leu_UUG & 1,56 & Leu_UUG & 0 & Leu_UUG & 0 & Leu_UUG & 1,3 \\
\hline & Leu_CUC & 1,42 & Leu_CUC & 1,88 & Leu_CUC & 0,67 & Leu_CUC & 1,83 \\
\hline & Leu_CUG & 2,43 & Leu_CUG & 3,75 & Leu_CUG & 2 & Leu_CUG & 2,61 \\
\hline \multirow[t]{2}{*}{ Lys } & Lys_AAA & 0,4 & Lys_AAA & 0,48 & Lys_AAA & 0,67 & Lys_AAA & 0,03 \\
\hline & Lys_AAG & 1,6 & Lys_AAG & 1,52 & Lys_AAG & 1,33 & Lys_AAG & 1,97 \\
\hline \multirow{2}{*}{ Phe } & Phe_UUU & 0,72 & Phe_UUU & 0,5 & Phe_UUU & 1,33 & Phe_UUU & 2 \\
\hline & Phe_UUC & 1,28 & Phe_UUC & 1,5 & Phe_UUC & 0,67 & Phe_UUC & 0 \\
\hline \multirow{4}{*}{ Pro } & Pro_CCU & 0,68 & Pro_CCU & 0 & Pro_CCU & 0 & Pro_CCU & 1,14 \\
\hline & Pro_CCA & 1,66 & Pro_CCA & 3,5 & Pro_CCA & 4 & Pro_CCA & 2 \\
\hline & Pro_CCC & 1,56 & Pro_CCC & 0 & Pro_CCC & 0 & Pro_CCC & 0,86 \\
\hline & Pro_CCG & 0,1 & Pro_CCG & 0,5 & Pro_CCG & 0 & Pro_CCG & 0 \\
\hline \multirow[t]{3}{*}{ Ser } & Ser_UCU & 2,39 & Ser_UCU & 0,43 & Ser_UCU & 3 & Ser_UCU & 2,1 \\
\hline & Ser_UCA & 0,4 & Ser_UCA & 0 & Ser_UCA & 0 & Ser_UCA & 0 \\
\hline & Ser_AGU & 0,34 & Ser_AGU & 0 & Ser_AGU & 0 & Ser_AGU & 0,6 \\
\hline
\end{tabular}




\begin{tabular}{l|llllllll} 
& Ser_UCC & 0,25 & Ser_UCC & 0 & Ser_UCC & 0 & Ser_UCC & 0 \\
Ser_UCG & 1,34 & Ser_UCG & $\mathbf{3 , 8 6}$ & Ser_UCG & 0 & Ser_UCG & 1,2 \\
Ser_AGC & 1,27 & Ser_AGC & 1,71 & Ser_AGC & 3 & Ser_AGC & 2,1 \\
Tyr & Thr_ACU & 0,63 & Thr_ACU & 1,2 & Thr_ACU & 0 & Thr_ACU & 1,29 \\
Thr_ACA & $\mathbf{1 , 6}$ & Thr_ACA & $\mathbf{1 , 6}$ & Thr_ACA & 0 & Thr_ACA & 0,57 \\
Thr_ACC & 1,47 & Thr_ACC & 0,4 & Thr_ACC & 1,33 & Thr_ACC & $\mathbf{2 , 1 4}$ \\
Val & Thr_ACG & 0,3 & Thr_ACG & 0,8 & Thr_ACG & $\mathbf{2 , 6 7}$ & Thr_ACG & 0 \\
Tyr_UAU & 0,79 & Tyr_UAU & $\mathbf{1 , 0 7}$ & Tyr_UAU & 0 & Tyr_UAU & 0,78 \\
Tyr_UAC & $\mathbf{1 , 2 1}$ & Tyr_UAC & 0,93 & Tyr_UAC & $\mathbf{2}$ & Tyr_UAC & $\mathbf{1 , 2 2}$ \\
Val_GUU & $\mathbf{1 , 3 2}$ & Val_GUU & $\mathbf{1 , 2 1}$ & Val_GUU & $\mathbf{1 , 8 2}$ & Val_GUU & $\mathbf{1 , 1 4}$ \\
Val_GUA & $\mathbf{0 , 0 3}$ & Val_GUA & 0,48 & Val_GUA & 0 & Val_GUA & 0
\end{tabular}

Supplementary Table 3: Average RSCU value of each codon per ABA/WDS gene. The most used codon for a given amino acid is indicated in bold.

(a) LP3-0 
Selecton Bayesian $\mathrm{Ka} / \mathrm{Ks}$ Results

\begin{tabular}{|c|c|c|c|c|c|c|c|c|}
\hline POS & AMINO & $\mathrm{Ka} / \mathrm{Ks}$ & [Confidence Int & erval] (* & if lower & [ bound $>$ & >1) & \\
\hline & & & & & $w=$ & $1.8 \mathrm{e}-65$ & 0.00052 & 0.0034 \\
\hline 1 & M & 0.063 & {$[1.8 \mathrm{e}-85,0.41]$} & & 0.16 & 8.16 & 0.15 & 0.15 \\
\hline 2 & s & 0.19 & {$[1.8 \mathrm{e}-\theta 5,1]$} & & 0.12 & 0.12 & 0.12 & 0.12 \\
\hline 3 & E & 0.043 & {$[1.8 \mathrm{e}-\theta 5,0.41]$} & & 0.17 & 0.17 & 0.17 & 0.16 \\
\hline 4 & $\mathrm{E}$ & 0.055 & {$[1.8 \mathrm{e}-85, \theta .41]$} & & $\theta .17$ & 0.17 & 0.16 & 0.15 \\
\hline 5 & k & 0.93 & {$[0.41,1]$} & & $4 \cdot 2 \mathrm{e}-14$ & $1 e-69$ & $2.7 e-67$ & $1.3 e-65$ \\
\hline 6 & H & 0.87 & {$[0.16,1]$} & & $1.2 \mathrm{e}-\theta 9$ & $9.6 e-67$ & $4 e-05$ & 0.00051 \\
\hline 7 & $\mathrm{H}$ & 0.79 & {$[0.076,1]$} & & $2.4 \mathrm{e}-89$ & $2 \mathrm{e}-96$ & $8.2 \mathrm{e}-05$ & 0.001 \\
\hline 8 & $\mathrm{H}$ & 0.056 & {$[1.8 \mathrm{e}-\theta 5,0.41]$} & & 0.16 & 0.16 & 0.16 & 0.15 \\
\hline 9 & H & 0.87 & {$[0.16,1]$} & & $9.5 e-10$ & $7.8 e-67$ & $3.3 e-65$ & 0.00042 \\
\hline 10 & $\mathrm{~L}$ & 0.74 & {$[0.033,1]$} & & $1.5 e-05$ & 0.00844 & 0.0029 & 0.01 \\
\hline 11 & L & 1 & {$[1,1]^{*}$} & $1.2 \mathrm{e}-19$ & $8.3 e-14$ & $1.5 e-10$ & $2.5 \mathrm{e}-68$ & $1.3 e-86$ \\
\hline 12 & H & 0.42 & {$[0.012,1]$} & & $5.5 e-85$ & 0.6916 & $\theta .01$ & 0.035 \\
\hline 13 & $\mathrm{H}$ & 0.052 & {$[1.8 \mathrm{e}-85,0.41]$} & & 0.16 & $\theta .16$ & 0.16 & 0.15 \\
\hline 14 & k & 0.04 & {$[1.8 \mathrm{e}-85,0.16]$} & & 0.17 & 0.17 & 0.17 & 0.16 \\
\hline 15 & $\mathrm{k}$ & 0.04 & {$[1.8 \mathrm{e}-\theta 5, \theta .16]$} & & $\theta .17$ & $\theta .17$ & 0.17 & 0.16 \\
\hline 16 & E & 0.055 & {$[1.8 \mathrm{e}-05,0.41]$} & & 0.17 & 0.17 & 0.16 & 0.15 \\
\hline 17 & D & 0.038 & {$[1.8 \mathrm{e}-\theta 5, \theta .16]$} & & 0.18 & 0.18 & 0.17 & 0.16 \\
\hline 18 & E & 0.94 & {$[0.41,1]$} & & $4 e-14$ & $9.4 e-1 \theta$ & $2.6 e-07$ & $1.2 \mathrm{e}-05$ \\
\hline 19 & s & 0.96 & {$[0.41,1]$} & & $2.9 \mathrm{e}-14$ & $7 e-10$ & $1.9 \mathrm{e}-07$ & $8.6 e-06$ \\
\hline $2 \theta$ & $\mathrm{E}$ & 0.92 & {$[0.41,1]$} & & $5.2 \mathrm{e}-14$ & $1.2 \mathrm{e}-69$ & $3.4 \mathrm{e}-67$ & $1.6 \mathrm{e}-85$ \\
\hline 21 & N & 0.97 & {$[0.41,1]$} & & $1.4 \mathrm{e}-14$ & $3.3 e-10$ & $9.1 \mathrm{e}-88$ & $4.3 e-86$ \\
\hline 22 & $\mathrm{v}$ & 0.97 & {$[0.41,1]$} & & $1.8 \mathrm{e}-14$ & $4 \cdot 2 \mathrm{e}-10$ & $1.1 \mathrm{e}-07$ & $5.2 \mathrm{e}-86$ \\
\hline 23 & $p$ & 0.99 & {$[0.41,1]$} & & $2.7 \mathrm{e}-15$ & $6.4 e-11$ & $1.8 \mathrm{e}-68$ & $8.4 \mathrm{e}-87$ \\
\hline 24 & s & 0.92 & {$[0.16,1]$} & & $4.5 e-10$ & $3.7 e-87$ & $1.6 \mathrm{e}-85$ & 0.0002 \\
\hline 25 & E & 0.93 & {$[0.16,1]$} & & $1.8 \mathrm{e}-10$ & $1.5 e-67$ & $6.6 \mathrm{e}-66$ & $9.1 e-05$ \\
\hline 26 & v & 0.08 & {$[1.8 \mathrm{e}-85,1]$} & & 0.15 & 0.15 & 0.15 & 0.14 \\
\hline 27 & v & 0.89 & {$[0.16,1]$} & & $8.7 e-10$ & $7.1 \mathrm{e}-67$ & $3 e-05$ & 0.00038 \\
\hline 28 & c & 0.82 & {$[8.076,1]$} & & $9.3 \mathrm{e}-66$ & 0.09027 & 0.0017 & 0.0062 \\
\hline 29 & A & 0.97 & {$[0.41,1]$} & & $1.4 e-10$ & $1.2 e-67$ & $4.9 \mathrm{e}-66$ & $6.4 \mathrm{e}-05$ \\
\hline 30 & E & 0.88 & {$[1.8 \mathrm{e}-85,1]$} & & $\theta .15$ & 0.15 & 0.15 & 0.14 \\
\hline 31 & $T$ & 0.85 & {$[0.076,1]$} & & $7.6 \mathrm{e}-66$ & 0.00022 & 0.0014 & 0.0051 \\
\hline 32 & $\mathrm{~T}$ & 0.25 & {$[1.8 \mathrm{e}-65,1]$} & & e.11 & $\theta .11$ & $\theta .11$ & $\theta .11$ \\
\hline 33 & $T$ & 0.28 & {$[1.8 \mathrm{e}-85,1]$} & & $\theta .1$ & 0.1 & 0.1 & 0.1 \\
\hline 34 & A & $\theta .82$ & {$[0.033,1]$} & & $9.6 e-86$ & 0.00028 & $\theta .0018$ & 0.0064 \\
\hline 35 & $\mathrm{r}$ & 0.069 & {$[1.8 \mathrm{e}-65,1]$} & & 0.15 & 0.15 & 0.15 & 0.15 \\
\hline 36 & G & 0.072 & {$[1.8 \mathrm{e}-85,1]$} & & $\theta .15$ & e.15 & 0.15 & 0.15 \\
\hline 37 & D & 0.26 & {$[0.012,1]$} & & $9.6 \mathrm{e}-85$ & 0.0027 & 0.017 & 0.059 \\
\hline 38 & E & 0.3 & {$[0.012,1]$} & & $8.1 \mathrm{e}-85$ & 0.6923 & 0.015 & 0.051 \\
\hline 39 & v & 0.062 & {$[1.8 \mathrm{e}-65,0.41]$} & & $\theta .16$ & 0.16 & 0.16 & 0.15 \\
\hline 48 & I & 8.7 & {$[0.033,1]$} & & $1.9 \mathrm{e}-65$ & 0.69054 & 0.0035 & 0.012 \\
\hline 41 & Q & 8.81 & {$[\boldsymbol{\theta} .076,1]$} & & $2.2 \mathrm{e}-69$ & $1.8 \mathrm{e}-86$ & $7.7 e-65$ & 0.00096 \\
\hline 42 & $s$ & 0.73 & {$[0.033,1]$} & & $1.7 \mathrm{e}-65$ & 0.60047 & 0.6031 & 0.011 \\
\hline 43 & A & 0.94 & {$[0.41,1]$} & & $3.1 \mathrm{e}-10$ & $2.6 \mathrm{e}-\theta 7$ & $1.1 \mathrm{e}-65$ & ө.00014 \\
\hline 44 & $\hat{D}$ & 0.34 & {$[0.012,1]$} & & $7.1 \mathrm{e}-05$ & 0.002 & 0.013 & 8.845 \\
\hline 45 & v & e.e61 & {$[1.8 \mathrm{e}-\theta 5, \theta .41]$} & & 0.16 & $\theta .16$ & 0.16 & 0.15 \\
\hline 46 & $\gamma$ & 8.066 & {$[1.8 \mathrm{e}-05,0.41]$} & & 0.15 & 0.15 & 0.15 & 0.15 \\
\hline 47 & A & 0.81 & {$[0.033,1]$} & & $1 \mathrm{e}-05$ & 0.00029 & 0.0019 & 0.0068 \\
\hline 48 & A & 0.21 & {$[1.8 \mathrm{e}-65,1]$} & & 0.12 & $\theta .12$ & 0.12 & 0.12 \\
\hline 49 & G & $\theta .18$ & {$[1.8 \mathrm{e}-65,1]$} & & 0.12 & $\theta .12$ & $\theta .12$ & $\theta .12$ \\
\hline so & $\mathrm{E}$ & 0.89 & {$[0.16,1]$} & & $7.2 \mathrm{e}-10$ & $5.9 \mathrm{e}-87$ & $2.5 \mathrm{e}-65$ & 0.80032 \\
\hline 51 & v & 0.17 & {$[1.8 \mathrm{e}-85,1]$} & & 0.13 & $\theta .13$ & 0.13 & $\theta .12$ \\
\hline 52 & $\mathrm{~N}$ & 0.96 & {$[0.41,1]$} & & $2 \mathrm{e}-10$ & $1.6 \mathrm{e}-67$ & $7 e-86$ & $9 e-05$ \\
\hline 53 & D & 0.91 & {$[0.16,1]$} & & $5.4 \mathrm{e}-10$ & $4.4 e-67$ & $1.9 \mathrm{e}-65$ & 8. 80024 \\
\hline 54 & D & 0.96 & {$[0.41,1]$} & & $2.3 e-14$ & $5.4 \mathrm{e}-10$ & $1.5 e-67$ & $6.8 \mathrm{e}-86$ \\
\hline 55 & k & 0.9 & {$[0.16,1]$} & & $6.7 \mathrm{e}-16$ & $5.5 e-87$ & $2.3 e-65$ & 0.0003 \\
\hline 56 & $\hat{f}$ & 1 & {$[1,1]^{*}$} & $1.9 \mathrm{e}-24$ & $3.7 \mathrm{e}-17$ & $4.4 e-13$ & $2.7 \mathrm{e}-10$ & $3.7 \mathrm{e}-68$ \\
\hline 57 & A & 0.97 & {$[0.41,1]$} & & $1.8 \mathrm{e}-18$ & $1.2 \mathrm{e}-12$ & $2.2 \mathrm{e}-69$ & $3.6 \mathrm{e}-87$ \\
\hline 58 & E & 6.91 & {$[0.16,1]$} & & $7 e-14$ & $1.7 \mathrm{e}-69$ & $4.5 \mathrm{e}-67$ & $2.1 \mathrm{e}-85$ \\
\hline 59 & r & 0.19 & {$[1.8 \mathrm{e}-85,1]$} & & 0.12 & $\theta .12$ & 0.12 & 0.12 \\
\hline 60 & E & 0.037 & {$[1.8 \mathrm{e}-85,0.16]$} & & 0.18 & 0.18 & $\theta .17$ & 0.16 \\
\hline 61 & $\mathrm{k}$ & $\theta .036$ & {$[1.8 \mathrm{e}-65,0.16]$} & & 0.17 & $\theta .17$ & 0.17 & $\theta .16$ \\
\hline 62 & A & 8.055 & {$[1.8 \mathrm{e}-05,0.41]$} & & 0.16 & 0.16 & 0.16 & 0.15 \\
\hline 63 & $\mathbf{R}$ & 1 & {$[1,1]^{*}$} & $4.9 \mathrm{e}-14$ & $4.5 e-11$ & $3.2 \mathrm{e}-69$ & $1.1 \mathrm{e}-67$ & $2.7 \mathrm{e}-66$ \\
\hline 64 & $\mathrm{k}$ & 0.36 & {$[0.012,1]$} & & $7.2 \mathrm{e}-05$ & $\theta .6021$ & 0.013 & 8.045 \\
\hline 65 & $\hat{E}$ & 0.054 & {$[1.8 \mathrm{e}-05,0.41]$} & & 0.17 & 0.17 & 0.17 & 0.16 \\
\hline 66 & E & 0.037 & {$[1.8 \mathrm{e}-\theta 5, \theta .16]$} & & 0.18 & 0.18 & 8.17 & 0.16 \\
\hline 67 & k & 8.039 & {$[1.8 \mathrm{e}-85,0.16]$} & & 0.17 & 0.17 & $\theta .17$ & 0.16 \\
\hline 68 & $\mathrm{H}$ & 0.051 & {$[1.8 \mathrm{e}-05,0.41]$} & & 0.16 & 0.16 & $\theta .16$ & 0.15 \\
\hline 69 & H & 8.847 & {$[1.8 \mathrm{e}-85,8.41]$} & & 0.17 & 0.16 & 0.16 & 0.15 \\
\hline $7 \theta$ & k & 8.04 & {$[1.8 \mathrm{e}-05,0.16]$} & & $\theta .17$ & 0.17 & $\theta .17$ & 0.16 \\
\hline 71 & $\mathrm{H}$ & 0.41 & {$[0.012,1]$} & & $5.9 \mathrm{e}-85$ & 0.0017 & 0.011 & 0.037 \\
\hline 72 & $\mathrm{~L}$ & 0.98 & {$[0.41,1]$} & & $6.6 \mathrm{e}-19$ & $4.5 e-13$ & $8 e-10$ & $1.3 \mathrm{e}-87$ \\
\hline 73 & $\mathrm{E}$ & 8.037 & {$[1.8 \mathrm{e}-\theta 5,0.16]$} & & 0.18 & 0.18 & 0.17 & 0.16 \\
\hline 74 & E & 0.91 & {$[0.16,1]$} & & $7.3 e-14$ & $1.7 \mathrm{e}-69$ & $4.7 e-67$ & $2.1 \mathrm{e}-05$ \\
\hline 75 & L & 0.94 & {$[0.41,1]$} & & $3 e-10$ & $2.5 e-07$ & $1 e-65$ & 8. 80013 \\
\hline 76 & G & 0.52 & {$[0.012,1]$} & & $4 e-05$ & e.e011 & $\theta .0073$ & 0.026 \\
\hline 77 & G & 0.81 & {$[\boldsymbol{\theta} . \boldsymbol{\theta} 76,1]$} & & $2.4 \mathrm{e}-89$ & $2 e-96$ & $8.3 e-65$ & 0.001 \\
\hline 78 & L & $\theta .16$ & {$[1.8 \mathrm{e}-65,1]$} & & 0.13 & 0.13 & 8.13 & 0.13 \\
\hline 79 & G & 0.083 & {$[1.8 \mathrm{e}-85,1]$} & & 0.15 & 0.15 & $\theta .15$ & 0.14 \\
\hline $8 \theta$ & T & 0.89 & {$[0.16,1]$} & & $8.1 \mathrm{e}-10$ & $6.6 \mathrm{e}-87$ & $2.8 \mathrm{e}-05$ & 8.60036 \\
\hline 81 & v & 0.85 & {$[0.16,1]$} & & $1.3 \mathrm{e}-\theta 9$ & $1.1 \mathrm{e}-06$ & $4.7 \mathrm{e}-65$ & 8. 80059 \\
\hline 82 & A & 0.085 & {$[1.8 \mathrm{e}-85,1]$} & & 0.15 & 0.15 & 0.15 & 0.14 \\
\hline 83 & A & 0.5 & {$[\theta .012,1]$} & & $3 e-05$ & ๑. 00085 & 0.0055 & 0.019 \\
\hline 84 & G & 0.084 & {$[1.8 \mathrm{e}-85,1]$} & & 0.15 & 0.15 & 0.15 & 0.14 \\
\hline 85 & A & 0.59 & {$[\boldsymbol{\theta} . \boldsymbol{\theta} 12,1]$} & & $3.2 \mathrm{e}-05$ & 0.00093 & 0.686 & 0.021 \\
\hline 86 & $\hat{F}$ & 0.7 & {$[0.033,1]$} & & $1.8 \mathrm{e}-05$ & 0.00053 & 0.0034 & 0.012 \\
\hline 87 & A & $\theta .1$ & {$[1.8 \mathrm{e}-\theta 5,1]$} & & 0.14 & 8.14 & 8.14 & 8.14 \\
\hline 88 & $\hat{L}$ & 0.94 & {$[0.41,1]$} & & $3.4 \mathrm{e}-10$ & $2.8 e-\theta 7$ & $1.2 \mathrm{e}-65$ & 8. 00015 \\
\hline
\end{tabular}




\begin{tabular}{|c|c|c|c|c|c|c|c|c|c|c|c|c|c|}
\hline 89 & H & 0.056 & {$[1.8 \mathrm{e}-05,0.41]$} & & 0.16 & 0.16 & $\theta .16$ & 6.15 & 0.14 & $\theta .11$ & $\theta .074$ & 0.026 & 0.018 \\
\hline 90 & E & 0.037 & {$[1.8 \mathrm{e}-05,0.16]$} & & 0.18 & $\theta .18$ & 0.17 & 0.16 & $\theta .14$ & $\theta .099$ & 0.053 & 0.014 & 0.0075 \\
\hline 91 & k & 0.836 & {$[1.8 \mathrm{e}-85,0.16]$} & & 0.17 & 0.17 & $\theta .17$ & 0.16 & 8.14 & 0.1 & 0.058 & 0.014 & 0.6055 \\
\hline 92 & H & 0.05 & {$[1.8 \mathrm{e}-05,0.41]$} & & 0.16 & 0.16 & 0.16 & 0.15 & ө.14 & 0.11 & 0.671 & 0.023 & $\theta .014$ \\
\hline 93 & A & 0.92 & {$[0.16,1]$} & & $5.5 e-1 \theta$ & $4.5 e-97$ & $1.9 \mathrm{e}-65$ & 0.00024 & 0.0016 & 0.0076 & 0.027 & 0.088 & 0.88 \\
\hline 94 & 5 & 0.95 & {$[0.41,1]$} & & $3.7 \mathrm{e}-14$ & $8.7 e-10$ & $2.4 \mathrm{e}-67$ & $1.1 \mathrm{e}-05$ & 8.60019 & $\theta .0019$ & 0.813 & 0.073 & 8.91 \\
\hline 95 & $\mathrm{k}$ & 0.039 & {$[1.8 \mathrm{e}-85,0.16]$} & & 0.17 & 0.17 & $\theta .17$ & 0.16 & $\theta .14$ & e.11 & 0.062 & 0.017 & 0.0071 \\
\hline 96 & $\mathrm{k}$ & 0.045 & {$[1.8 \mathrm{e}-\theta 5,0.41]$} & & 0.17 & 0.17 & 0.17 & 0.16 & $\theta .14$ & 0.11 & 0.066 & 0.019 & $\theta .011$ \\
\hline 97 & D & 8.843 & {$[1.8 \mathrm{e}-65,0.41]$} & & 0.17 & 0.17 & $\theta .17$ & $\theta .16$ & 8.14 & 0.1 & 0.859 & 8.017 & 0.012 \\
\hline 98 & P & 0.17 & {$[1.8 \mathrm{e}-\theta 5,1]$} & & 0.13 & 0.13 & 0.13 & 0.12 & 0.12 & $\theta .11$ & $\theta .093$ & 0.059 & 0.11 \\
\hline 99 & E & 0.042 & {$[1.8 \mathrm{e}-65,0.41]$} & & 0.17 & 0.17 & $\theta .17$ & 0.16 & $\theta .14$ & 0.1 & 0.057 & 0.016 & 0.011 \\
\hline 160 & $\mathrm{~N}$ & 1 & {$[1,1]^{*}$} & $2.1 \mathrm{e}-19$ & $1.4 \mathrm{e}-13$ & $2.5 e-16$ & $4.2 \mathrm{e}-68$ & $2.1 \mathrm{e}-66$ & $5.1 \mathrm{e}-85$ & 0.00084 & 6.016 & 6.98 & \\
\hline 101 & A & e.e87 & {$[1.8 \mathrm{e}-65,1]$} & & e.15 & 0.15 & 0.15 & 0.14 & 0.13 & 0.11 & 0.083 & 8.037 & 0.043 \\
\hline 102 & H & 0.052 & {$[1.8 \mathrm{e}-05,0.41]$} & & 0.16 & 0.16 & 0.16 & 0.15 & $\theta .14$ & 0.11 & 8.073 & 0.025 & 0.015 \\
\hline 103 & R & 0.96 & {$[0.41,1]$} & & $2.3 e-14$ & $5.3 e-10$ & $1.5 e-67$ & $6.7 e-06$ & 0.00012 & 0.0013 & 0.009 & 0.059 & 0.93 \\
\hline 104 & H & 0.052 & {$[1.8 \mathrm{e}-85,6.41]$} & & 0.16 & 0.16 & 0.16 & 0.15 & 0.14 & $\theta .11$ & $\theta .073$ & 0.025 & 0.015 \\
\hline 105 & $\mathrm{k}$ & 0.844 & {$[1.8 \mathrm{e}-65,0.41]$} & & 0.17 & 0.17 & 0.17 & 0.16 & 0.14 & $\theta .11$ & 0.866 & 0.019 & $\theta .01$ \\
\hline 106 & I & 0.82 & {$[0.076,1]$} & & $7.9 \mathrm{e}-06$ & 0.00023 & 0.0015 & 0.0054 & e.014 & 0.033 & 0.867 & 0.13 & 0.75 \\
\hline 107 & E & 0.41 & {$[0.012,1]$} & & $5.9 \mathrm{e}-65$ & $\theta .0017$ & 0.011 & 0.037 & 0.09 & 0.16 & 0.23 & 0.19 & 0.28 \\
\hline 108 & E & $\theta .048$ & {$[1.8 \mathrm{e}-65,0.41]$} & & 0.17 & 0.17 & 0.17 & $\theta .16$ & 0.14 & $\theta .1$ & $\theta .061$ & 0.019 & 0.016 \\
\hline 109 & E & 8.043 & {$[1.8 \mathrm{e}-65,0.41]$} & & 0.17 & 0.17 & 0.17 & 0.16 & $\theta .14$ & $\theta .1$ & 0.059 & 0.017 & 0.012 \\
\hline 110 & I & 0.68 & {$[8.033,1]$} & & $2.1 \mathrm{e}-05$ & 0.6006 & 0.6039 & 0.014 & 0.035 & 0.072 & 0.12 & 0.17 & 0.58 \\
\hline 111 & A & 0.11 & {$[1.8 \mathrm{e}-65,1]$} & & 0.14 & 0.14 & 0.14 & $\theta .14$ & 0.13 & 0.11 & 0.087 & 0.043 & 0.059 \\
\hline 112 & A & 0.68 & {$[0.033,1]$} & & $2.2 \mathrm{e}-85$ & 0.60062 & 0.804 & 0.014 & 0.036 & 0.074 & 0.13 & 0.17 & 0.58 \\
\hline 113 & $\hat{A}$ & 0.93 & {$[8.16,1]$} & & $4 e-10$ & $3.3 e-67$ & $1.4 \mathrm{e}-65$ & ө.80018 & 0.0013 & 0.006 & 0.023 & 0.883 & 0.89 \\
\hline 114 & A & 0.62 & {$[0.033,1]$} & & $2.8 \mathrm{e}-65$ & 0.60081 & 0.0852 & 0.018 & 0.046 & 0.092 & 0.15 & 0.18 & 0.51 \\
\hline 115 & A & 0.11 & {$[1.8 \mathrm{e}-85,1]$} & & 0.14 & 0.14 & 0.14 & 0.14 & 0.13 & 0.11 & e.e87 & 0.044 & 0.06 \\
\hline 116 & $\mathrm{v}$ & 0.057 & {$[1.8 \mathrm{e}-85,0.41]$} & & 0.16 & 0.16 & 0.16 & 0.15 & 0.14 & 0.11 & 0. 875 & 8.026 & 0.018 \\
\hline 117 & G & $\theta .091$ & {$[1.8 \mathrm{e}-85,1]$} & & 0.15 & 0.15 & 0.15 & 0.14 & 0.13 & 0.11 & $\theta .086$ & 0.04 & 0.845 \\
\hline 118 & A & 0.92 & {$[0.16,1]$} & & $4.1 \mathrm{e}-10$ & $3.4 \mathrm{e}-67$ & $1.4 \mathrm{e}-65$ & 0.00018 & 0.0013 & 0.0063 & 0.025 & 0.09 & 0.88 \\
\hline 119 & G & 0.055 & {$[1.8 \mathrm{e}-65,0.41]$} & & 0.16 & 0.16 & 8.16 & 0.15 & 8.14 & $\theta .11$ & 0.076 & 8.827 & 0.016 \\
\hline $12 \theta$ & G & 0.62 & {$[0.033,1]$} & & $2.6 e-05$ & 0.60075 & 0.8848 & 0.017 & $\theta .043$ & 0.089 & 0.15 & $\theta .19$ & 0.51 \\
\hline 121 & $\gamma$ & 8.076 & {$[1.8 \mathrm{e}-65,1]$} & & 0.15 & 0.15 & 0.15 & 0.15 & 8.13 & 0.12 & 8.884 & 0.037 & 0.031 \\
\hline 122 & v & 0.5 & {$[\theta .012,1]$} & & $4.2 \mathrm{e}-65$ & 0.6012 & 0.6078 & 0.027 & 0.067 & $\theta .13$ & 0.2 & 0.2 & 0.37 \\
\hline 123 & $F$ & $\theta .16$ & {$[1.8 \mathrm{e}-\theta 5,1]$} & & 0.13 & 0.13 & $\theta .13$ & 0.13 & 0.12 & $\theta .11$ & ө.093 & 0.059 & 0.11 \\
\hline 124 & H & 0.055 & {$[1.8 \mathrm{e}-05,0.41]$} & & 0.16 & 0.16 & 0.16 & 0.15 & 0.14 & 0.11 & 8. 874 & 0.026 & $\theta .017$ \\
\hline 125 & $\mathrm{E}$ & 0.043 & {$[1.8 \mathrm{e}-05,6.41]$} & & 0.17 & $\theta .17$ & $\theta .17$ & 0.16 & 0.14 & 0.1 & 0.059 & 8.017 & 0.012 \\
\hline 126 & H & 0.057 & {$[1.8 \mathrm{e}-85,8.41]$} & & 0.16 & 0.16 & $\theta .16$ & 0.15 & $\theta .14$ & 0.11 & 0.074 & 0.026 & 0.019 \\
\hline 127 & H & 0.054 & {$[1.8 \mathrm{e}-85,0.41]$} & & $\theta .16$ & $\theta .16$ & $\theta .16$ & $\theta .15$ & $\theta .14$ & $\theta .11$ & 0.073 & 0.025 & $\theta .016$ \\
\hline 128 & E & 0.042 & {$[1.8 \mathrm{e}-05,0.41]$} & & 0.17 & 0.17 & 0.17 & 0.16 & 0.14 & $\theta .1$ & 0.057 & 0.016 & 0.011 \\
\hline 129 & $\mathrm{k}$ & 8.04 & {$[1.8 \mathrm{e}-85,0.16]$} & & 0.17 & 0.17 & 0.17 & $\theta .16$ & 0.14 & $\theta .11$ & $\theta .061$ & 0.016 & $\theta .008$ \\
\hline 130 & $\mathrm{k}$ & 0.045 & {$[1.8 \mathrm{e}-85,0.41]$} & & 0.17 & 0.17 & 0.17 & 0.16 & 0.14 & 0.11 & 8.864 & 0.018 & 0.011 \\
\hline 131 & E & 8.055 & {$[1.8 \mathrm{e}-85,8.41]$} & & 0.17 & 0.17 & 0.16 & 0.15 & 0.14 & 0.11 & 8.066 & 8.022 & 8.02 \\
\hline 132 & s & $\theta .72$ & {$[0.033,1]$} & & $1.8 \mathrm{e}-65$ & 0.60051 & 0.0033 & $\theta .012$ & 0.03 & $\theta .062$ & $\theta .11$ & 0.15 & 0.63 \\
\hline 133 & k & 8.06 & {$[1.8 \mathrm{e}-65,0.41]$} & & $\theta .16$ & 0.16 & 0.16 & 0.15 & 0.14 & 0.11 & 0.077 & 0.028 & 0.021 \\
\hline 134 & $\hat{E}$ & 0.052 & {$[1.8 \mathrm{e}-\theta 5, \theta .41]$} & & 0.17 & 0.17 & 0.17 & 0.16 & 0.14 & $\theta .1$ & 0.062 & 0.02 & 0.018 \\
\hline 135 & E & 0.44 & {$[0.012,1]$} & & $5.3 e-65$ & $\theta .6015$ & 0.0098 & 0.034 & 0.082 & 0.15 & 0.22 & 0.19 & $\theta .31$ \\
\hline 136 & E & $\theta$ & {$[\theta$.} & & $1.1 \mathrm{e}-14$ & $2.6 \mathrm{e}-10$ & $7 e-08$ & $3.3 \mathrm{e}-06$ & $6 e-65$ & 0.08066 & 0.0052 & 0.043 & 0.95 \\
\hline 137 & $\mathrm{k}$ & 8.46 & {$[0.012,1]$} & & $4.9 \mathrm{e}-65$ & 0.0014 & 0.0091 & 0.032 & 0.077 & 0.15 & 0.21 & 0.19 & 0.34 \\
\hline 138 & E & 0.054 & {$[1.8 \mathrm{e}-\theta 5,0.41]$} & & 0.17 & $\theta .17$ & 0.16 & $\theta .16$ & 0.14 & 0.1 & 0.064 & 0.021 & 0.02 \\
\hline 139 & A & $\theta .66$ & {$[0.033,1]$} & & $2.5 e-65$ & 0.00071 & 0.0046 & 0.016 & 0.041 & 0.082 & 0.13 & 0.16 & 0.56 \\
\hline 140 & E & 8.87 & {$[0.16,1]$} & & $1.6 \mathrm{e}-69$ & $1.3 \mathrm{e}-86$ & $5.5 e-85$ & 0.00068 & 0.0844 & $\theta .018$ & 0.053 & 0.12 & 0.8 \\
\hline 141 & G & $\theta .066$ & {$[1.8 \mathrm{e}-65,0.41]$} & & 0.15 & $\theta .15$ & $\theta .15$ & $\theta .15$ & 0.14 & $\theta .12$ & 0.082 & 0.033 & $\theta .024$ \\
\hline 142 & k & 8.48 & {$[0.012,1]$} & & $4.6 \mathrm{e}-65$ & 0.0013 & 0.0085 & 0.03 & 0.073 & 0.14 & 0.2 & 0.19 & 0.36 \\
\hline 143 & k & 0.71 & {$[0.076,1]$} & & $3.3 e-69$ & $2.7 e-86$ & 0.00011 & 0.0014 & 0.6094 & 0.641 & 0.12 & 0.24 & 0.59 \\
\hline 144 & H & 0.054 & {$[1.8 \mathrm{e}-\theta 5,0.41]$} & & $\theta .16$ & $\theta .16$ & 0.16 & 0.15 & $\theta .14$ & $\theta .11$ & 0.074 & 0.025 & $\theta .016$ \\
\hline 145 & H & 6.6 & {$[0.033,1]$} & & $1.4 e-65$ & 0.60041 & 0.0027 & 0.0098 & 0.027 & 0.063 & 0.12 & 0.18 & 0.59 \\
\hline 146 & H & $\theta .46$ & {$[0.012,1]$} & & $5.1 \mathrm{e}-65$ & $\theta .0015$ & 0.0093 & 0.032 & 0.079 & 0.15 & 0.21 & 0.19 & 0.33 \\
\hline 147 & L & 0.8 & {$[0.033,1]$} & & $1.1 \mathrm{e}-65$ & $\theta .00031$ & 0.002 & 0.0072 & $\theta .019$ & 0.041 & $\theta .077$ & 0.13 & 0.72 \\
\hline 148 & $F$ & $\theta .16$ & {$[1.8 \mathrm{e}-65,1]$} & & 0.13 & 0.13 & 0.13 & 0.13 & 0.12 & 0.11 & 0.093 & 0.058 & 0.1 \\
\hline 149 & $\mathrm{r}$ & 8.47 & {$[1.8 \mathrm{e}-\theta 5,1]$} & & 0.073 & 0.073 & 0.073 & 0.073 & 0.073 & 0.073 & 0.073 & 0.073 & 0.41 \\
\hline 150 & v & 8.47 & [1 $8 \mathrm{e}-05$ & & 0.073 & 0.673 & 0.073 & 0.073 & 0.073 & 0.673 & 0.073 & 0.073 & 0.41 \\
\hline 151 & $\mathbf{R}$ & 0.47 & {$[1.8 \mathrm{e}-65,1]$} & & 0.073 & 0.073 & 0.073 & 0.073 & 0.073 & 0.073 & 0.673 & 0.073 & 0.41 \\
\hline 152 & c & e.47 & {$[1.8 \mathrm{e}-85,1]$} & & 0.073 & 0.073 & 0.073 & 0.073 & 0.073 & 0.073 & 0.073 & 0.073 & 0.41 \\
\hline 153 & H & 0.47 & & & 0.073 & 0.673 & 0.073 & 0.073 & 0.873 & 8.873 & 0.073 & 0.073 & 0.41 \\
\hline
\end{tabular}

Supplementary Table 4: Ka/Ks values per LP3-0 amino acid. First are represented amino acid position, then amino acid, w-score, confidence interval and Bayesian posterior probabilities. 


\section{(b) LP3-1}

Selecton Bayesian Ka/Ks Results

\begin{tabular}{|c|c|c|c|c|c|c|c|c|}
\hline POS & AMINO & $\mathrm{Ka} / \mathrm{Ks}$ & [Confidence & Interval] (* & if lower & r bound & $>1)$ & \\
\hline & & & & & $w=$ & $6.2 e-10$ & $4.4 \mathrm{e}-87$ & $2 e-85$ \\
\hline 1 & M & 0.13 & {$[6.2 \mathrm{e}-1 \theta, 1]$} & & $\theta .12$ & $\theta .12$ & 0.12 & 0.12 \\
\hline 2 & s & e.25 & {$[6.2 \mathrm{e}-1 \theta, 1]$} & & 0.1 & 0.1 & e.1 & 0.1 \\
\hline 3 & E & $\theta .14$ & {$[6.2 \mathrm{e}-1 \theta, 1]$} & & 0.12 & $\theta .12$ & 0.12 & 0.12 \\
\hline 4 & E & 0.95 & {$[0.26,1]$} & & $4.7 e-15$ & $4.4 \mathrm{e}-13$ & $9.3 \mathrm{e}-10$ & $2 e-67$ \\
\hline 5 & K & e.11 & {$[6.2 \mathrm{e}-1 \theta, 1]$} & & 0.12 & e.12 & 0.12 & 0.12 \\
\hline 6 & $Q$ & 8.85 & {$[0.054,1]$} & & $5.8 \mathrm{e}-10$ & $4.2 \mathrm{e}-67$ & $1.9 \mathrm{e}-65$ & 0.00028 \\
\hline 7 & H & 0.12 & {$[6.2 \mathrm{e}-1 \theta, 1]$} & & 0.12 & 0.12 & 0.12 & 0.12 \\
\hline 8 & $\mathrm{H}$ & e.97 & {$[0.26,1]$} & & $2.5 e-12$ & $1.8 \mathrm{e}-69$ & $8.2 \mathrm{e}-68$ & $1.3 e-06$ \\
\hline 9 & H & 0.13 & {$[6.2 \mathrm{e}-1 \theta, 1]$} & & 0.12 & 0.12 & $\theta .12$ & $\theta .12$ \\
\hline 10 & L & 0.96 & {$[0.26,1]$} & & $6.8 e-11$ & $4.8 \mathrm{e}-68$ & $2.2 \mathrm{e}-86$ & $3.2 \mathrm{e}-05$ \\
\hline 11 & $\mathrm{~F}$ & $\theta .26$ & {$[6.2 \mathrm{e}-1 \theta, 1]$} & & 0.098 & 0.098 & 0.098 & 0.098 \\
\hline 12 & H & 0.97 & {$[0.26,1]$} & & $2.4 \mathrm{e}-15$ & $2.3 e-13$ & $4 \cdot 3 \mathrm{e}-10$ & $9.3 \mathrm{e}-68$ \\
\hline 13 & H & e.14 & {$[6.2 \mathrm{e}-1 \theta, 1]$} & & 0.12 & $\theta .12$ & 0.12 & $\theta .12$ \\
\hline 14 & H & e.85 & {$[0.054,1]$} & & $5 e-10$ & $3.6 e-07$ & $1.6 \mathrm{e}-05$ & 0.00024 \\
\hline 15 & K & 0.087 & {$[6.2 \mathrm{e}-10,1]$} & & $\theta .13$ & $\theta .13$ & $\theta .13$ & $\theta .13$ \\
\hline 16 & E & 0.15 & {$[6.2 \mathrm{e}-10,1]$} & & 0.12 & 0.12 & $\theta .12$ & 0.12 \\
\hline 17 & D & 8.94 & {$[0.26,1]$} & & $3.5 e-15$ & $5 e-13$ & $1.1 \mathrm{e}-69$ & $2.3 e-67$ \\
\hline 18 & G & 8.92 & {$[8.26,1]$} & & $1.9 \mathrm{e}-10$ & $1.4 \mathrm{e}-97$ & $6.4 \mathrm{e}-86$ & $9.3 \mathrm{e}-65$ \\
\hline 19 & G & 6.97 & {$[0.26,1]$} & & 5. $5 \mathrm{e}-15$ & $2.5 e-13$ & $5.2 \mathrm{e}-10$ & $1.1 \mathrm{e}-87$ \\
\hline $2 \theta$ & $\mathrm{E}$ & $\theta .84$ & {$[0.054,1]$} & & $6.4 \mathrm{e}-10$ & $4.6 \mathrm{e}-07$ & $2.1 \mathrm{e}-05$ & 0.00031 \\
\hline 21 & $Q$ & e.97 & {$[0.26,1]$} & & $1.1 \mathrm{e}-14$ & $1.9 \mathrm{e}-13$ & $4 e-10$ & $8.6 e-08$ \\
\hline 22 & v & 0.37 & {$[6.2 \mathrm{e}-10,1]$} & & 0.083 & 0.683 & 0.083 & 0.083 \\
\hline 23 & I & 0.38 & {$[6.2 \mathrm{e}-1 \theta, 1]$} & & 0.081 & e. 081 & 0.081 & 0.081 \\
\hline 24 & E & 0.35 & {$[6.2 \mathrm{e}-10,1]$} & & 0.085 & 0.085 & 0.085 & 0.085 \\
\hline 25 & s & $\theta .38$ & {$[6.2 \mathrm{e}-10,1]$} & & 0.081 & 0.081 & 0. 081 & 0.081 \\
\hline 26 & $\mathrm{~T}$ & 0.38 & {$[6.2 \mathrm{e}-1 \theta, 1]$} & & 0.081 & 0.881 & 0.081 & 0.081 \\
\hline 27 & D & e. 36 & {$[6.2 \mathrm{e}-10,1]$} & & 0.085 & 0.085 & 0.085 & 0.085 \\
\hline 28 & v & 0.37 & {$[6.2 \mathrm{e}-10,1]$} & & 0.082 & $\theta .082$ & 0.082 & 0.082 \\
\hline 29 & v & 0.38 & {$[6.2 \mathrm{e}-10,1]$} & & 0.082 & 0.082 & 0.082 & 0.082 \\
\hline 30 & A & 6.89 & {$[0.054,1]$} & & $3.4 \mathrm{e}-10$ & $2.4 e-67$ & $1.1 \mathrm{e}-65$ & 8.80016 \\
\hline 31 & A & 0.18 & {$[6.2 \mathrm{e}-10,1]$} & & 0.11 & 8.11 & 0.11 & 0.11 \\
\hline 32 & G & 8.99 & {$[1,1]^{*}$} & $7.2 e-17$ & $7.2 \mathrm{e}-14$ & $1.6 \mathrm{e}-10$ & $3.4 \mathrm{e}-68$ & $2.1 \mathrm{e}-06$ \\
\hline 33 & $\mathrm{~N}$ & 0.95 & {$[0.26,1]$} & & $5.2 \mathrm{e}-15$ & $4.2 \mathrm{e}-13$ & $8.8 \mathrm{e}-10$ & $1.9 \mathrm{e}-87$ \\
\hline 34 & v & e.88 & {$[0.054,1]$} & & $4.1 \mathrm{e}-10$ & $3 e-67$ & $1.4 \mathrm{e}-85$ & 0.0002 \\
\hline 35 & D & 8.99 & {$[1,1]^{*}$} & $5.8 \mathrm{e}-16$ & $6.5 e-14$ & $6.7 \mathrm{e}-11$ & $1.4 \mathrm{e}-68$ & $9 e-67$ \\
\hline 36 & E & 0.97 & {$[8.26,1]$} & & $1.2 \mathrm{e}-14$ & $1.9 \mathrm{e}-13$ & $3.9 \mathrm{e}-10$ & $8.4 \mathrm{e}-68$ \\
\hline 37 & $\gamma$ & e.15 & {$[6.2 \mathrm{e}-1 \theta, 1]$} & & $\theta .12$ & 0.12 & 0.12 & 0.12 \\
\hline 38 & E & 0.14 & {$[6.2 \mathrm{e}-10,1]$} & & 0.12 & 0.12 & 0.12 & 0.12 \\
\hline 39 & K & 0.087 & {$[6.2 \mathrm{e}-1 \theta, 1]$} & & 0.13 & 0.13 & 0.13 & 0.13 \\
\hline 40 & A & 0.92 & {$[0.26,1]$} & & $2 e-1 \theta$ & $1.5 e-87$ & $6.7 \mathrm{e}-96$ & $9.8 \mathrm{e}-05$ \\
\hline 41 & $\mathrm{~K}$ & 0.87 & {$[0.054,1]$} & & $4.7 \mathrm{e}-10$ & $3.4 \mathrm{e}-97$ & $1.5 \mathrm{e}-65$ & 0.00023 \\
\hline 42 & K & ө. 087 & {$[6.2 \mathrm{e}-1 \theta, 1]$} & & e.13 & 0.13 & $\theta .13$ & 0.13 \\
\hline 43 & D & 0.88 & {$[0.854,1]$} & & $5.2 \mathrm{e}-10$ & $3.7 e-67$ & $1.7 \mathrm{e}-65$ & 0.00025 \\
\hline 44 & E & $\theta .14$ & {$[6.2 \mathrm{e}-1 \theta, 1]$} & & 0.12 & $\theta .12$ & 0.12 & 0.12 \\
\hline 45 & k & 0.087 & {$[6.2 \mathrm{e}-1 \theta, 1]$} & & 8.13 & $\theta .13$ & $\theta .13$ & 0.13 \\
\hline 46 & H & 0.13 & {$[6.2 \mathrm{e}-1 \theta, 1]$} & & 0.12 & 0.12 & 0.12 & 0.12 \\
\hline 47 & $\mathrm{H}$ & 0.14 & {$[6.2 \mathrm{e}-10,1]$} & & 0.12 & $\theta .12$ & 0.12 & 0.12 \\
\hline 48 & $\mathrm{k}$ & 0.087 & {$[6.2 \mathrm{e}-10,1]$} & & 0.13 & 0.13 & 0.13 & 0.13 \\
\hline 49 & H & 0.96 & {$[0.26,1]$} & & $7.1 \mathrm{e}-11$ & $5 e-68$ & $2.3 \mathrm{e}-86$ & $3.4 \mathrm{e}-65$ \\
\hline 50 & M & e.13 & {$[6.2 \mathrm{e}-1 \theta, 1]$} & & 0.12 & $\theta .12$ & 0.12 & 0.12 \\
\hline 51 & E & 0.14 & {$[6.2 \mathrm{e}-10,1]$} & & 0.12 & 0.12 & 0.12 & 0.12 \\
\hline 52 & H & 0.13 & {$[6.2 \mathrm{e}-10,1]$} & & 0.12 & 0.12 & 0.12 & 0.12 \\
\hline 53 & L & 0.26 & {$[6.2 \mathrm{e}-10,1]$} & & 0.099 & 0.099 & 0.099 & 0.099 \\
\hline 54 & G & 0.13 & {$[6,2 \mathrm{e}-10,1]$} & & 0.12 & 0.12 & 0.12 & 0.12 \\
\hline 55 & E & e.15 & {$[6.2 \mathrm{e}-10,1]$} & & 0.12 & 0.12 & 0.12 & 0.12 \\
\hline 56 & M & 8.93 & {$[0.26,1]$} & & $1.8 e-10$ & $1.3 \mathrm{e}-67$ & $6 e-06$ & $8.8 e-05$ \\
\hline 57 & G & 0.12 & {$[6.2 \mathrm{e}-1 \theta, 1]$} & & 0.12 & 0.12 & $\theta .12$ & 0.12 \\
\hline 58 & $\mathrm{~T}$ & 0.89 & {$[8.054,1]$} & & $3.4 \mathrm{e}-10$ & $2.5 e-87$ & $1.1 \mathrm{e}-85$ & ө.e0016 \\
\hline 59 & v & 0.17 & {$[6.2 \mathrm{e}-1 \theta, 1]$} & & 0.11 & 0.11 & 0.11 & 0.11 \\
\hline 60 & A & 0.19 & {$[6.2 \mathrm{e}-10,1]$} & & 0.11 & $\theta .11$ & 0.11 & 0.11 \\
\hline 61 & A & e.19 & {$[6.2 \mathrm{e}-1 \theta, 1]$} & & 0.11 & $\theta .11$ & 0.11 & 0.11 \\
\hline 62 & G & $\theta .12$ & {$[6.2 \mathrm{e}-1 \theta, 1]$} & & 0.12 & $\theta .12$ & 0.12 & 0.12 \\
\hline 63 & A & 0.87 & {$[0.054,1]$} & & $4,3 e-10$ & $3.1 \mathrm{e}-67$ & $1.4 \mathrm{e}-85$ & 0.00021 \\
\hline 64 & $\mathrm{~F}$ & 0.27 & {$[6.2 \mathrm{e}-10,1]$} & & 0.097 & 0.097 & 0.097 & 0.097 \\
\hline 65 & A & $\theta .17$ & {$[6.2 \mathrm{e}-1 \theta, 1]$} & & 0.11 & $\theta .11$ & 0.11 & 0.11 \\
\hline 66 & L & 0.19 & {$[6.2 \mathrm{e}-10,1]$} & & 0.11 & 0.11 & 0.11 & 0.11 \\
\hline 67 & H & 0.85 & {$[0.054,1]$} & & $5 e-10$ & $3.6 \mathrm{e}-67$ & $1.6 \mathrm{e}-85$ & 0.00024 \\
\hline 68 & $\mathrm{E}$ & 0.14 & {$[6.2 \mathrm{e}-1 \theta, 1]$} & & 0.12 & $\theta .12$ & 0.12 & 0.12 \\
\hline 69 & K & 0.1 & {$[6.2 \mathrm{e}-10,1]$} & & 0.13 & 0.13 & 0.13 & 0.13 \\
\hline 70 & H & 0.88 & {$[0.054,1]$} & & $4.1 \mathrm{e}-10$ & $2.9 \mathrm{e}-67$ & $1.3 e-65$ & 0.00019 \\
\hline 71 & A & 8.98 & {$[0.26,1]$} & & $4.3 e-16$ & $1.6 \mathrm{e}-13$ & $3.3 \mathrm{e}-10$ & $7 e-08$ \\
\hline 72 & D & 0.84 & {$[0.054,1]$} & & $6 e-10$ & $4.3 e-97$ & $2 \mathrm{e}-65$ & 0.00029 \\
\hline 73 & $\mathrm{k}$ & 0.07 & {$[6.2 \mathrm{e}-10,1]$} & & 0.13 & $\theta .13$ & 0.13 & 0.13 \\
\hline 74 & K & 0.07 & {$[6.2 \mathrm{e}-10,1]$} & & $\theta .13$ & $\theta .13$ & 0.13 & 0.13 \\
\hline 75 & D & $\theta .093$ & {$[6.2 \mathrm{e}-10,1]$} & & 0.13 & $\theta .13$ & 0.13 & 0.13 \\
\hline 76 & $p$ & 0.22 & {$[6.2 \mathrm{e}-10,1]$} & & $\theta .1$ & $\theta .1$ & $\theta .1$ & $\theta .1$ \\
\hline 77 & E & $\theta .11$ & {$[6.2 \mathrm{e}-1 \theta, 1]$} & & 0.13 & $\theta .13$ & 0.13 & 0.13 \\
\hline 78 & H & e. 84 & {$[0.054,1]$} & & $5.6 e-10$ & $4 e-67$ & $1.8 \mathrm{e}-65$ & 0.00027 \\
\hline 79 & A & 0.15 & {$[6.2 \mathrm{e}-1 \theta, 1]$} & & 0.12 & 0.12 & 0.12 & 0.12 \\
\hline 80 & H & $\theta .13$ & {$[6.2 \mathrm{e}-1 \theta, 1]$} & & $\theta .12$ & $\theta .12$ & 0.12 & 0.12 \\
\hline 81 & R & 8.87 & {$[0.054,1]$} & & $4.4 \mathrm{e}-10$ & $3.1 \mathrm{e}-67$ & $1.4 \mathrm{e}-85$ & 0.00021 \\
\hline 82 & H & $\theta .11$ & {$[6.2 \mathrm{e}-10,1]$} & & 0.12 & $\theta .12$ & $\theta .12$ & 0.12 \\
\hline 83 & $\mathrm{~K}$ & 0.07 & {$[6.2 \mathrm{e}-1 \theta, 1]$} & & 8.13 & 0.13 & 0.13 & 0.13 \\
\hline 84 & I & 0.21 & {$[6.2 \mathrm{e}-1 \theta, 1]$} & & 0.11 & 0.11 & $\theta .11$ & e.11 \\
\hline 85 & $\mathrm{E}$ & $\theta .11$ & {$[6.2 \mathrm{e}-1 \theta, 1]$} & & $\theta .13$ & $\theta .13$ & $\theta .13$ & 0.13 \\
\hline 86 & E & $\theta .11$ & {$[6.2 \mathrm{e}-10,1]$} & & $\theta .13$ & $\theta .13$ & $\theta .13$ & 0.13 \\
\hline 87 & E & $\theta .11$ & {$[6.2 \mathrm{e}-1 \theta, 1]$} & & 0.13 & 8.13 & 8.13 & 0.13 \\
\hline 88 & v & 0.89 & {$[0.054,1]$} & & $3.6 \mathrm{e}-10$ & $2.5 e-97$ & $1.2 \mathrm{e}-85$ & 0.00017 \\
\hline
\end{tabular}




\begin{tabular}{|c|c|c|c|}
\hline 89 & A & 0.16 & {$[6.2 \mathrm{e}-1 \theta, 1]$} \\
\hline 90 & A & $\theta .15$ & {$[6.2 \mathrm{e}-10,1]$} \\
\hline 91 & A & 0.88 & {$[0.054,1]$} \\
\hline 92 & A & 0.98 & {$[0.26,1]$} \\
\hline 93 & A & $\theta .16$ & {$[6.2 \mathrm{e}-1 \theta, 1]$} \\
\hline 94 & v & $\theta .1$ & {$[6.2 \mathrm{e}-10,1]$} \\
\hline 95 & G & 0.11 & {$[6.2 \mathrm{e}-10,1]$} \\
\hline 96 & A & 0.16 & {$[6.2 \mathrm{e}-1 \theta, 1]$} \\
\hline 97 & G & 0.064 & {$[6.2 \mathrm{e}-1 \theta, 1]$} \\
\hline 98 & G & 8.13 & {$[6.2 \mathrm{e}-1 \mathrm{\theta}, 1]$} \\
\hline 99 & $\gamma$ & 0.87 & {$[0.054,1]$} \\
\hline 100 & v & 0.12 & {$[6.2 \mathrm{e}-10,1]$} \\
\hline 101 & $\mathrm{f}$ & 0.26 & {$[6.2 \mathrm{e}-10,1]$} \\
\hline 102 & H & $\theta .11$ & {$[6.2 \mathrm{e}-1 \theta, 1]$} \\
\hline 103 & E & $\theta .094$ & {$[6.2 \mathrm{e}-10,1]$} \\
\hline 104 & H & $\theta .12$ & {$[6.2 \mathrm{e}-10,1]$} \\
\hline 105 & H & $\theta .11$ & {$[6.2 \mathrm{e}-10,1]$} \\
\hline 106 & E & 8.74 & {$[\theta . \theta 13,1]$} \\
\hline 107 & k & 8.064 & {$[6.2 \mathrm{e}-10,1]$} \\
\hline 108 & $\mathrm{k}$ & $\theta .081$ & {$[6.2 \mathrm{e}-1 \mathrm{\theta}, 1]$} \\
\hline 109 & E & 8.26 & {$[6.2 \mathrm{e}-10,1]$} \\
\hline 110 & s & 0.35 & {$[6.2 \mathrm{e}-10,1]$} \\
\hline 111 & $\mathrm{k}$ & 0.25 & {$[6.2 \mathrm{e}-10,1]$} \\
\hline 112 & E & 0.26 & {$[6.2 \mathrm{e}-10,1]$} \\
\hline 113 & E & 0.26 & {$[6.2 \mathrm{e}-10,1]$} \\
\hline 114 & E & 0.26 & {$[6.2 \mathrm{e}-10,1]$} \\
\hline 115 & k & 0.26 & {$[6.2 \mathrm{e}-10,1]$} \\
\hline 116 & $\mathrm{E}$ & 0.26 & {$[6.2 \mathrm{e}-1 \theta, 1]$} \\
\hline 117 & A & $\theta .31$ & {$[6.2 \mathrm{e}-1 \theta, 1]$} \\
\hline 118 & E & 0.24 & {$[6.2 \mathrm{e}-10,1]$} \\
\hline 119 & G & 0.31 & {$[6.2 \mathrm{e}-10,1]$} \\
\hline $12 \theta$ & $\mathrm{k}$ & 0.93 & {$[0.26,1]$} \\
\hline 121 & K & 0.24 & {$[6.2 \mathrm{e}-1 \theta, 1]$} \\
\hline 122 & $\mathrm{H}$ & 0.3 & {$[6.2 \mathrm{e}-16,1]$} \\
\hline 123 & H & $\theta .3$ & {$[6.2 \mathrm{e}-1 \mathrm{\theta}, 1]$} \\
\hline 124 & H & 0.3 & {$[6.2 \mathrm{e}-10,1]$} \\
\hline 125 & L & $\theta .35$ & {$[6.2 \mathrm{e}-10,1]$} \\
\hline 126 & $\mathrm{~F}$ & 0.36 & {$[6.2 \mathrm{e}-10,1]$} \\
\hline
\end{tabular}

\begin{tabular}{|c|c|c|c|c|c|c|c|c|}
\hline 11 & 0.11 & .11 & 11 & 11 & 11 & .11 & .677 & . 13 \\
\hline 12 & e.12 & e.12 & ө.12 & 0.12 & 0.11 & 0.11 & .076 & 9.12 \\
\hline-10 & $2.9 \mathrm{e}-07$ & $1.3 e-65$ & 0.6001 & 0.001 & 0.007 & 0.032 & .12 & .84 \\
\hline $8 e-12$ & $1.2 \mathrm{e}-69$ & $5.7 \mathrm{e}-68$ & $8.7 e-07$ & $9.5 e-06$ & 0.00012 & 0.0017 & a31 & \\
\hline 12 & e.12 & 0.12 & 0.12 & 0.11 & 0.11 & 0.11 & .077 & 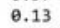 \\
\hline & 8.13 & 0.13 & A & A & 12 & 11 & .069 & A7: \\
\hline 12 & 0.12 & 0.12 & Q. 11 & 17 & 12 & .11 & .873 & .084 \\
\hline & & & & & & & & 13 \\
\hline & & & & & & & 86 & \\
\hline 12 & 0.12 & 0.12 & 0.12 & 0.1. & & & & \\
\hline$e-1 \theta$ & $3.2 \mathrm{e}-07$ & $1.5 \mathrm{e}-65$ & $\theta$. & & & & & \\
\hline 12 & 0.12 & 0.12 & 0.12 & 0.12 & 8,12 & 11 & 872 & .09 \\
\hline & & & & & & & & \\
\hline & & & & & & & & \\
\hline 13 & $\theta$ & B. & 0 & e. & 1. & & 59 & .07 \\
\hline 2 & & & & & & & & \\
\hline 2 & & & & & & & & \\
\hline $1 e-69$ & $7.9 \mathrm{e}-07$ & $3.6 \mathrm{e}-65$ & 0.00053 & 0.t & 0.021 & 2 & & .68 \\
\hline 13 & $\theta .13$ & 0.13 & 8. 13 & & & & & a41 \\
\hline & & & & & & & & 057 \\
\hline & & & & & & & & \\
\hline .0 & & & & & & & & 32 \\
\hline & & & & & & & & 22 \\
\hline & & & & & & & & \\
\hline & & & & & & & & \\
\hline$\theta$ & & & & & & & & \\
\hline & & & & & & & & \\
\hline & & & & & & & & \\
\hline & & & & & & & & \\
\hline & & & & & & & & \\
\hline & & & & & & & & \\
\hline & & & & & & & & \\
\hline$\sigma$ & $\theta$. & e. & B. & $\theta$ & & & & \\
\hline & & & & & & & & \\
\hline & & & & & & & & \\
\hline & & & & & & & & \\
\hline & & & & & & & & \\
\hline & & & & & & 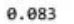 & 881 & 0.33 \\
\hline
\end{tabular}

Supplementary Table 5: Ka/Ks values per LP3-1 amino acid. First are represented amino acid position, then amino acid, w-score, confidence interval and Bayesian posterior probabilities. 
(c) LP3-3

Selecton Bayesian Ka/Ks Results

\begin{tabular}{|c|c|c|c|c|c|c|c|c|c|}
\hline POS & AMINO & $\mathrm{Ka} / \mathrm{Ks}$ & [Confidence Interval] (* & $\begin{array}{l}\text { if lower } \\
w=\end{array}$ & $\begin{array}{l}{\left[\begin{array}{c}\text { bound } \\
6.2 \mathrm{e}-10\end{array}\right.} \\
\end{array}$ & $\begin{array}{l}\text { 1) } \\
4.4 \mathrm{e}-67\end{array}$ & $2 e-05$ & $\begin{array}{l}\text { POSTERIO } \\
\theta .0003\end{array}$ & $\begin{array}{l}\text { OR PROBAB } \\
\theta .0023\end{array}$ \\
\hline 1 & D & 0.59 & {$[6.2 \mathrm{e}-16,2.9]$} & 0.1 & 0.1 & 0.1 & 0.1 & 0.1 & $\theta .1$ \\
\hline 2 & E & 0.59 & {$[6.2 \mathrm{e}-10,2.9]$} & e.1 & $\theta .1$ & $\theta .1$ & 0.1 & $\theta .1$ & $\theta .1$ \\
\hline 3 & $\mathrm{~N}$ & 0.59 & {$[6.2 \mathrm{e}-10,2.9]$} & $\theta .1$ & 8.1 & $\theta .1$ & 0.1 & 0.1 & $\theta .1$ \\
\hline 4 & D & 6.59 & {$[6.2 \mathrm{e}-10,2.9]$} & 0.1 & $\theta .1$ & $\theta .1$ & 0.1 & 0.1 & 0.1 \\
\hline 5 & $\mathrm{~N}$ & 0.59 & {$[6.2 \mathrm{e}-10,2.9]$} & e.1 & 8.1 & 0.1 & 0.1 & 0.1 & e.1 \\
\hline 6 & p & 6.45 & {$[6.2 \mathrm{e}-10,2.9]$} & 0.11 & $\theta .11$ & 0.11 & 0.11 & 0.11 & 0.11 \\
\hline 7 & p & 6.42 & {$[6.2 \mathrm{e}-10,2.9]$} & $\theta .11$ & $\theta .11$ & 0.11 & 0.11 & 0.11 & 0.11 \\
\hline 8 & s & 0.4 & {$[6.2 \mathrm{e}-10,2.9]$} & 0.11 & 0.11 & 0.11 & $\theta .11$ & 0.11 & 0.11 \\
\hline 9 & E & 0.2 & {$[6.2 \mathrm{e}-10,2.9]$} & 0.12 & 0.12 & 0.12 & 0.12 & 0.12 & 0.12 \\
\hline 10 & v & $\theta .31$ & {$[6.2 \mathrm{e}-10,2.9]$} & $\theta .11$ & $\theta .11$ & $\theta .11$ & $\theta .11$ & $\theta .11$ & 0.11 \\
\hline 11 & v & 0.31 & {$[6.2 \mathrm{e}-10,2.9]$} & 0.11 & e.11 & 0.11 & 0.11 & 0.11 & 0.11 \\
\hline 12 & $\mathrm{Y}$ & 6.39 & {$[6.2 \mathrm{e}-10,2.9]$} & 0.11 & $\theta .11$ & 0.11 & 0.11 & 0.11 & 0.11 \\
\hline 13 & $s$ & 0.43 & {$[6.2 \mathrm{e}-10,2.9]$} & $\theta .11$ & $\theta .11$ & $\theta .11$ & 0.11 & $\theta .11$ & 0.11 \\
\hline 14 & E & 0.2 & {$[6.2 \mathrm{e}-10,2.9]$} & 0.12 & 0.12 & 0.12 & 0.12 & 0.12 & 0.12 \\
\hline 15 & T & 0.4 & {$[6.2 \mathrm{e}-10,2.9]$} & 0.11 & 0.11 & 0.11 & 0.11 & 0.11 & 0.11 \\
\hline 16 & T & 0.4 & {$[6.2 \mathrm{e}-10,2.9]$} & 0.11 & 0.11 & 0.11 & 0.11 & 0.11 & 0.11 \\
\hline 17 & $T$ & $\theta .41$ & {$[6.2 \mathrm{e}-10,2.9]$} & 0.11 & 0.11 & 0.11 & 0.11 & 0.11 & 0.11 \\
\hline 18 & A & 0.32 & {$[6.2 \mathrm{e}-10,2.9]$} & 0.11 & 0.11 & 0.11 & 0.11 & 0.11 & 0.11 \\
\hline 19 & $\mathrm{r}$ & 6.33 & {$[6.2 \mathrm{e}-10,2.9]$} & $\theta .11$ & $\theta .11$ & $\theta .11$ & 0.11 & 0.11 & 0.11 \\
\hline $2 \theta$ & 6 & 6.31 & {$[6.2 \mathrm{e}-10,2.9]$} & 0.11 & e.11 & 0.11 & 0.11 & 0.11 & 0.11 \\
\hline 21 & D & 0.19 & {$[6.2 \mathrm{e}-10,2.9]$} & 0.12 & $\theta .12$ & 0.12 & 0.12 & 0.12 & 0.12 \\
\hline 22 & E & 0.18 & {$[6.2 \mathrm{e}-10,2.9]$} & 0.12 & 0.12 & 0.12 & 0.12 & 0.12 & 0.12 \\
\hline 23 & v & 0.2 & {$[6.2 \mathrm{e}-10,2.9]$} & 0.12 & 0.12 & 0.12 & 0.12 & 0.12 & 0.12 \\
\hline 24 & I & 0.37 & {$[6.2 \mathrm{e}-10,2.9]$} & 0.11 & $\theta .11$ & $\theta .11$ & 0.11 & 0.11 & $\theta .11$ \\
\hline 25 & Q & 0.36 & {$[6.2 \mathrm{e}-10,2.9]$} & $\theta .11$ & 0.11 & 0.11 & 0.11 & 0.11 & 0.11 \\
\hline 26 & s & 0.36 & {$[6.2 \mathrm{e}-10,2.9]$} & 0.11 & 0.11 & 0.11 & 0.11 & 0.11 & 0.11 \\
\hline 27 & A & $\theta .36$ & {$[6.2 \mathrm{e}-10,2.9]$} & 0.11 & $\theta .11$ & 0.11 & 0.11 & 0.11 & 0.11 \\
\hline 28 & D & 0.17 & {$[6.2 \mathrm{e}-10,2.9]$} & $\theta .12$ & 0.12 & 0.12 & 0.12 & 0.12 & 0.12 \\
\hline 29 & v & 0.2 & {$[6.2 \mathrm{e}-1 \theta, 2.9]$} & 0.12 & 0.12 & 0.12 & 0.12 & 0.12 & 0.12 \\
\hline 30 & $\gamma$ & 6.35 & {$[6.2 \mathrm{e}-10,2.9]$} & 0.11 & 0.11 & 0.11 & 0.11 & 0.11 & 0.11 \\
\hline 31 & A & 0.28 & {$[6.2 \mathrm{e}-10,2.9]$} & 0.12 & 0.12 & 0.12 & 0.12 & 0.12 & 0.12 \\
\hline 32 & $\mathrm{~T}$ & 2.6 & {$[0.054,2.9]$} & $2.5 e-10$ & $1.8 e-87$ & $8.1 \mathrm{e}-66$ & 0.00012 & 0.00092 & 0.0049 \\
\hline 33 & G & 0.2 & {$[6.2 \mathrm{e}-1 \theta, 2.9]$} & 0.12 & $\theta .12$ & 8.12 & $\theta .12$ & 0.12 & 0.12 \\
\hline 34 & $\mathrm{~N}$ & 2.8 & {$[2.9,2.9]^{*}$} & $3.3 e-15$ & $7.1 e-14$ & $1.5 e-1 \theta$ & $3.2 \mathrm{e}-08$ & $2 e-86$ & $5.6 e-85$ \\
\hline 35 & v & 0.22 & {$[6.2 \mathrm{e}-10,2.9]$} & 0.12 & 0.12 & 0.12 & 0.12 & 0.12 & 0.12 \\
\hline 36 & $\mathrm{~N}$ & 2.3 & {$[0.054,2.9]$} & $4.9 \mathrm{e}-10$ & $3.5 e-67$ & $1.6 \mathrm{e}-65$ & 0.00023 & 0.0018 & $\theta .0097$ \\
\hline 37 & $s$ & 2.9 & {$[2.9,2.9]^{*}$} & $4.3 e-2 \theta=$ & $2.2 e-14$ & $4 \cdot 6 e-11$ & $9.8 \mathrm{e}-69$ & $6 e-07$ & $1.7 \mathrm{e}-65$ \\
\hline 38 & D & 8.17 & {$[6.2 \mathrm{e}-10,2.9]$} & 0.12 & 0.12 & 0.12 & 0.12 & 0.12 & 0.12 \\
\hline 39 & E & 0.16 & {$[6.2 \mathrm{e}-1 \theta, 2.9]$} & 0.12 & 0.12 & 0.12 & 0.12 & 0.12 & 0.12 \\
\hline $4 \theta$ & $\gamma$ & $\theta .35$ & {$[6.2 \mathrm{e}-10,2.9]$} & $\theta .11$ & $\theta .11$ & 0.11 & 0.11 & 0.11 & 0.11 \\
\hline 41 & E & 0.16 & {$[6.2 \mathrm{e}-1 \theta, 2.9]$} & 0.12 & 0.12 & 0.12 & 0.12 & 0.12 & 0.12 \\
\hline 42 & $\mathrm{k}$ & $\theta .15$ & {$[6.2 \mathrm{e}-1 \theta, 2.9]$} & $\theta .12$ & $\theta .12$ & $\theta .12$ & 0.12 & 0.12 & 0.12 \\
\hline 43 & A & 0.25 & {$[6.2 \mathrm{e}-10,2.9]$} & $\theta .12$ & 0.12 & 8.12 & 0.12 & 0.12 & 0.12 \\
\hline 44 & $\mathbf{R}$ & 2.5 & {$[0.054,2.9]$} & $2.9 \mathrm{e}-10$ & $2.1 e-87$ & $9.6 \mathrm{e}-66$ & 0.00014 & 0.0011 & 0.0059 \\
\hline 45 & $\mathrm{k}$ & 0.15 & {$[6.2 \mathrm{e}-1 \theta, 2.9]$} & 0.12 & $\theta .12$ & 0.12 & 0.12 & $\theta .12$ & $\theta .12$ \\
\hline 46 & E & 0.24 & {$[6.2 \mathrm{e}-10,2.9]$} & $\theta .12$ & $\theta .12$ & $\theta .12$ & 0.12 & 0.12 & 0.12 \\
\hline 47 & E & 0.16 & {$[6.2 \mathrm{e}-10,2.9]$} & 0.12 & 0.12 & $\theta .12$ & 0.12 & 0.12 & $\theta .12$ \\
\hline 48 & $\mathrm{k}$ & $\theta .15$ & {$[6.2 \mathrm{e}-10,2.9]$} & 0.12 & 0.12 & 0.12 & 0.12 & 0.12 & 0.12 \\
\hline 49 & H & 0.27 & {$[6.2 \mathrm{e}-10,2.9]$} & 0.12 & 0.12 & 0.12 & 0.12 & 0.12 & 0.12 \\
\hline 50 & H & 0.32 & {$[6.2 \mathrm{e}-10,2.9]$} & 0.11 & $\theta .11$ & 0.11 & 0.11 & 0.11 & 0.11 \\
\hline 51 & $\mathrm{k}$ & $\theta .15$ & {$[6.2 \mathrm{e}-10,2.9]$} & 0.12 & 0.12 & 0.12 & 0.12 & 0.12 & 0.12 \\
\hline 52 & H & $\theta .27$ & {$[6.2 \mathrm{e}-10,2.9]$} & $\theta .12$ & 0.12 & $\theta .12$ & 0.12 & 0.12 & 0.12 \\
\hline 53 & M & 2.5 & {$[0.054,2.9]$} & $2.8 \mathrm{e}-10$ & $2 e-67$ & $9.1 \mathrm{e}-66$ & 0.00013 & 0.001 & 0.0055 \\
\hline 54 & E & $\theta .16$ & {$[6.2 \mathrm{e}-1 \theta, 2.9]$} & 0.12 & $\theta .12$ & 8.12 & 0.12 & 0.12 & $\theta .12$ \\
\hline 55 & E & $\theta .23$ & {$[6.2 \mathrm{e}-10,2.9]$} & $\theta .12$ & 8.12 & $\theta .12$ & 0.12 & $\theta .12$ & $\theta .12$ \\
\hline 56 & v & 2.6 & {$[0.26,2.9]$} & $1.9 \mathrm{e}-10$ & $1.3 e-67$ & $6.1 \mathrm{e}-06$ & $8.9 \mathrm{e}-05$ & 0.0007 & 0.0038 \\
\hline 57 & G & 0.23 & {$[6.2 \mathrm{e}-16,2.9]$} & e.12 & 0.12 & 0.12 & 0.12 & 0.12 & 0.12 \\
\hline 58 & G & 0.31 & {$[6.2 \mathrm{e}-10,2.9]$} & $\theta .11$ & 0.11 & $\theta .11$ & 0.11 & $\theta .11$ & $\theta .11$ \\
\hline 59 & $\mathrm{~L}$ & 0.37 & {$[6.2 \mathrm{e}-10,2.9]$} & 0.11 & 0.11 & $\theta .11$ & 0.11 & 0.11 & 0.11 \\
\hline 60 & G & 0.31 & {$[6.2 \mathrm{e}-10,2.9]$} & 0.11 & $\theta .11$ & $\theta .11$ & 0.11 & 0.11 & 0.11 \\
\hline 61 & $\begin{array}{llllll} & \end{array}$ & 2.9 & {$[2.9,2.9]^{*}$} & $5.8 \mathrm{e}-2 \theta$ & $3 e-14$ & $6.2 \mathrm{e}-11$ & $1.3 e-68$ & $8.1 \mathrm{e}-07$ & $2.3 e-65$ \\
\hline 62 & M & 2.5 & {$[0.054,2.9]$} & $3.1 \mathrm{e}-10$ & $2.2 \mathrm{e}-97$ & $1 e-05$ & 0.00015 & 0.0012 & 0.0062 \\
\hline 63 & A & 6.34 & {$[6.2 \mathrm{e}-10,2.9]$} & 0.11 & 0.11 & $\theta .11$ & $\theta .11$ & 0.11 & 0.11 \\
\hline 64 & T & 0.37 & {$[6.2 \mathrm{e}-10,2.9]$} & $\theta .11$ & $\theta .11$ & $\theta .11$ & 0.11 & 0.11 & 0.11 \\
\hline 65 & G & $\theta .31$ & {$[6.2 \mathrm{e}-10,2.9]$} & $\theta .11$ & $\theta .11$ & $\theta .11$ & $\theta .11$ & 0.11 & 0.11 \\
\hline 66 & A & 0.34 & {$[6.2 \mathrm{e}-10,2.9]$} & 0.11 & $\theta .11$ & 0.11 & 0.11 & $\theta .11$ & 0.11 \\
\hline 67 & $\mathrm{~F}$ & 0.42 & {$[6.2 \mathrm{e}-10,2.9]$} & $\theta .11$ & 0.11 & 0.11 & 0.11 & $\theta .11$ & 0.11 \\
\hline 68 & A & 8.36 & {$[6.2 \mathrm{e}-10,2.9]$} & $\theta .11$ & 0.11 & 0.11 & 0.11 & 0.11 & 0.11 \\
\hline 69 & $\mathrm{~L}$ & 0.45 & {$[6.2 \mathrm{e}-10,2.9]$} & $\theta .11$ & 0.11 & $\theta .11$ & $\theta .11$ & 0.11 & 0.11 \\
\hline $7 \theta$ & $\mathrm{H}$ & $\theta .31$ & {$[6.2 \mathrm{e}-10,2.9]$} & 0.11 & 0.11 & $\theta .11$ & 0.11 & 0.11 & 0.11 \\
\hline 71 & $E$ & 0.16 & {$[6.2 \mathrm{e}-1 \theta, 2.9]$} & $\theta .12$ & $\theta .12$ & 0.12 & 0.12 & 0.12 & 0.12 \\
\hline 72 & $\mathrm{k}$ & 0.15 & {$[6.2 \mathrm{e}-10,2.9]$} & $\theta .12$ & 0.12 & 0.12 & 0.12 & 0.12 & $\theta .12$ \\
\hline 73 & H & 0.31 & {$[6.2 \mathrm{e}-10,2.9]$} & $\theta .11$ & $\theta .11$ & $\theta .11$ & 0.11 & $\theta .11$ & 0.11 \\
\hline 74 & A & $\theta .36$ & {$[6.2 \mathrm{e}-10,2.9]$} & 0.11 & 0.11 & 0.11 & 0.11 & 0.11 & $\theta .11$ \\
\hline 75 & $E$ & $\theta .23$ & {$[6.2 \mathrm{e}-10,2.9]$} & $\theta .12$ & 0.12 & 0.12 & 0.12 & 0.12 & 0.12 \\
\hline 76 & $\mathrm{k}$ & $\theta .15$ & {$[6.2 \mathrm{e}-10,2.9]$} & $\theta .12$ & 0.12 & $\theta .12$ & 0.12 & 0.12 & 0.12 \\
\hline 77 & $\mathrm{k}$ & 0.15 & {$[6.2 \mathrm{e}-10,2.9]$} & 0.12 & 0.12 & 0.12 & 0.12 & 0.12 & 0.12 \\
\hline 78 & D & 0.17 & {$[6.2 \mathrm{e}-10,2.9]$} & 0.12 & $\theta .12$ & 0.12 & 0.12 & 0.12 & $\theta .12$ \\
\hline 79 & p & $\theta .44$ & {$[6.2 \mathrm{e}-10,2.9]$} & $\theta .11$ & $\theta .11$ & $\theta .11$ & $\theta .11$ & $\theta .11$ & $\theta .11$ \\
\hline 80 & $\mathrm{E}$ & 0.19 & {$[6.2 \mathrm{e}-10,2.9]$} & 0.12 & $\theta .12$ & 0.12 & 0.12 & 0.12 & 0.12 \\
\hline 81 & H & 0.34 & {$[6.2 \mathrm{e}-10,2.9]$} & $\theta .11$ & $\theta .11$ & $\theta .11$ & 0.11 & 0.11 & 0.11 \\
\hline 82 & A & 0.32 & {$[6.2 \mathrm{e}-10,2.9]$} & $\theta .11$ & $\theta .11$ & $\theta .11$ & 0.11 & $\theta .11$ & 0.11 \\
\hline 83 & H & 0.34 & {$[6.2 \mathrm{e}-10,2.9]$} & 0.11 & 0.11 & 0.11 & 0.11 & 0.11 & 0.11 \\
\hline 84 & $\mathbf{R}$ & 0.31 & {$[6.2 \mathrm{e}-10,2.9]$} & $\theta .11$ & 0.11 & $\theta .11$ & 0.11 & 0.11 & 6.11 \\
\hline 85 & H & $\theta .37$ & {$[6.2 \mathrm{e}-10,2.9]$} & $\theta .11$ & $\theta .11$ & $\theta .11$ & $\theta .11$ & $\theta .11$ & $\theta .11$ \\
\hline 86 & $\mathrm{k}$ & $\theta .21$ & {$[6.2 \mathrm{e}-10,2.9]$} & $\theta .12$ & $\theta .12$ & 0.12 & 0.12 & 0.12 & $\theta .12$ \\
\hline 87 & I & $\theta .37$ & {$[6.2 \mathrm{e}-10,2.9]$} & $\theta .11$ & $\theta .11$ & $\theta .11$ & 0.11 & 0.11 & $\theta .11$ \\
\hline 88 & E & 0.3 & {$[6.2 \mathrm{e}-1 \theta, 2.9]$} & 0.12 & 0.12 & 0.12 & 0.12 & $\theta .12$ & 0.11 \\
\hline
\end{tabular}




\begin{tabular}{|c|c|c|c|c|c|c|c|c|c|c|c|c|}
\hline 89 & E & 0.23 & {$[6.2 \mathrm{e}-10,2.9]$} & 0.12 & 0.12 & 0.12 & 0.12 & 0.12 & 0.12 & 0.12 & 0.1 & 0.067 \\
\hline 90 & $\mathrm{E}$ & 0.23 & {$[6.2 \mathrm{e}-10,2.9]$} & 0.12 & 0.12 & 0.12 & 0.12 & 0.12 & 0.12 & 0.12 & 0.1 & 0.067 \\
\hline 91 & I & 0.37 & {$[6.2 \mathrm{e}-10,2.9]$} & 0.11 & 0.11 & 0.11 & 0.11 & 0.11 & 0.11 & 0.11 & 0.11 & 0.12 \\
\hline 92 & A & 0.41 & {$[6.2 \mathrm{e}-10,2.9]$} & 0.11 & 0.11 & 0.11 & 0.11 & 0.11 & 0.11 & 0.11 & 0.1 & 0.13 \\
\hline 93 & A & 0.41 & {$[6.2 \mathrm{e}-10,2.9]$} & 0.11 & 0.11 & 0.11 & 0.11 & 0.11 & 0.11 & 0.11 & 0.1 & 0.13 \\
\hline 94 & A & 0.41 & {$[6.2 \mathrm{e}-10,2.9]$} & 0.11 & 0.11 & 0.11 & 0.11 & 0.11 & 0.11 & 0.11 & 0.1 & 0.13 \\
\hline 95 & A & 0.35 & {$[6.2 \mathrm{e}-16,2.9]$} & 0.11 & 0.11 & 0.11 & 0.11 & 0.11 & 0.11 & 0.11 & 0.11 & 0.11 \\
\hline 96 & A & 0.59 & {$[6.2 \mathrm{e}-16,2.9]$} & 0.1 & 0.1 & 0.1 & 0.1 & 0.1 & 0.1 & 0.1 & 0.1 & 0.19 \\
\hline 97 & v & 0.59 & {$[6.2 \mathrm{e}-10,2.9]$} & 0.1 & 0.1 & 0.1 & 0.1 & 0.1 & 0.1 & 0.1 & 0.1 & 0.19 \\
\hline 98 & G & 0.59 & {$[6.2 \mathrm{e}-16,2.9]$} & 0.1 & 0.1 & 0.1 & 0.1 & 0.1 & 0.1 & 0.1 & 0.1 & 0.19 \\
\hline 99 & E & 0.59 & {$[6.2 \mathrm{e}-10,2.9]$} & 0.1 & 0.1 & 0.1 & 0.1 & 0.1 & 0.1 & 0.1 & 0.1 & 0.19 \\
\hline 100 & G & 0.59 & {$[6.2 \mathrm{e}-10,2.9]$} & 0.1 & 0.1 & 0.1 & 0.1 & 0.1 & 0.1 & 0.1 & 0.1 & 0.19 \\
\hline 101 & G & 0.59 & {$[6.2 \mathrm{e}-10,2.9]$} & 0.1 & 0.1 & 0.1 & 0.1 & 0.1 & 0.1 & 0.1 & 0.1 & 0.19 \\
\hline
\end{tabular}

Supplementary Table 6: Ka/Ks values per LP3-3 amino acid. First are represented amino acid position, then amino acid, w-score, confidence interval and Bayesian posterior probabilities. 
(a) ASR1

Selecton Bayesian Ka/Ks Results

Displayed on sequence

\begin{tabular}{|c|c|c|c|c|c|c|c|c|}
\hline POS & AMINO & $\mathrm{Ka} / \mathrm{Ks}$ & [Confidence Inte & erval] (* & if lower & $r$ bound $>$ & >1) & \\
\hline & & & & & $w=$ & $\theta .60074$ & $\theta .607$ & 0.023 \\
\hline 1 & M & 0.025 & {$[0.80874,0.1]$} & & 0.3 & 8.27 & 0.21 & 0.13 \\
\hline 2 & E & $\theta .17$ & {$[0.023,0.55]$} & & $6.2 \mathrm{e}-65$ & $\theta .0951$ & 0.045 & 0.15 \\
\hline 3 & E & $\theta .014$ & {$[0.80074,0.053]$} & & 0.39 & $\theta .32$ & 0.19 & 0.08 \\
\hline 4 & E & 0.014 & {$[0.08074,0.053]$} & & 0.39 & 8. 32 & $\theta .19$ & 0.08 \\
\hline 5 & k & 0.051 & {$[0.607,0.18]$} & & e. 018 & 6.15 & e.31 & 0.31 \\
\hline 6 & H & 0.097 & {$[8.023,8.3]$} & & 0.60022 & $\theta .617$ & 0.13 & 0.31 \\
\hline 7 & H & 0.016 & {$[0.06074,0.1]$} & & 0.37 & 8.31 & 0.2 & 0.092 \\
\hline 8 & H & 0.015 & {$[0.00074,0.1]$} & & 0.37 & 8.31 & 0.2 & 0.087 \\
\hline 9 & H & 0.015 & {$[0.08974,6.1]$} & & 0.37 & 0.31 & 0.2 & 0.087 \\
\hline 10 & H & $\theta .21$ & {$[0.023,0.55]$} & & $3.6 e-05$ & $\theta .003$ & $\theta .028$ & $\theta .1$ \\
\hline 11 & $\mathrm{~L}$ & 0.32 & {$[0.1,0.55]$} & & $8.4 \mathrm{e}-68$ & $7 e-65$ & 0.0022 & 0.02 \\
\hline 12 & $\mathrm{~F}$ & 0.69 & {$[0.3,1]$} & $6.8 e-18$ & $8 e-12$ & $1.9 \mathrm{e}-68$ & $3.9 \mathrm{e}-86$ & 0.00022 \\
\hline 13 & H & 0.015 & {$[0.00074,0.1]$} & & e.37 & $\theta .31$ & 0.2 & 0.087 \\
\hline 14 & H & 0.22 & {$[0.053,0.55]$} & & $6.5 e-69$ & $4.7 \mathrm{e}-65$ & 0.0038 & 0.051 \\
\hline 15 & $\mathrm{k}$ & $\theta .015$ & {$[0.80974,8.1]$} & & 0.37 & $\theta .31$ & 0.2 & 0.087 \\
\hline 16 & D & 0.22 & {$[0.853,0.55]$} & & $1.1 \mathrm{e}-68$ & $7.8 e-65$ & 0.0058 & 0.067 \\
\hline 17 & $\mathrm{k}$ & $\theta .27$ & {$[0.053,0.55]$} & & $2.5 e-69$ & $1.9 e-65$ & 0.0017 & 0.026 \\
\hline 18 & A & 6.11 & {$[0.023,0.3]$} & & 0.00025 & 8.019 & 0.13 & 0.29 \\
\hline 19 & E & 0.35 & {$[0.053,1]$} & & $3.1 \mathrm{e}-67$ & 8. 80024 & 0.6064 & 0.044 \\
\hline $2 \theta$ & E & 0.9 & {$[0.55,1]$} & & $5.1 \mathrm{e}-21$ & $4.4 e-14$ & $2.4 \mathrm{e}-10$ & $9.1 \mathrm{e}-08$ \\
\hline 21 & G & 0.83 & {$[0.3,1]$} & $3.2 \mathrm{e}-2 \theta$ & $2,8 e-13$ & $1.6 \mathrm{e}-69$ & $5.7 \mathrm{e}-67$ & $4.7 e-65$ \\
\hline 22 & P & 8.77 & {$[0.3,1]$} & $2.3 e-16$ & $1.6 \mathrm{e}-10$ & $1.8 \mathrm{e}-87$ & $1.9 \mathrm{e}-65$ & 0.00056 \\
\hline 23 & v & 0.47 & {$[0.18,1]$} & & $1.2 \mathrm{e}-12$ & $8.6 e-68$ & $2.9 \mathrm{e}-85$ & e. 0012 \\
\hline 24 & D & 0.55 & {$[0.1,1]$} & $5.6 e-12$ & $3.8 \mathrm{e}-67$ & $9.8 e-65$ & 0.0028 & 0.023 \\
\hline 25 & $\gamma$ & 0.096 & {$[0.023,0.3]$} & & 0.00021 & 8.617 & 0.12 & 0.31 \\
\hline 26 & $\mathrm{E}$ & 0.27 & {$[0.053,1]$} & & $4.3 \mathrm{e}-69$ & $3.1 e-85$ & 0.0026 & 0.036 \\
\hline 27 & $\mathrm{k}$ & 0.016 & {$[0.00074,0.1]$} & & e. 36 & e. 31 & 0.2 & 0.093 \\
\hline 28 & E & 0.014 & {$[0.00074,0.1]$} & & 0.38 & 0.32 & 0.19 & 0.082 \\
\hline 29 & I & 0.41 & {$[0.1,1]$} & $5.8 e-12$ & $4.3 e-67$ & e.e0014 & $\theta .0051$ & 0.052 \\
\hline 30 & $\mathrm{k}$ & 0.015 & {$[0.86974,6.1]$} & & 0.37 & 0.31 & 0.2 & 0.088 \\
\hline 31 & H & 0.056 & {$[0.007,0.18]$} & & 0.016 & 0.13 & 0.29 & 0.31 \\
\hline 32 & H & 0.016 & {$[0.06074,0.1]$} & & 0.36 & $\theta .31$ & 0.2 & 0.095 \\
\hline 33 & $\mathrm{k}$ & 0.015 & {$[0.06974,0.1]$} & & 0.37 & $\theta .31$ & 0.2 & 0.088 \\
\hline 34 & H & $\theta .016$ & {$[0.00074,0.1]$} & & 0.37 & e.31 & 0.2 & 0.092 \\
\hline 35 & L & 0.49 & {$[0.18,1]$} & & $7.9 \mathrm{e}-13$ & $5.9 \mathrm{e}-68$ & $2 e-65$ & 0.00088 \\
\hline 36 & E & 0.052 & {$[0.607,0.18]$} & & $\theta .019$ & $\theta .15$ & $\theta .31$ & 0.3 \\
\hline 37 & Q & $\theta .099$ & {$[0.023,0.3]$} & & 0.00022 & e.017 & 0.12 & 0.3 \\
\hline 38 & I & $\theta .11$ & {$[0.007,0.3]$} & & 0.0062 & 0.855 & 0.15 & 0.24 \\
\hline 39 & G & 0.018 & {$[0.80974,0.1]$} & & 8.34 & 0.3 & 0.21 & 0.11 \\
\hline $4 \theta$ & $\mathrm{k}$ & $\theta .2$ & {$[0.053,0.55]$} & & $7.1 \mathrm{e}-87$ & e. 60056 & 0.015 & 0.099 \\
\hline 41 & L & 6.41 & {$[0.1,1]$} & $2.9 \mathrm{e}-10$ & $2.2 e-86$ & 8.60023 & 0.8045 & 0.036 \\
\hline 42 & G & 0.017 & {$[\theta .80974, \theta .1]$} & & 0.35 & 6.3 & 0.2 & 0.099 \\
\hline 43 & T & 0.087 & {$[0.007,0.3]$} & & e.0091 & 0.078 & 0.2 & 0.28 \\
\hline 44 & v & 6.53 & {$[0.18,1]$} & & $4.2 \mathrm{e}-15$ & $2.9 \mathrm{e}-69$ & $3 e-06$ & 6.60027 \\
\hline 45 & A & 0.025 & {$[0.00074,0.1]$} & & 0.3 & 0.27 & 0.21 & 0.13 \\
\hline 46 & A & 0.021 & {$[0.00074,0.1]$} & & 0.33 & 0.29 & 0.21 & 0.12 \\
\hline 47 & G & 0.028 & {$[8.68074,0.18]$} & & 0.29 & 8.26 & 0.21 & 0.14 \\
\hline 48 & A & $\theta .021$ & {$[0.00074, \theta .1]$} & & 0.33 & 0.29 & $\theta .21$ & 0.12 \\
\hline 49 & $\mathrm{r}$ & 0.14 & {$[0.023,0.3]$} & & $8.7 e-65$ & 0.0972 & 0.86 & 0.19 \\
\hline 50 & A & 8.026 & {$[0.80074,0.18]$} & & 0.3 & 0.27 & 0.21 & 0.13 \\
\hline 51 & L & 0.033 & {$[0.00074, \theta .18]$} & & 0.27 & e.25 & 0.21 & 0.15 \\
\hline 52 & H & $\theta .11$ & {$[0.023,0.3]$} & & 0.00016 & 0.013 & 0.097 & 0.26 \\
\hline 53 & E & 0.014 & {$[0.60974,0.053]$} & & 6.39 & 6.32 & 0.19 & 0.078 \\
\hline 54 & $\mathrm{k}$ & 0.015 & {$[0.00074,0.1]$} & & 0.37 & e. 31 & 0.2 & 0.088 \\
\hline 55 & H & 0.016 & {$[0.60874,0.1]$} & & 0.37 & $\theta .31$ & 0.2 & $\theta .092$ \\
\hline 56 & E & 0.098 & {$[0.023,0.3]$} & & 0.00027 & $\theta . \theta 2$ & 0.14 & 0.31 \\
\hline 57 & A & 0.024 & {$[0.00074,0.1]$} & & e.31 & 0.28 & 0.21 & 0.13 \\
\hline 58 & $\mathrm{k}$ & 0.091 & {$[0.023,0.3]$} & & 0.00026 & $\theta .02$ & 0.14 & 0.32 \\
\hline 59 & $\mathrm{k}$ & 0.016 & {$[0.00874,0.1]$} & & 0.36 & 6.31 & 0.2 & 0.093 \\
\hline 60 & D & 0.013 & {$[0.00074,0.053]$} & & 0.4 & e.32 & 0.19 & 0.072 \\
\hline 61 & $\mathrm{p}$ & 0.32 & {$[0.053,0.55]$} & & $1 e-87$ & $8.5 e-65$ & 0.8026 & 0.023 \\
\hline 62 & E & 8.053 & {$[0.007,0.18]$} & & e. 019 & 8.15 & 0.31 & 0.3 \\
\hline 63 & H & 0.056 & {$[0.607,0.18]$} & & 0.016 & 8.13 & 0.29 & e. 31 \\
\hline 64 & A & $\theta .36$ & {$[0.1,1]$} & $6.6 \mathrm{e}-10$ & $5.1 \mathrm{e}-06$ & $\theta .6005$ & $\theta .0089$ & 0.062 \\
\hline 65 & H & 0.016 & {$[0.00074,0.1]$} & & 0.37 & $\theta .31$ & 0.2 & 0.091 \\
\hline 66 & $\mathrm{k}$ & $\theta .33$ & {$[0.1,1]$} & $1 e-\theta 9$ & $7.8 \mathrm{e}-66$ & 6.69071 & 0.012 & 0.082 \\
\hline 67 & H & 0.015 & {$[0.00974,0.1]$} & & 0.37 & $\theta .31$ & $\theta .2$ & 0.087 \\
\hline 68 & k & 0.014 & {$[0.00074,0.1]$} & & 0.38 & 0.32 & 0.2 & 0.083 \\
\hline 69 & I & $\theta .15$ & {$[0.023,0.3]$} & & $7.4 \mathrm{e}-05$ & 0.0062 & 0.053 & 0.17 \\
\hline 70 & E & 0.093 & {$[0.023,0.3]$} & & 0.00029 & $\theta .022$ & $\theta .15$ & 0.32 \\
\hline 71 & E & 8.014 & {$[0.00074,0.1]$} & & 0.39 & 0.32 & 0.19 & 0.08 \\
\hline 72 & E & 0.014 & {$[0.08074,0.053]$} & & 0.39 & e. 32 & 0.19 & 0.08 \\
\hline 73 & I & 0.25 & {$[8.853,8.55]$} & & $3,3 e-67$ & 8.e9026 & 0.8074 & 0.055 \\
\hline 74 & A & 0.1 & {$[0.607,0.3]$} & & 0.0071 & 0.062 & 0.16 & 0.25 \\
\hline 75 & A & 0.025 & {$[0.60874,0.18]$} & & 0.3 & 0.27 & 0.21 & 0.13 \\
\hline 76 & A & 0.08 & {$[0.087, \theta .3]$} & & 0.0098 & $\theta .084$ & $\theta .21$ & 0.29 \\
\hline 77 & A & 0.3 & {$[0.053,0.55]$} & & $1.4 \mathrm{e}-67$ & 8. 80011 & 0.6035 & 0.03 \\
\hline 78 & A & 0.082 & {$[0.607,0.3]$} & & 0.0094 & e.681 & 0.2 & 0.28 \\
\hline 79 & v & 0.16 & {$[0.023,0.55]$} & & $7.4 e-65$ & e.e961 & 0.052 & 0.17 \\
\hline $8 \theta$ & G & $\theta .017$ & {$[0.06074,0.1]$} & & e. 35 & 0.3 & 0.2 & 0.1 \\
\hline 81 & A & 0.26 & {$[0.053,8.55]$} & & $3.2 \mathrm{e}-67$ & 0.00025 & 0.6071 & 0.052 \\
\hline 82 & G & 0.16 & {$[0.023,0.55]$} & & $6.7 e-65$ & 0.0955 & 0.048 & 0.16 \\
\hline 83 & G & $\theta .019$ & {$[0.08074,0.1]$} & & 0.34 & 0.3 & 0.21 & 0.11 \\
\hline 84 & $F$ & 0.28 & {$[8.853,8.55]$} & & $1.5 e-65$ & $\theta .0013$ & 0.013 & 0.055 \\
\hline 85 & A & $\theta .24$ & {$[0.053,0.55]$} & & $3.3 e-67$ & 8.69026 & $\theta .6074$ & 0.055 \\
\hline 86 & $\mathrm{~F}$ & 0.12 & {$[0.007,0.3]$} & & 9.0053 & 0.648 & 0.13 & 0.22 \\
\hline 87 & H & 0.018 & {$[\theta .80074, \theta .1]$} & & 0.35 & 0.3 & 0.2 & $\theta .1$ \\
\hline 88 & E & 0.014 & {$[\theta .80974, \theta .053]$} & & 0.39 & 0.32 & $\theta .19$ & 0.079 \\
\hline
\end{tabular}




\begin{tabular}{|c|c|c|c|c|c|c|c|c|c|c|c|c|c|}
\hline 89 & H & 0.018 & {$[8.80974,8.1]$} & & 0.35 & 0.3 & 0.2 & 0.1 & 0.035 & 0.0075 & 0.6008 & $1.9 \mathrm{e}-05$ & $1.6 e-67$ \\
\hline 90 & H & 0.019 & {$[0.00074,0.1]$} & & 0.34 & 8.29 & 0.21 & $\theta .11$ & $\theta .041$ & 0.0099 & 0.0012 & $3.3 e-05$ & $2.4 \mathrm{e}-07$ \\
\hline 91 & E & 0.014 & {$[0.80974,0.053]$} & & 0.39 & 8.32 & 0.19 & 0.08 & 0.021 & 0.6034 & 0.08033 & $1.9 \mathrm{e}-05$ & $1.2 \mathrm{e}-06$ \\
\hline 92 & $\mathrm{k}$ & 0.015 & {$[0.00074,0.1]$} & & $\theta .37$ & $\theta .31$ & $\theta .2$ & 0.088 & 0.025 & 0.0038 & $\theta .60026$ & $3 e-96$ & $2.3 e-68$ \\
\hline 93 & $\mathrm{k}$ & 0.015 & {$[0.80874, \theta .1]$} & & 0.37 & 8.31 & 0.2 & 0.088 & 0.025 & 0.0038 & 0.08026 & $3 e-66$ & $2.3 e-68$ \\
\hline 94 & D & 0.33 & {$[0.1,1]$} & $2.8 \mathrm{e}-11$ & $1.8 \mathrm{e}-06$ & $\theta .00047$ & 0.013 & 0.095 & 0.27 & 0.35 & 0.22 & 0.844 & \\
\hline 95 & A & 0.068 & {$[0.007,0.18]$} & & $\theta .013$ & $\theta .11$ & 0.25 & $\theta .3$ & 0.22 & 0.092 & $\theta .02$ & $\theta .0014$ & $3.9 \mathrm{e}-65$ \\
\hline 96 & $\hat{\mathrm{k}}$ & 0.097 & {$[\theta .023, \theta .3]$} & & 0.00023 & $\theta .018$ & 0.13 & 0.31 & 0.33 & $\theta .17$ & 0.04 & 0.0028 & 0.00013 \\
\hline 97 & $\mathrm{k}$ & 0.1 & {$[0.023,0.3]$} & & ө. 00019 & 8.015 & 0.11 & 0.28 & 0.34 & 0.2 & $\theta .053$ & 8.0035 & $9.1 \mathrm{e}-05$ \\
\hline 98 & E & $\theta .15$ & {$[0.023,0.55]$} & & $1.9 \mathrm{e}-06$ & $\theta .0914$ & 0.033 & 0.17 & 0.34 & 0.3 & $\theta .13$ & 0.025 & 0.0028 \\
\hline 99 & $\mathrm{E}$ & 0.22 & {$[0.053,0.55]$} & & $6.4 \mathrm{e}-97$ & 0.0005 & 0.013 & 0.085 & 0.23 & 0.33 & 0.25 & 0.083 & $\theta .01$ \\
\hline 100 & K & 0.28 & {$[0.1,0.55]$} & & $1 e-69$ & $7.9 e-06$ & 0.60082 & 0.016 & 0.11 & 0.31 & 0.4 & 0.15 & 0.013 \\
\hline 101 & k & 0.099 & {$[0.023,0.3]$} & & 0.00027 & $\theta .02$ & $\theta .14$ & $\theta .31$ & $\theta .31$ & 0.16 & 0.046 & 0.0065 & 0.00054 \\
\hline 102 & A & 0.26 & {$[0.053,8.55]$} & & $2.1 \mathrm{e}-\theta 7$ & 0.60017 & 0.8051 & 0.041 & 0.15 & 0.31 & 0.34 & 0.14 & 0.0093 \\
\hline 103 & E & 0.52 & {$[0.18,1]$} & & $1.2 \mathrm{e}-17$ & $8.4 e-11$ & $3 e-67$ & $6 e-05$ & 0.0026 & 0.04 & 0.25 & 0.59 & 0.12 \\
\hline 104 & G & 0.032 & {$[0.00974,0.18]$} & & 0.27 & e.25 & 0.21 & 0.14 & 0.082 & 0.035 & 0.6095 & 0.00077 & $8.5 e-06$ \\
\hline 105 & G & 8.28 & {$[8.053,1]$} & & $3 e-87$ & 8.60024 & 0.0067 & 0.049 & 0.16 & 0.29 & 0.3 & $\theta .16$ & 0.031 \\
\hline 106 & H & $\theta .13$ & {$[0.023,0.3]$} & & e. 00012 & 0.6999 & 0.079 & 0.22 & 0.32 & e.25 & $\theta .1$ & 0.015 & ө.00094 \\
\hline 107 & H & $\theta .019$ & {$[0.00074,0.1]$} & & e. 34 & $\theta .3$ & 0.21 & 0.11 & 0.039 & 0.0087 & $\theta .001$ & $3.3 \mathrm{e}-65$ & $7.4 \mathrm{e}-\theta 7$ \\
\hline 108 & H & 0.02 & {$[8.60974,0.1]$} & & 0.3 & 8.29 & 0.21 & $\theta .12$ & 0.047 & 0.613 & $\theta .0018$ & $7 e-65$ & $1.1 \mathrm{e}-06$ \\
\hline 109 & L & e.12 & {$[0.007,0.3]$} & & 0.005 & $\theta .845$ & 0.13 & 0.22 & 0.26 & 0.21 & 0.11 & 0.021 & 8.00044 \\
\hline 110 & $\mathrm{~F}$ & 0.051 & {$[0.68974,6.3]$} & & 0.22 & 8.21 & 0.19 & 0.16 & 0.11 & 0.069 & $\theta .031$ & 0.0065 & 0.00022 \\
\hline
\end{tabular}

Supplementary Table 7: Ka/Ks values per ASR1 amino acid. First are represented amino acid position, then amino acid, w-score, confidence interval and Bayesian posterior probabilities. 


\section{(b) ASR2}

Selecton Bayesian $\mathrm{Ka} / \mathrm{Ks}$ Results

\begin{tabular}{|c|c|c|c|c|c|c|c|c|}
\hline POS & AMINO & $\mathrm{Ka} / \mathrm{Ks}$ & [Confidence Int & erval] (* & if lower & $r$ bound & $>$ 1) & \\
\hline & & & & & $w=$ & $\theta .0912$ & 0.6097 & 0.03 \\
\hline 1 & M & 0.041 & {$[0.8012, \theta .2]$} & & 0.27 & 8.25 & 0.2 & 0.14 \\
\hline 2 & A & 0.31 & {$[0.064,0.57]$} & & $3.1 \mathrm{e}-85$ & 0.002 & 0.016 & 0.059 \\
\hline 3 & E & $\theta .026$ & {$[0.0012, \theta .12]$} & & $\theta .34$ & 0.29 & $\theta .2$ & 0.11 \\
\hline 4 & E & 0.026 & {$[0.0012,0.12]$} & & 0.34 & 0.29 & 0.2 & 0.11 \\
\hline 5 & k & 0.096 & {$[0.0097,0.32]$} & & 0.013 & 0.097 & 0.21 & 0.27 \\
\hline 6 & H & 0.21 & {$[0.03,0.57]$} & & $\theta .00011$ & $\theta .8966$ & 0.047 & 0.14 \\
\hline 7 & $Q$ & 0.17 & {$[0.0012,0.57]$} & & $\theta .13$ & 0.13 & 0.13 & 0.13 \\
\hline 8 & $\mathrm{H}$ & $\theta .16$ & {$[0.0012, \theta .57]$} & & $\theta .13$ & 0.13 & $\theta .13$ & $\theta .13$ \\
\hline 9 & H & 0.03 & {$[0.0012,0.2]$} & & 0.31 & 0.28 & 0.2 & 0.12 \\
\hline 10 & H & 0.029 & {$[\theta . \theta 012, \theta .2]$} & & $\theta .32$ & 0.28 & 0.2 & $\theta .12$ \\
\hline 11 & H & 0.03 & {$[\theta . \theta 012, \theta .2]$} & & 0.31 & 0.28 & $\theta .2$ & $\theta .12$ \\
\hline 12 & L & $\theta .06$ & {$[0.0012,0.32]$} & & 8.23 & 0.21 & 0.19 & $\theta .15$ \\
\hline 13 & $\mathrm{~F}$ & e.19 & {$[0.6097,0.57]$} & & 0.0043 & 0.034 & 0.092 & $\theta .16$ \\
\hline 14 & H & 0.029 & {$[\theta .0012, \theta .2]$} & & 0.32 & 0.28 & 0.2 & $\theta .12$ \\
\hline 15 & H & 0.029 & {$[\theta .0012, \theta .2]$} & & 0.32 & 0.28 & 0.2 & 0.12 \\
\hline 16 & k & 0.035 & {$[\theta .0012, \theta .2]$} & & 0.3 & 0.26 & $\theta .2$ & $\theta .13$ \\
\hline 17 & $\mathrm{~N}$ & 0.25 & {$[0.83,0.57]$} & & $8 e-05$ & 0.005 & 0.036 & $\theta .11$ \\
\hline 18 & $\mathrm{k}$ & 8.56 & {$[0.2,1]$} & $3.8 \mathrm{e}-11$ & $1.8 \mathrm{e}-67$ & $1.7 e-65$ & 0.0004 & 0.0047 \\
\hline 19 & E & 0.3 & {$[8.03,0.57]$} & & $5.3 e-65$ & 8.0033 & 0.025 & 0.081 \\
\hline $2 \theta$ & D & $\theta .23$ & {$[0.03,0.57]$} & & 0.00015 & 0.0087 & 0.057 & 0.15 \\
\hline 21 & E & 0.38 & {$[0.12,0.57]$} & & $5.5 e-\theta 8$ & $4.5 e-65$ & 0.6017 & 0.018 \\
\hline 22 & G & 0.55 & {$[0.2,1]$} & $1.5 \mathrm{e}-10$ & $6.8 \mathrm{e}-97$ & $5.4 e-65$ & 0.001 & 0.6088 \\
\hline 23 & G & 0.36 & {$[0.864,0.57]$} & & $2.9 \mathrm{e}-67$ & e.e0015 & 0.0036 & 0.025 \\
\hline 24 & p & 0.3 & {$[0.864,8.57]$} & & $3.2 \mathrm{e}-65$ & 0.0021 & 0.017 & 0.062 \\
\hline 25 & v & 0.5 & {$[0.2,1]$} & $4.2 \mathrm{e}-10$ & $1.9 \mathrm{e}-86$ & 0.80614 & 0.0024 & 0.018 \\
\hline 26 & D & 0.39 & {$[0.064,1]$} & & $5.2 \mathrm{e}-97$ & 0.09026 & 0.0054 & 0.032 \\
\hline 27 & y & $\theta .031$ & {$[\theta .0012, \theta .2]$} & & 0.31 & 0.27 & 0.21 & $\theta .13$ \\
\hline 28 & E & $\theta .32$ & {$[0.064,0.57]$} & & $8.3 e-97$ & $\theta .80041$ & 0.0084 & 0.048 \\
\hline 29 & k & 0.026 & {$[0.0012,0.12]$} & & 0.33 & 0.29 & 0.2 & 0.11 \\
\hline 30 & E & 0.027 & {$[0.0012, \theta .12]$} & & 0.34 & 0.29 & 0.2 & 0.11 \\
\hline 31 & v & 0.25 & {$[0.03,0.57]$} & & ๑. 00013 & 8.6976 & 0.05 & $\theta .13$ \\
\hline 32 & k & 0.025 & {$[0.0012, \theta .12]$} & & $\theta .34$ & 8.29 & 0.2 & $\theta .11$ \\
\hline 33 & H & 0.029 & {$[0.0012,0.2]$} & & 0.32 & 0.28 & 0.2 & 0.12 \\
\hline 34 & H & 0.029 & {$[\theta . \theta 012, \theta .2]$} & & 0.32 & 0.28 & 0.2 & $\theta .12$ \\
\hline 35 & s & 0.22 & {$[0.03,0.57]$} & & ө. 00014 & 8.6986 & 0.058 & $\theta .15$ \\
\hline 36 & H & 0.03 & {$[\theta . \theta 012, \theta .2]$} & & 0.31 & 0.27 & 0.2 & 0.12 \\
\hline 37 & L & 0.34 & {$[0.064,8.57]$} & & $1.3 e-65$ & ө.e0091 & 0.0084 & 0.037 \\
\hline 38 & $\mathrm{E}$ & 0.026 & {$[\theta . \theta 012, \theta .12]$} & & Q. 34 & 0.29 & 0.2 & 0.11 \\
\hline 39 & k & 0.32 & {$[0.864,8.57]$} & & $5.6 \mathrm{e}-87$ & 0.00029 & 0.0063 & 0.04 \\
\hline $4 \theta$ & I & 0.16 & {$[0.0097,0.57]$} & & 0.0055 & 0.043 & 0.11 & 0.19 \\
\hline 41 & G & $\theta .03$ & {$[0.0012,0.2]$} & & $\theta .31$ & 8.27 & 0.2 & 0.13 \\
\hline 42 & E & $\theta .15$ & {$[0.0097,0.57]$} & & 0.0076 & 0.058 & $\theta .14$ & $\theta .22$ \\
\hline 43 & i & $\theta .19$ & {$[0.0097,0.57]$} & & 8.0042 & 8.033 & 8.89 & 0.16 \\
\hline 44 & G & 0.028 & {$[0.0012, \theta .12]$} & & 0.32 & 0.28 & $\theta .2$ & 0.12 \\
\hline 45 & A & $\theta .13$ & {$[0.8097,0.57]$} & & 0.0079 & 0.06 & $\theta .15$ & 0.22 \\
\hline 46 & $\mathrm{v}$ & 0.37 & {$[0.12,0.57]$} & & $2.2 \mathrm{e}-87$ & e.e0012 & 0.0028 & 0.021 \\
\hline 47 & A & $\theta .04$ & {$[\theta . \theta 012, \theta .2]$} & & 0.27 & 0.25 & $\theta .2$ & 0.14 \\
\hline 48 & $\hat{A}$ & 0.04 & {$[\theta .8012, \theta .2]$} & & 0.27 & 0.25 & 0.2 & 0.14 \\
\hline 49 & G & 0.03 & {$[0.0012, \theta .2]$} & & 0.31 & 0.27 & 0.2 & 0.13 \\
\hline 50 & A & $\theta .04$ & {$[0.0012,0.2]$} & & 0.27 & 0.25 & 0.2 & 0.14 \\
\hline 51 & $\hat{L}$ & 0.38 & {$[0.12,0.57]$} & & $1.9 e-87$ & 0.6001 & 0.0024 & 0.018 \\
\hline 52 & A & 0.038 & {$[8.0012, \theta .2]$} & & 0.28 & 0.25 & 0.2 & 0.14 \\
\hline 53 & L & 0.085 & {$[0.6012,0.57]$} & & 0.19 & 0.18 & 0.17 & 0.15 \\
\hline 54 & H & e.11 & {$[0.0097,0.32]$} & & 0.011 & e.e83 & $\theta .19$ & 0.26 \\
\hline 55 & E & 0.026 & {$[0.0012,0.12]$} & & 0.34 & 0.29 & 0.2 & $\theta .11$ \\
\hline 56 & k & 0.025 & {$[0.0012, \theta .12]$} & & 0.34 & 0.29 & $\theta .2$ & $\theta .11$ \\
\hline 57 & H & 0.029 & {$[\theta . \theta 012, \theta .2]$} & & 0.32 & 0.28 & 0.2 & $\theta .12$ \\
\hline 58 & $\mathrm{k}$ & $\theta .18$ & {$[0.03,0.57]$} & & $\theta .00016$ & $\theta .6998$ & 0.867 & 0.18 \\
\hline 59 & A & 0.16 & {$[0.0097,0.57]$} & & 0.0064 & 0.049 & 0.13 & 0.2 \\
\hline 60 & $\hat{\mathrm{k}}$ & 0.085 & {$[0.0097,0.32]$} & & 0.016 & $\theta .11$ & 0.24 & 0.28 \\
\hline 61 & $\mathrm{k}$ & 0.025 & {$[0.0012, \theta .12]$} & & 0.34 & 0.29 & $\theta .2$ & $\theta .11$ \\
\hline 62 & D & 0.026 & {$[0.0012, \theta .12]$} & & 0.35 & 0.29 & 0.19 & $\theta .1$ \\
\hline 63 & p & 0.2 & {$[0.0097,0.57]$} & & 0.0041 & 8.833 & 0.089 & 0.16 \\
\hline 64 & E & 0.026 & {$[\theta . \theta 012, \theta .12]$} & & 0.34 & 0.29 & 0.2 & $\theta .11$ \\
\hline 65 & H & 0.33 & {$[0.064,0.57]$} & & $6.6 \mathrm{e}-\theta 7$ & 0.09033 & 0.0071 & 0.044 \\
\hline 66 & A & 0.041 & {$[\theta .8012, \theta .2]$} & & 0.27 & 0.25 & 0.2 & 0.14 \\
\hline 67 & H & 0.029 & {$[0.0012, \theta .2]$} & & 0.32 & 0.28 & 0.2 & 0.12 \\
\hline 68 & k & 0.16 & {$[0.03,0.57]$} & & 0.0002 & 0.012 & 0.078 & 0.2 \\
\hline 69 & H & 0.029 & {$[\theta . \theta 012, \theta .2]$} & & 0.32 & 0.28 & 0.2 & 0.12 \\
\hline 70 & $\mathrm{k}$ & 0.025 & {$[0.0012,0.12]$} & & $\theta .34$ & 0.29 & $\theta .2$ & 0.11 \\
\hline 71 & I & 0.18 & {$[0.0097,0.57]$} & & 0.0049 & 0.038 & $\theta .1$ & 8.17 \\
\hline 72 & $\mathrm{E}$ & 0.098 & {$[0.0097,0.32]$} & & 0.015 & $\theta .11$ & 0.22 & $\theta .26$ \\
\hline 73 & E & 0.027 & {$[0.0012,0.12]$} & & $\theta .34$ & 0.29 & $\theta .2$ & 0.11 \\
\hline 74 & $\mathrm{E}$ & 0.026 & {$[0.0012, \theta .12]$} & & 0.34 & $\theta .29$ & 0.2 & $\theta .11$ \\
\hline 75 & I & $\theta .16$ & {$[0.0097,0.57]$} & & 0.0056 & 0.043 & $\theta .11$ & $\theta .19$ \\
\hline 76 & A & 0.042 & {$[0.8012,0.2]$} & & 0.27 & 0.24 & 0.2 & 0.14 \\
\hline 77 & $\hat{A}$ & 0.044 & {$[\theta .0012, \theta .2]$} & & 0.26 & $\theta .24$ & 0.2 & 0.14 \\
\hline 78 & v & 0.25 & {$[8.03,0.57]$} & & $5.8 e-65$ & 0.8937 & 0.028 & 0.096 \\
\hline 79 & A & $\theta .14$ & {$[0.0097,0.57]$} & & 0.0073 & 0.656 & 0.14 & 0.22 \\
\hline 80 & $\hat{A}$ & 0.044 & {$[\theta .0012, \theta .2]$} & & 0.26 & 0.24 & 8.2 & 0.14 \\
\hline 81 & $\mathrm{v}$ & $\theta .14$ & {$[0.0897,0.57]$} & & 0.0072 & 0.055 & 0.14 & 0.22 \\
\hline 82 & G & 0.03 & {$[0.0012, \theta .2]$} & & 0.31 & 0.27 & 0.2 & 0.12 \\
\hline 83 & A & $\theta .28$ & {$[0.064,0.57]$} & & $4.1 \mathrm{e}-65$ & 0.0926 & 0.021 & 0.075 \\
\hline 84 & G & $\theta .12$ & {$[0.8097,0.32]$} & & 0.009 & 0.868 & $\theta .16$ & 0.24 \\
\hline 85 & G & 0.031 & {$[0.0012,0.2]$} & & 0.3 & 0.27 & 0.2 & 0.13 \\
\hline 86 & $\mathrm{~F}$ & $\theta .18$ & {$[0.0097,0.57]$} & & 0.0045 & 0.036 & 0.096 & 0.17 \\
\hline 87 & A & 0.041 & {$[8.8012,0.2]$} & & 0.27 & 0.25 & 0.2 & 0.14 \\
\hline 88 & $\hat{F}$ & 0.059 & {$[0.8012, \theta .32]$} & & 0.22 & 0.21 & $\theta .19$ & 0.15 \\
\hline
\end{tabular}




\begin{tabular}{|c|c|c|c|}
\hline 89 & $\mathrm{H}$ & 0.03 & {$[8.0012, \theta .2]$} \\
\hline 90 & E & 0.026 & {$[0.0012, \theta .12]$} \\
\hline 91 & H & 0.03 & {$[0.0012,0.2]$} \\
\hline 92 & H & 8.03 & {$[0.0012, \theta .2]$} \\
\hline 93 & Q & $\theta .13$ & {$[0.0097,0.57]$} \\
\hline 94 & k & 0.026 & {$[0.8012,0.12]$} \\
\hline 95 & $\mathrm{k}$ & 0.027 & {$[0.0012,0.12]$} \\
\hline 96 & D & $\theta .11$ & {$[0.0097,0.57]$} \\
\hline 97 & A & 0.14 & {$[0.8097,0.57]$} \\
\hline 98 & $\mathrm{k}$ & 0.025 & {$[0.0012, \theta .12]$} \\
\hline 99 & $\mathrm{k}$ & 0.092 & {$[0.8097,6.32]$} \\
\hline 100 & E & 8.84 & {$[8.0012,0.2]$} \\
\hline 101 & $\mathrm{k}$ & $\theta .43$ & {$[0.12,1]$} \\
\hline 102 & $\mathrm{k}$ & $\theta .18$ & {$[8.6097,0.57]$} \\
\hline 103 & E & $\theta .04$ & {$[0 . \theta 012, \theta .2]$} \\
\hline 104 & v & 0.2 & {$[0.0097,0.57]$} \\
\hline 105 & E & 0.46 & {$[0.12,1]$} \\
\hline 106 & G & 0.05 & {$[0.0012,0.32]$} \\
\hline 107 & G & $\theta .41$ & {$[0.12,1]$} \\
\hline 108 & H & 0.072 & {$[0.0012,0.57]$} \\
\hline 109 & H & 0.22 & {$[0.03,0.57]$} \\
\hline 110 & H & 0.23 & {$[0.03,0.57]$} \\
\hline 111 & H & 0.23 & {$[0.03,0.57]$} \\
\hline 112 & H & 0.11 & {$[0.6097,0.32]$} \\
\hline 113 & H & 0.32 & {$[0.064,0.57]$} \\
\hline 114 & $\mathrm{Y}$ & 0.26 & {$[8.03,8.57]$} \\
\hline
\end{tabular}

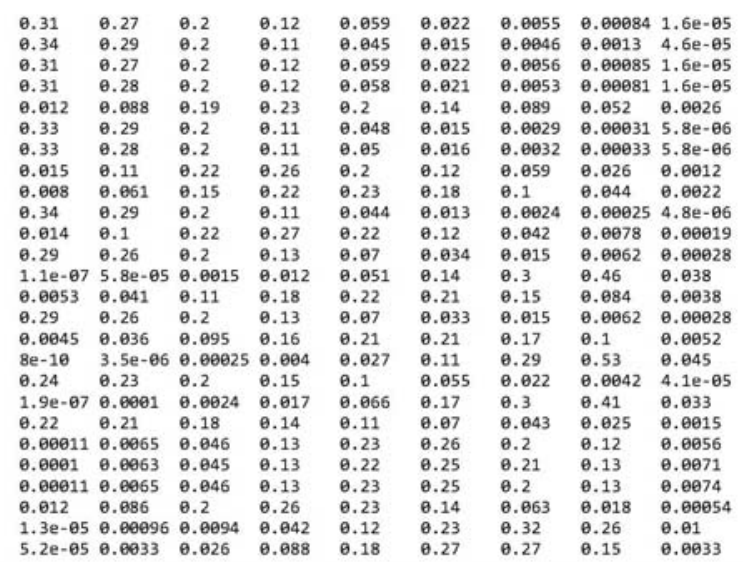

Supplementary Table 8: Ka/Ks values per ASR2 amino acid. First are represented amino acid position, then amino acid, w-score, confidence interval and Bayesian posterior probabilities. 
(c) ASR3

Selecton Bayesian $\mathrm{Ka} / \mathrm{Ks}$ Results

\begin{tabular}{|c|c|c|c|c|c|c|c|c|}
\hline POS & AMINO & $\mathrm{Ka} / \mathrm{Ks}$ & [Confidence Interval] (* & if lower & $r$ bound & $>$ 1) & & POSTERI \\
\hline & & & & $w=$ & ө. & 0.0036 & 0.019 & 0.059 \\
\hline 1 & M & 0.29 & {$[\theta .80917,1]$} & 0.13 & 8.13 & 0.13 & 0.12 & 0.11 \\
\hline 2 & A & 0.92 & {$[0.28,1]$} & $1.4 e-68$ & $6.1 \mathrm{e}-66$ & ө.08017 & 0.0016 & 0.0079 \\
\hline 3 & E & $\theta .16$ & {$[\theta .80017,1]$} & $\theta .18$ & 0.18 & $\theta .17$ & 0.15 & 0.12 \\
\hline 4 & E & 0.18 & {$[6.88017,1]$} & 0.17 & 0.17 & 0.16 & 0.14 & 0.12 \\
\hline 5 & $\mathrm{k}$ & $\theta .18$ & {$[0.80017,1]$} & 0.17 & 0.17 & 0.16 & 0.14 & 0.12 \\
\hline 6 & $Q$ & 0.23 & {$[8.68017,1]$} & 0.15 & $\theta .15$ & 0.15 & 0.14 & 0.11 \\
\hline 7 & H & 0.22 & {$[8.00017,1]$} & $\theta .15$ & 0.15 & 0.15 & 0.14 & 0.12 \\
\hline 8 & H & 0.73 & {$[0.059,1]$} & ө. 00011 & 0.0923 & $\theta .012$ & 0.035 & 0.071 \\
\hline 9 & $\mathbf{R}$ & 0.75 & {$[0.059,1]$} & 0.0001 & $\theta .0921$ & 0.011 & 0.032 & 0.065 \\
\hline 10 & $\ddot{L}$ & 0.9 & {$[0.14,1]$} & $2.2 \mathrm{e}-05$ & 0.00647 & 0.0025 & 0.0077 & 0.018 \\
\hline 11 & $\mathrm{~F}$ & $\theta .42$ & {$[0.08017,1]$} & 0.1 & $\theta .1$ & $\theta .1$ & 0.098 & 0.093 \\
\hline 12 & H & 0.71 & {$[0.059,1]$} & ө. & 0.0927 & 0.014 & 0.039 & 0.078 \\
\hline 13 & H & 0.2 & {$[\theta . \theta 0017,1]$} & $\theta .16$ & $\theta .16$ & $\theta .16$ & 0.14 & $\theta .12$ \\
\hline 14 & k & 0.89 & {$[0.28,1]$} & $3 e-68$ & $1.3 e-65$ & ө. 00036 & 0.0032 & 0.015 \\
\hline 15 & N & $\theta .64$ & {$[0.059,1]$} & $\theta .00019$ & 6.0039 & $\theta .02$ & 0.055 & 0.1 \\
\hline 16 & $\mathbf{R}$ & 0.97 & {$[0,49,1]$} & 1. $2 \mathrm{e}-15$ & $2.2 \mathrm{e}-10$ & $1.8 \mathrm{e}-67$ & $1.5 e-05$ & 0.00039 \\
\hline 17 & E & $\theta .14$ & {$[8.80017,1]$} & 0.18 & 0.18 & 0.17 & $\theta .15$ & 0.12 \\
\hline 18 & E & $\theta .64$ & {$[0.059,1]$} & 0.00019 & 0.0939 & 0.02 & 0.056 & 0.1 \\
\hline 19 & $E$ & 0.6 & {$[0.019,1]$} & 0.00022 & 8.0046 & 0.024 & 0.065 & 0.12 \\
\hline $2 \theta$ & G & $\theta .89$ & {$[0.28,1]$} & $1.3 \mathrm{e}-05$ & 0.09028 & 0.0016 & 0.0057 & 0.016 \\
\hline 21 & G & 0.93 & {$[0.28,1]$} & $1.2 \mathrm{e}-98$ & $5.2 \mathrm{e}-66$ & 8.60015 & 0.0014 & 0.007 \\
\hline 22 & $p$ & 0.91 & {$[0.28,1]$} & $1.7 \mathrm{e}-68$ & $7.5 e-66$ & 0.60021 & 0.0019 & 0.0094 \\
\hline 23 & v & 0.76 & {$[0.059,1]$} & $9.5 e-05$ & 0.092 & 0.01 & 0.03 & 0.062 \\
\hline 24 & D & 0.59 & {$[0.019,1]$} & 0.00025 & 0.0052 & 0.026 & 0.071 & 0.13 \\
\hline 25 & H & 0.73 & {$[0.859,1]$} & 0.00011 & 0.0924 & 0.012 & 0.036 & 0.072 \\
\hline 26 & K & 0.94 & {$[8,49,1]$} & $7.1 \mathrm{e}-12$ & $6.5 e-68$ & $9.5 \mathrm{e}-66$ & 0.00026 & 0.0028 \\
\hline 27 & $\mathrm{~K}$ & $\theta .13$ & {$[\theta .00017,1]$} & 0.19 & 0.19 & 0.18 & 0.16 & 0.12 \\
\hline 28 & k & 0.85 & {$[0.14,1]$} & $5.5 e-98$ & $2.4 e-65$ & e. 00065 & 0.0055 & 0.024 \\
\hline 29 & $\mathrm{v}$ & 8.95 & {$[0.49,1]$} & $4.7 \mathrm{e}-12$ & $4.3 e-68$ & $6.3 e-66$ & 0.00018 & 0.002 \\
\hline 30 & k & $\theta .15$ & {$[0.08017,1]$} & 0.18 & 0.18 & 0.17 & 0.15 & 0.12 \\
\hline 31 & H & e.19 & {$[0.00017,1]$} & 0.16 & 0.16 & 0.16 & 0.14 & 0.12 \\
\hline 32 & H & $\theta .18$ & {$[8.80817,1]$} & $\theta .17$ & 0.17 & $\theta .16$ & 0.14 & 0.12 \\
\hline 33 & 5 & 0.89 & {$[0.28,1]$} & $2.9 \mathrm{e}-98$ & $1.2 \mathrm{e}-65$ & 8.60034 & 0.0031 & 0.014 \\
\hline 34 & H & 0.66 & {$[0.059,1]$} & ө.00017 & 8.0934 & ө. 018 & 0.05 & 0.096 \\
\hline 35 & $\mathrm{~L}$ & 0.36 & {$[8.86017,1]$} & $\theta .12$ & 0.12 & 8.11 & 0.11 & $\theta .1$ \\
\hline 36 & $Q$ & 0.88 & {$[0.28,1]$} & $3.4 \mathrm{e}-68$ & $1.5 e-65$ & 0.6804 & 0.0035 & 0.016 \\
\hline 37 & K & 0.88 & {$[0.28,1]$} & $3.3 e-68$ & $1.5 e-65$ & 0.0004 & 0.0035 & 0.016 \\
\hline 38 & I & 0.99 & {$[0.81,1]$} & $2.1 \mathrm{e}-16$ & $4.1 \mathrm{e}-11$ & $3.3 \mathrm{e}-68$ & $3 e-06$ & $8.6 \mathrm{e}-05$ \\
\hline 39 & G & 0.67 & {$[0.059,1]$} & $\theta .00016$ & 0.0033 & 0.017 & 0.048 & 0.093 \\
\hline $4 \theta$ & E & 0.63 & {$[0.019,1]$} & $\theta .00021$ & 0.0943 & 0.022 & 0.06 & 0.11 \\
\hline 41 & L & 0.93 & {$[0.28,1]$} & $1.3 e-68$ & $5.5 e-66$ & 8.68015 & 0.0014 & 0.0073 \\
\hline 42 & G & $\theta .18$ & {$[8.00017,1]$} & 6.17 & 0.17 & 0.16 & $\theta .14$ & 0.12 \\
\hline 43 & A & 0.76 & {$[0.059,1]$} & $9.5 e-65$ & 0.002 & $\theta .01$ & 0.03 & 0.062 \\
\hline 44 & v & 0.95 & {$[0.49,1]$} & $4 e-12$ & $3.7 \mathrm{e}-68$ & $5.4 \mathrm{e}-66$ & 0.00015 & 0.0018 \\
\hline 45 & A & 0.24 & {$[0.80017,1]$} & 0.15 & 0.15 & 8.14 & 0.13 & 0.11 \\
\hline 46 & A & 0.26 & {$[0.00017,1]$} & 0.14 & 0.14 & 0.14 & 0.13 & 0.11 \\
\hline 47 & G & $\theta .19$ & {$[0.80017,1]$} & 0.16 & 0.16 & 0.16 & 0.14 & 0.12 \\
\hline 48 & A & 0.74 & {$[0.059,1]$} & $\theta .0001$ & 0.0922 & $\theta .011$ & 0.033 & 0.066 \\
\hline 49 & 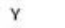 & $\theta .91$ & {$[0.28,1]$} & $1.7 \mathrm{e}-68$ & $7.4 \mathrm{e}-66$ & 8. 60021 & 0.0019 & 0.6093 \\
\hline 50 & A & 0.79 & {$[0.059,1]$} & $7.3 \mathrm{e}-65$ & 0.0915 & 0.808 & 0.024 & 0.05 \\
\hline 51 & $\hat{L}$ & 0.94 & {$[0.28,1]$} & $8.8 \mathrm{e}-69$ & $3.9 \mathrm{e}-66$ & 8.00011 & 0.001 & 0.0054 \\
\hline 52 & H & $\theta .66$ & {$[0.859,1]$} & ө. 80017 & 0.0934 & $\theta .018$ & 0.05 & 0.096 \\
\hline 53 & E & $\theta .14$ & {$[8.80917,1]$} & 0.18 & 0.18 & $\theta .17$ & 0.15 & 0.12 \\
\hline 54 & k & 0.15 & {$[0.08017,1]$} & $\theta .18$ & 0.18 & 0.17 & $\theta .15$ & 0.12 \\
\hline 55 & H & 0.2 & {$[0.00017,1]$} & 0.16 & 0.16 & $\theta .16$ & 0.14 & 0.12 \\
\hline 56 & K & 0.15 & {$[\theta .80817,1]$} & 0.18 & 0.18 & 0.17 & e.15 & 0.12 \\
\hline 57 & A & 0.77 & {$[0.059,1]$} & $8.5 e-65$ & $\theta .0918$ & e. 8693 & 0.027 & 0.056 \\
\hline 58 & $k$ & $\theta .15$ & {$[0.80817,1]$} & 0.18 & 0.18 & 0.17 & 0.15 & 0.12 \\
\hline 59 & $\mathrm{k}$ & $\theta .13$ & {$[0.00017,1]$} & 0.19 & $\theta .19$ & 0.18 & 0.16 & 0.12 \\
\hline 60 & D & $\theta .14$ & {$[0.80017,1]$} & $\theta .18$ & 0.18 & e.17 & 0.15 & 0.12 \\
\hline 61 & $P$ & 0.32 & {$[8.88017,1]$} & 0.13 & $\theta .13$ & 6.12 & 0.12 & 0.11 \\
\hline 62 & E & 0.14 & {$[8.00017,1]$} & 0.18 & 0.18 & 0.17 & 0.15 & 0.12 \\
\hline 63 & N & 0.65 & {$[0.059,1]$} & $\theta . \theta 0018$ & 8. 8037 & 0.019 & 0.053 & 0.1 \\
\hline 64 & A & $\theta .76$ & {$[0.859,1]$} & $9.2 \mathrm{e}-65$ & $\theta .0819$ & 8.8099 & 0.029 & 0.06 \\
\hline 65 & H & 0.69 & {$[0.059,1]$} & ๑. 00014 & 0.0029 & 0.015 & 0.042 & 0.084 \\
\hline 66 & k & $\theta .86$ & {$[0.14,1]$} & $4.5 e-68$ & $1.9 \mathrm{e}-65$ & 8. 80053 & 0.0046 & 0.021 \\
\hline 67 & H & 0.2 & {$[0.60017,1]$} & 0.16 & $\theta .16$ & $\theta .16$ & 0.14 & 0.12 \\
\hline 68 & $k$ & 0.15 & {$[8.80817,1]$} & $\theta .18$ & $\theta .18$ & 0.17 & 0.15 & 0.12 \\
\hline 69 & I & 0.26 & {$[0.00017,1]$} & $\theta .14$ & 0.14 & 0.14 & 0.13 & 0.11 \\
\hline 70 & $\mathrm{k}$ & 0.84 & {$[8.14,1]$} & $5.9 e-68$ & $2.6 e-65$ & 0.60069 & 0.0059 & 0.026 \\
\hline 71 & $\mathrm{Q}$ & 0.65 & {$[0.059,1]$} & 0.00019 & 0.094 & 0.02 & 0.056 & 0.1 \\
\hline 72 & E & $\theta .14$ & {$[0.00017,1]$} & $\theta .18$ & 0.18 & $\theta .17$ & 0.15 & 0.12 \\
\hline 73 & I & 0.27 & {$[6.80017,1]$} & 0.14 & $\theta .14$ & 8.14 & 0.13 & 0.11 \\
\hline 74 & A & 0.25 & {$[0.00017,1]$} & 0.15 & 0.14 & 0.14 & 0.13 & 0.11 \\
\hline 75 & A & 0.25 & {$[0.00017,1]$} & 0.15 & 0.15 & 0.14 & $\theta .13$ & $\theta .11$ \\
\hline 76 & v & 0.75 & {$[0.859,1]$} & $9.7 e-65$ & 0.002 & 0.01 & 0.03 & 0.063 \\
\hline 77 & A & $\theta .23$ & {$[0.00017,1]$} & $\theta .15$ & 0.15 & 0.15 & $\theta .13$ & 0.12 \\
\hline 78 & A & 0.24 & {$[0.00017,1]$} & $\theta .15$ & $\theta .15$ & e.14 & $\theta .13$ & $\theta .11$ \\
\hline 79 & v & 0.23 & {$[0.00917,1]$} & 0.15 & $\theta .15$ & 0.15 & 0.14 & 0.12 \\
\hline 80 & G & $\theta .19$ & {$[8.00017,1]$} & $\theta .17$ & $\theta .16$ & 0.16 & 0.14 & 0.12 \\
\hline 81 & A & 0.78 & {$[0.059,1]$} & $8.2 \mathrm{e}-05$ & ๑. 8017 & 0.6089 & 0.026 & 0.055 \\
\hline 82 & G & 0.7 & {$[0.059,1]$} & $\theta .00013$ & $\theta .6927$ & $\theta .014$ & 0.04 & 0.08 \\
\hline 83 & G & 0.19 & {$[0.00017,1]$} & 0.16 & 0.16 & 0.16 & 0.14 & 0.12 \\
\hline 84 & $\vec{F}$ & $\theta .84$ & {$[0.14,1]$} & $4.9 e-65$ & $\theta .001$ & 8. 8054 & 0.016 & 0.036 \\
\hline 85 & A & 0.76 & {$[0.059,1]$} & $9.1 \mathrm{e}-85$ & 0.6019 & 0.0099 & 0.029 & 0.06 \\
\hline 86 & $\mathrm{~F}$ & 0.4 & {$[0.00017,1]$} & $\theta .1$ & 0.1 & 0.1 & 0.1 & 0.095 \\
\hline 87 & H & 0.16 & {$[8.00017,1]$} & 0.18 & 0.17 & 8.17 & 0.15 & 0.12 \\
\hline 88 & $E$ & $\theta .14$ & {$[0.00017,1]$} & 0.19 & e.18 & $\theta .17$ & 0.15 & 0.12 \\
\hline
\end{tabular}




\begin{tabular}{|c|c|c|c|}
\hline 89 & H & 0.16 & {$[0.60017,1]$} \\
\hline 90 & H & $\theta .16$ & {$[0.00017,1]$} \\
\hline 91 & Q & 0.95 & {$[0.49,1]$} \\
\hline 92 & $\mathrm{k}$ & 0.15 & {$[0.80017,1]$} \\
\hline 93 & $k$ & 0.13 & {$[\theta . \theta 0917,1]$} \\
\hline 94 & E & 0.87 & {$[0.28,1]$} \\
\hline 95 & A & 0.8 & {$[0.059,1]$} \\
\hline 96 & k & 0.15 & {$[0.00017,1]$} \\
\hline 97 & K & 0.13 & {$[0.00017,1]$} \\
\hline 98 & E & 0.14 & {$[0.00917,1]$} \\
\hline 99 & k & 0.86 & {$[0.14,1]$} \\
\hline 100 & k & 0.65 & {$[0.059,1]$} \\
\hline 101 & A & $\theta .68$ & {$[0.059,1]$} \\
\hline 102 & A & 0.23 & {$[0.00917,1]$} \\
\hline 103 & E & 0.93 & {$[0.49,1]$} \\
\hline 104 & k & 0.94 & {$[0.49,1]$} \\
\hline 105 & G & 0.88 & {$[0.28,1]$} \\
\hline 106 & $\mathbf{R}$ & 0.83 & {$[0.14,1]$} \\
\hline 107 & H & 0.7 & {$[0.059,1]$} \\
\hline & H & & {$[0.00017,1]$} \\
\hline
\end{tabular}

\begin{tabular}{|c|c|c|c|c|c|c|c|c|}
\hline 9.17 & 0.17 & 0.16 & 0.15 & 0.12 & 0.083 & 0.048 & 0.022 & 0.071 \\
\hline 0.18 & 0.17 & 0.17 & $\theta .15$ & 0.12 & 0.083 & 0.847 & $\theta .021$ & 0.066 \\
\hline $3 \mathrm{e}$. & $4.8 \mathrm{e}-68$ & $7.1 \mathrm{e}-86$ & 0.0002 & 0.0022 & 8.013 & e.047 & $\theta .11$ & 0.82 \\
\hline 6.18 & 6.18 & 0.17 & 0.15 & 0.12 & 0.081 & 0.045 & $\theta .02$ & 0.06 \\
\hline 19 & 0.18 & 0.18 & 0.15 & 0.12 & 0.077 & 0.04 & $\theta .016$ & 0.047 \\
\hline $4 e-68$ & $1.7 \mathrm{e}-65$ & 8.68047 & ๑. 6041 & 8.019 & 0.052 & 0.098 & $\theta .13$ & 0.7 \\
\hline $6.8 \mathrm{e}-65$ & $\theta .6914$ & 8.6074 & 0.022 & 0.847 & 0.079 & ө.11 & 0.12 & 0.62 \\
\hline 8.18 & e.18 & 8.17 & 0.15 & 0.12 & 0.081 & 0.045 & $\theta .02$ & 0.06 \\
\hline 0.19 & 0.19 & 0.18 & 0.16 & 0.12 & 8.076 & 0.039 & $\theta .015$ & 0.044 \\
\hline 0.18 & e.18 & 0.17 & 8.15 & 0.12 & 0.077 & 0.841 & 0.017 & 0.054 \\
\hline $5.1 \mathrm{e}-68$ & $2.2 \mathrm{e}-65$ & 8.8006 & 0.0052 & 8.023 & 0.061 & 8.11 & 8.13 & 0.67 \\
\hline$\theta e 018$ & 0.6938 & ө.019 & 0.054 & 0.1 & 8.1 & & & 0.44 \\
\hline$\theta .00017$ & $\theta .0934$ & $\theta .018$ & 0.049 & 0.093 & $\theta .13$ & $\theta .13$ & 8.11 & 0.47 \\
\hline 15 & e.15 & $\theta .15$ & 8.13 & 8.12 & 0.089 & A & $\theta .034$ & 0.12 \\
\hline $9.4 \mathrm{e}-12$ & $8.6 e-68$ & $1.2 \mathrm{e}-85$ & $\theta .00034$ & 0.0036 & 0.019 & $\theta .062$ & 0.13 & 0.79 \\
\hline $6.4 \mathrm{e}-12$ & $5.8 \mathrm{e}-68$ & $8.5 e-86$ & ө.00024 & $\theta .0026$ & 0.015 & .053 & 8.12 & 0.81 \\
\hline $3.5 \mathrm{e}-68$ & $1.5 e-85$ & 8.00842 & 0.0037 & 0.8 & 0.049 & 0.096 & $\theta .1$ & \\
\hline $3.7 \mathrm{e}-65$ & 6.69078 & $\theta .0043$ & 0.014 & $\theta .035$ & 0.068 & 0.1 & $\theta .12$ & 0.65 \\
\hline$\theta .00013$ & 0.0928 & 0.014 & 8.841 & 0.081 & 0.1 & & & 0.49 \\
\hline$\theta .16$ & 0.16 & 8.16 & $\theta .14$ & $\theta .12$ & 0.087 & 0.854 & $\theta .028$ & 0.09 \\
\hline
\end{tabular}

Supplementary Table 9: Ka/Ks values per ASR3 amino acid. First are represented amino acid position, then amino acid, w-score, confidence interval and Bayesian posterior probabilities. 
(d) ASR4

Selecton Bayesian $\mathrm{Ka} / \mathrm{Ks}$ Results Displayed on sequence

\begin{tabular}{|c|c|c|c|c|c|c|c|c|c|}
\hline POS & AMINO & $\mathrm{Ka} / \mathrm{Ks}$ & [Confidence Interval] (* & $\begin{array}{l}\text { if low } \\
\mathrm{w}=\end{array}$ & $\begin{array}{l}r \text { bound } \\
6.9 \mathrm{e}-65\end{array}$ & $\begin{array}{l}>1) \\
\theta .0014\end{array}$ & 0.007 & $\begin{array}{l}\text { POSTEI } \\
\theta .021\end{array}$ & $\begin{array}{l}\text { OR PROE } \\
0.051\end{array}$ \\
\hline 1 & $M$ & 0,41 & {$[6,9 \mathrm{e}-05,1]$} & 0.083 & 0.983 & 0.083 & 0.083 & 0.083 & 0.083 \\
\hline 2 & A & 0.41 & {$[6.9 \mathrm{e}-05,1]$} & 0.083 & 0.083 & 0.083 & 0.083 & 0.083 & 0.083 \\
\hline 3 & $\hat{E}$ & 0.41 & {$[6.9 \mathrm{e}-85,1]$} & 0.083 & 0.083 & 0.083 & 0.083 & 0.083 & 0.083 \\
\hline 4 & E & $\theta .41$ & {$[6.9 \mathrm{e}-65,1]$} & 0.083 & 0.083 & 0.083 & 0.083 & 0.083 & 0.083 \\
\hline 5 & k & $\theta .41$ & {$[6.9 \mathrm{e}-05,1]$} & 0.083 & 0.083 & 0.083 & 0.083 & 0.083 & 0.083 \\
\hline 6 & K & 0.41 & {$[6.9 \mathrm{e}-65,1]$} & 0.083 & 0.083 & 0.083 & 0.083 & 0.083 & 0.083 \\
\hline 7 & H & 6.41 & {$[6.9 \mathrm{e}-05,1]$} & 0.083 & 0.083 & 0.083 & 0.083 & 0.083 & 0.083 \\
\hline 8 & H & 0.41 & {$[6.9 \mathrm{e}-05,1]$} & 0.083 & 0.083 & 0.083 & (. 883 & 0.083 & 0.083 \\
\hline 9 & $\mathrm{~F}$ & 0.41 & {$[6.9 \mathrm{e}-65,1]$} & 0.083 & 0.083 & 0.083 & 0.083 & 0.083 & 0.083 \\
\hline 10 & G & $\theta .41$ & {$[6.9 \mathrm{e}-05,1]$} & 0.083 & 0.083 & 0.083 & ө.e83 & 0.083 & 0.083 \\
\hline 11 & G & $\theta .41$ & {$[6.9 \mathrm{e}-65,1]$} & 0.083 & e. 683 & 0.083 & 0.083 & 0.083 & 0.083 \\
\hline 12 & L & $\theta .41$ & {$[6.9 \mathrm{e}-65,1]$} & 0.083 & 0.083 & 0.083 & 0.083 & 0.083 & 0.083 \\
\hline 13 & $\mathrm{~F}$ & $\theta .41$ & {$[6.9 \mathrm{e}-05,1]$} & 0.083 & 0.083 & 0.083 & 0.083 & 0.083 & 0.083 \\
\hline 14 & $\mathrm{~N}$ & 0.41 & {$[6.9 \mathrm{e}-05,1]$} & 0.083 & 0.083 & 0.083 & 0.083 & 0.083 & 0.083 \\
\hline 15 & $\mathrm{H}$ & $\theta .41$ & {$[6.9 \mathrm{e}-\theta 5,1]$} & 0.083 & 0.083 & 0.083 & 0.083 & 0.083 & 0.083 \\
\hline 16 & H & 0.41 & {$[6.9 \mathrm{e}-05,1]$} & 0.083 & 0.083 & 0.083 & 0.083 & 0.083 & 0.083 \\
\hline 17 & K & $\theta .41$ & {$[6.9 \mathrm{e}-05,1]$} & 0.083 & 0.083 & 0.083 & 0.083 & 0.083 & 0.083 \\
\hline 18 & $\mathrm{~N}$ & 8.41 & {$[6.9 \mathrm{e}-65,1]$} & 0.083 & 0.083 & 0.083 & 0.083 & 0.083 & 0.083 \\
\hline 19 & k & 0.41 & {$[6.9 \mathrm{e}-\theta 5,1]$} & 0.083 & 0.083 & 0.683 & 0.083 & 0.083 & 0.083 \\
\hline $2 \theta$ & E & $\theta .41$ & {$[6.9 \mathrm{e}-85,1]$} & 0.083 & e.e83 & 0.083 & 0.083 & 0.083 & 0.083 \\
\hline 21 & E & 0.41 & {$[6.9 \mathrm{e}-05,1]$} & 0.083 & 0.083 & 0.083 & 0.083 & 0.083 & 0.083 \\
\hline 22 & D & 0.41 & {$[6.9 \mathrm{e}-65,1]$} & 0.083 & 0.083 & 0.083 & 8. 883 & 0.083 & 0.083 \\
\hline 23 & $\mathrm{~T}$ & $\theta .41$ & {$[6.9 \mathrm{e}-65,1]$} & 0.083 & e.083 & 0.083 & 0.883 & 0.083 & 0.083 \\
\hline 24 & $p$ & 0.41 & {$[6.9 \mathrm{e}-05,1]$} & 0.083 & 0.083 & 0.083 & 0.083 & 0.083 & 0.083 \\
\hline 25 & I & 0.41 & {$[6.9 \mathrm{e}-\theta 5,1]$} & 0.083 & 6.e83 & 0.083 & 0.083 & 0.083 & 0.083 \\
\hline 26 & $\mathrm{E}$ & $\theta .41$ & {$[6.9 \mathrm{e}-05,1]$} & 0.083 & 0.083 & 0.083 & 0.083 & 0.083 & 0.083 \\
\hline 27 & K & 0.41 & {$[6.9 \mathrm{e}-05,1]$} & 0.083 & 0.083 & 0.083 & 0.083 & 0.083 & 0.083 \\
\hline 28 & $\mathrm{~T}$ & 0.41 & {$[6.9 \mathrm{e}-05,1]$} & 0.083 & 0.083 & 0.083 & 0.083 & 0.083 & 0.083 \\
\hline 29 & $\mathrm{~T}$ & 0.41 & {$[6.9 \mathrm{e}-65,1]$} & 0.083 & $\theta .083$ & 0.083 & 0.083 & 0.083 & 0.083 \\
\hline 30 & $\mathrm{y}$ & 0.41 & {$[6.9 \mathrm{e}-85,1]$} & 0.083 & 0.083 & 0.083 & 0.083 & 0.083 & 0.083 \\
\hline 31 & $\mathrm{E}$ & 0.41 & {$[6.9 \mathrm{e}-05,1]$} & 0.083 & 0.083 & 0.083 & 0.083 & 0.083 & 0.083 \\
\hline 32 & E & 0.41 & {$[6.9 \mathrm{e}-05,1]$} & 0.083 & 0.083 & 0.083 & 0.083 & 0.083 & 0.083 \\
\hline 33 & $\mathrm{~T}$ & 0.41 & {$[6.9 \mathrm{e}-05,1]$} & 0.083 & 0.083 & 0.083 & 0.083 & 0.083 & 0.083 \\
\hline 34 & $T$ & 0.41 & {$[6.9 \mathrm{e}-05,1]$} & 0.083 & 0.e83 & 0.083 & 0.083 & 0.083 & 0.083 \\
\hline 35 & r & 0.41 & {$[6.9 \mathrm{e}-85,1]$} & 0.083 & 0.083 & 0.083 & 0.083 & 0.083 & 0.083 \\
\hline 36 & $\mathrm{E}$ & 0.41 & {$[6.9 \mathrm{e}-05,1]$} & 0.083 & 0.083 & 0.083 & 0.083 & 0.083 & 0.083 \\
\hline 37 & D & $\theta .41$ & {$[6.9 \mathrm{e}-\theta 5,1]$} & 0.083 & 0.083 & 0.083 & 0.883 & 0.083 & 0.083 \\
\hline 38 & 5 & 0.41 & {$[6.9 \mathrm{e}-85,1]$} & 0.083 & 0.083 & 0.083 & 0.083 & 0.083 & 0.083 \\
\hline 39 & $\mathrm{E}$ & 0.41 & {$[6.9 \mathrm{e}-\theta 5,1]$} & 0.083 & 0.083 & 0.083 & 0.083 & 0.083 & 0.083 \\
\hline 40 & k & 0.41 & {$[6.9 \mathrm{e}-85,1]$} & 0.083 & 0.083 & 0.083 & 0.083 & 0.083 & 0.083 \\
\hline 41 & $\mathrm{~T}$ & 0.41 & {$[6.9 \mathrm{e}-65,1]$} & 0.083 & 0.083 & 0.083 & 0.083 & 0.083 & 0.083 \\
\hline 42 & $s$ & $\theta .41$ & {$[6.9 \mathrm{e}-65,1]$} & 0.083 & 0.083 & 0.083 & 0.083 & 0.083 & 0.083 \\
\hline 43 & $\vec{T}$ & 0.41 & {$[6.9 \mathrm{e}-05,1]$} & 0.083 & 0.083 & 0.083 & 0.083 & 0.083 & 0.083 \\
\hline 44 & $\mathrm{r}$ & $\theta .41$ & {$[6.9 \mathrm{e}-05,1]$} & 0.083 & 0.083 & 0.083 & 9.083 & 0. 883 & 0.083 \\
\hline 45 & $G$ & 0.41 & {$[6.9 \mathrm{e}-05,1]$} & 0.083 & 0.083 & 0.083 & 0.083 & 0.083 & 0.083 \\
\hline 46 & D & 0.41 & {$[6.9 \mathrm{e}-85,1]$} & 0.083 & 0.083 & 0.083 & 0.083 & 0.083 & 0.083 \\
\hline 47 & $\mathrm{~N}$ & $\theta .41$ & {$[6.9 \mathrm{e}-05,1]$} & 0.083 & 0.083 & 0.083 & ө.883 & 0.083 & 0.083 \\
\hline 48 & $T$ & 0.41 & {$[6.9 \mathrm{e}-65,1]$} & 0.083 & 0.083 & 0.083 & 0.883 & 0.083 & 0.083 \\
\hline 49 & $\dot{\gamma}$ & 0.41 & {$[6.9 \mathrm{e}-05,1]$} & 0.083 & 0.083 & 0.083 & 0.083 & 0.083 & 0.083 \\
\hline 50 & $G$ & $\theta .41$ & {$[6.9 \mathrm{e}-05,1]$} & 0.083 & 0.e83 & 0.083 & 0.083 & 0.083 & 0.083 \\
\hline 51 & $\mathrm{E}$ & 0.41 & {$[6.9 \mathrm{e}-85,1]$} & 0.083 & 0.083 & 0.083 & 0.083 & 0.083 & 0.083 \\
\hline 52 & K & 0.41 & {$[6.9 \mathrm{e}-65,1]$} & 0.083 & e. 083 & 0.083 & 0.083 & 0.083 & 0.083 \\
\hline 53 & $\mathrm{~T}$ & 0.41 & {$[6.9 \mathrm{e}-05,1]$} & 0.083 & 0.083 & 0.083 & 0.083 & 0.083 & 0.083 \\
\hline 54 & s & 0.41 & {$[6.9 \mathrm{e}-65,1]$} & 0.083 & 0.083 & 0.083 & 0.083 & 0.083 & 0.083 \\
\hline 55 & $\mathrm{y}$ & 0.41 & {$[6.9 \mathrm{e}-05,1]$} & 0.083 & 0.083 & 0.083 & 0.083 & 0.083 & 0.083 \\
\hline 56 & G & 0.41 & {$[6.9 \mathrm{e}-05,1]$} & 0.083 & 0.083 & 0.083 & 0.883 & 0.083 & 0.083 \\
\hline 57 & D & $\theta .41$ & {$[6.9 \mathrm{e}-85,1]$} & 0.083 & 0.083 & 0.083 & 0.083 & 0.083 & 0.083 \\
\hline 58 & D & 0.41 & {$[6.9 \mathrm{e}-05,1]$} & 0.083 & 0.083 & 0.083 & 0.083 & 0.083 & 0.083 \\
\hline 59 & $T$ & 0.41 & {$[6.9 \mathrm{e}-85,1]$} & 0.083 & 0.883 & 0.083 & 0.083 & 0.083 & 0.083 \\
\hline 60 & $\mathrm{r}$ & $\theta .41$ & {$[6.9 \mathrm{e}-65,1]$} & 0.083 & 0.083 & 0.083 & 0.883 & 0.083 & 0.083 \\
\hline 61 & $G$ & e.41 & {$[6.9 \mathrm{e}-05,1]$} & 0.083 & 0.083 & 0.083 & 0.083 & 0.083 & 0.083 \\
\hline 62 & k & 0.41 & {$[6.9 \mathrm{e}-65,1]$} & 0.083 & 0.083 & 0.083 & 0.083 & 0.083 & 0.083 \\
\hline 63 & $\hat{\mathrm{k}}$ & $\theta .41$ & {$[6.9 \mathrm{e}-05,1]$} & 0.083 & 0.083 & 0.083 & 0.083 & 0.083 & 0.083 \\
\hline 64 & $\mathrm{~T}$ & 0.41 & {$[6.9 \mathrm{e}-05,1]$} & 0.083 & 0.083 & 0.083 & 0.083 & 0.083 & 0.083 \\
\hline 65 & $T$ & 8.41 & {$[6.9 \mathrm{e}-65,1]$} & 0.083 & 0.083 & 0.083 & 8.883 & 0.083 & 0.083 \\
\hline 66 & $\mathrm{~T}$ & 0.41 & {$[6.9 \mathrm{e}-65,1]$} & 0.083 & 0.083 & 0.083 & 0.083 & 0.883 & 0.083 \\
\hline 67 & $\mathrm{y}$ & 0.41 & {$[6.9 \mathrm{e}-05,1]$} & 0.083 & 0.083 & 0.083 & 0.883 & 0.083 & 0.083 \\
\hline 68 & G & 0.41 & {$[6.9 \mathrm{e}-65,1]$} & 0.083 & 0.083 & 0.083 & 0.083 & 0.083 & 0.083 \\
\hline 69 & D & 0.41 & {$[6.9 \mathrm{e}-05,1]$} & 0.083 & e.e83 & 0.083 & 0.083 & 0.083 & 0.083 \\
\hline 70 & D & $\theta .41$ & {$[6.9 \mathrm{e}-65,1]$} & 0.083 & 0.083 & 0.083 & 0.883 & 0.083 & 0.083 \\
\hline 71 & $\mathrm{~N}$ & 0.41 & {$[6.9 \mathrm{e}-65,1]$} & 0.083 & 0.883 & 0.083 & 0.083 & 0.083 & 0.083 \\
\hline 72 & k & 0.41 & {$[6.9 \mathrm{e}-05,1]$} & 0.083 & e.e83 & 0.083 & 0.083 & e.e83 & 0.083 \\
\hline 73 & $\ddot{\gamma}$ & 0.41 & {$[6.9 \mathrm{e}-65,1]$} & 0.083 & 0.083 & 0.083 & 0.083 & 0.083 & 0.083 \\
\hline 74 & s & $\theta .41$ & {$[6.9 \mathrm{e}-\theta 5,1]$} & 0.083 & 0.083 & 0.083 & 0.083 & 0.083 & 0.083 \\
\hline 75 & $\mathrm{E}$ & $\theta .41$ & {$[6.9 \mathrm{e}-05,1]$} & 0.083 & 8. 083 & 0.083 & 0.083 & 0.083 & 0.083 \\
\hline 76 & k & 0.41 & {$[6.9 \mathrm{e}-\theta 5,1]$} & 0.083 & 0.083 & 0.083 & 0.083 & 0.083 & 0.083 \\
\hline 77 & $T$ & 0.41 & {$[6.9 \mathrm{e}-05,1]$} & 0.083 & 0.083 & 0.083 & ө.e83 & 0.083 & 0.083 \\
\hline 78 & $s$ & 0.41 & {$[6.9 \mathrm{e}-\theta 5,1]$} & 0.083 & 0.083 & 0.083 & 0.083 & 0.083 & 0.083 \\
\hline 79 & $\mathrm{y}$ & 0.41 & {$[6.9 \mathrm{e}-\theta 5,1]$} & 0.083 & 0.083 & 0.083 & 0.883 & 0.083 & 0.083 \\
\hline 80 & G & 0.41 & {$[6.9 \mathrm{e}-05,1]$} & 0.083 & 0.083 & 0.083 & 0.083 & 0.083 & 0.083 \\
\hline 81 & D & 0.41 & {$[6.9 \mathrm{e}-05,1]$} & 0.083 & e.e83 & 0.083 & 0.083 & 0.083 & 0.083 \\
\hline 82 & D & 0.41 & {$[6.9 \mathrm{e}-05,1]$} & 0.083 & 8.083 & 0.083 & 0.083 & 0.083 & 0.083 \\
\hline 83 & $T$ & 0.41 & {$[6.9 \mathrm{e}-65,1]$} & 0.083 & 8.e83 & 0.083 & 0.883 & 0.083 & 0.083 \\
\hline 84 & $y$ & 0.41 & {$[6.9 \mathrm{e}-05,1]$} & 0.083 & 0.e83 & 0.083 & 0.083 & 0.083 & 0.083 \\
\hline 85 & D & $\theta .41$ & {$[6.9 \mathrm{e}-\theta 5,1]$} & 0.083 & e.e83 & 0.083 & 8.883 & 0.883 & 0.083 \\
\hline 86 & E & e.41 & {$[6.9 \mathrm{e}-\theta 5,1]$} & 0.083 & 0.e83 & 0.083 & $\theta .083$ & 0.083 & 0.083 \\
\hline 87 & K & 0.41 & {$[6.9 \mathrm{e}-05,1]$} & 0.083 & Q.083 & 0.083 & 0.083 & 0.083 & 0.083 \\
\hline 88 & $\mathrm{~T}$ & 0.41 & {$[6.9 \mathrm{e}-65,1]$} & 0.083 & 0.083 & 0.083 & 0.083 & 0.083 & 0.083 \\
\hline
\end{tabular}




\begin{tabular}{|c|c|c|c|c|}
\hline 89 & $\mathrm{~N}$ & $\theta .41$ & {$[6.9 \mathrm{e}-85,1]$} & 0.083 \\
\hline 90 & T & 8.41 & {$[6.9 \mathrm{e}-65,1]$} & 0.083 \\
\hline 91 & $r$ & $\theta .41$ & {$[6.9 \mathrm{e}-85,1]$} & 0.083 \\
\hline 92 & G & 0.41 & {$[6.9 \mathrm{e}-85,1]$} & 8.083 \\
\hline 93 & D & 0.41 & {$[6.9 \mathrm{e}-85,1]$} & 0.083 \\
\hline 94 & E & 0.41 & {$[6.9 \mathrm{e}-\theta 5,1]$} & 0.083 \\
\hline 95 & $\mathrm{~N}$ & 0.41 & {$[6.9 \mathrm{e}-85,1]$} & 0.083 \\
\hline 96 & k & $\theta .41$ & {$[6.9 \mathrm{e}-85,1]$} & 0.083 \\
\hline 97 & $\mathrm{Y}$ & 0.41 & {$[6.9 \mathrm{e}-05,1]$} & 0.083 \\
\hline 98 & G & $\theta .41$ & {$[6.9 \mathrm{e}-85,1]$} & 0.083 \\
\hline 99 & E & 0.41 & {$[6.9 \mathrm{e}-05,1]$} & 0.083 \\
\hline 100 & k & $\theta .41$ & {$[6.9 \mathrm{e}-65,1]$} & 0.083 \\
\hline 101 & T & 0.41 & {$[6.9 \mathrm{e}-65,1]$} & 0.083 \\
\hline 102 & s & 0.41 & {$[6.9 \mathrm{e}-\theta 5,1]$} & 0.083 \\
\hline 103 & $\mathrm{Y}$ & 8.41 & {$[6.9 \mathrm{e}-85,1]$} & 0.083 \\
\hline 104 & $s$ & 0.41 & {$[6.9 \mathrm{e}-85,1]$} & 8.083 \\
\hline 105 & E & 0.41 & {$[6.9 \mathrm{e}-85,1]$} & 0.083 \\
\hline 106 & G & 0.41 & {$[6.9 \mathrm{e}-05,1]$} & 0.083 \\
\hline 187 & D & $\theta .41$ & {$[6.9 \mathrm{e}-85,1]$} & 0.083 \\
\hline 108 & D & 0.41 & {$[6.9 \mathrm{e}-05,1]$} & 0.083 \\
\hline 109 & $\mathrm{~N}$ & $\theta .41$ & {$[6.9 \mathrm{e}-85,1]$} & 0.083 \\
\hline 110 & k & 0.41 & {$[6.9 \mathrm{e}-85,1]$} & 0.083 \\
\hline 111 & $\mathrm{r}$ & 0.41 & {$[6.9 \mathrm{e}-85,1]$} & 0.083 \\
\hline 112 & G & $\theta .41$ & {$[6.9 \mathrm{e}-85,1]$} & 0.083 \\
\hline 113 & E & 0.41 & {$[6.9 \mathrm{e}-85,1]$} & 0.083 \\
\hline 114 & k & 0.41 & {$[6.9 \mathrm{e}-85,1]$} & 6.083 \\
\hline 115 & $\mathrm{~T}$ & $\theta .41$ & {$[6.9 \mathrm{e}-85,1]$} & 0.083 \\
\hline 116 & s & 0.41 & {$[6.9 \mathrm{e}-85,1]$} & 0.083 \\
\hline 117 & r & 0.41 & {$[6.9 \mathrm{e}-85,1]$} & 0.083 \\
\hline 118 & G & $\theta .41$ & {$[6.9 \mathrm{e}-85,1]$} & 0.083 \\
\hline 119 & G & 0.41 & {$[6.9 \mathrm{e}-85,1]$} & 0.083 \\
\hline $12 \theta$ & D & 0.41 & {$[6.9 \mathrm{e}-85,1]$} & 0.083 \\
\hline 121 & $\mathrm{~T}$ & 0.41 & {$[6.9 \mathrm{e}-05,1]$} & 0.083 \\
\hline 122 & $\mathrm{Y}$ & $\theta .41$ & {$[6.9 \mathrm{e}-85,1]$} & 0.083 \\
\hline 123 & G & 0.41 & {$[6.9 \mathrm{e}-85,1]$} & 0.083 \\
\hline 124 & E & 0.41 & {$[6.9 \mathrm{e}-85,1]$} & 0.083 \\
\hline 125 & k & 0.41 & {$[6.9 \mathrm{e}-05,1]$} & 0.083 \\
\hline 126 & $\ddot{p}$ & 0.41 & {$[6.9 \mathrm{e}-\theta 5,1]$} & 6.e83 \\
\hline 127 & $\mathrm{~T}$ & 0.41 & {$[6.9 \mathrm{e}-05,1]$} & 0.083 \\
\hline 128 & s & 0.41 & {$[6.9 \mathrm{e}-85,1]$} & 0.083 \\
\hline 129 & $\mathrm{r}$ & $\theta .41$ & {$[6.9 \mathrm{e}-85,1]$} & 0.083 \\
\hline $13 \theta$ & G & $\theta .41$ & {$[6.9 \mathrm{e}-05,1]$} & 0.083 \\
\hline 131 & G & $\theta .41$ & {$[6.9 \mathrm{e}-85,1]$} & 0.083 \\
\hline 132 & D & $\theta .41$ & {$[6.9 \mathrm{e}-05,1]$} & 0.083 \\
\hline 133 & $\mathrm{~N}$ & $\theta .41$ & {$[6.9 \mathrm{e}-05,1]$} & 0.083 \\
\hline 134 & T & 0.41 & {$[6.9 \mathrm{e}-85,1]$} & 0.083 \\
\hline 135 & $\gamma$ & $\theta .41$ & {$[6.9 \mathrm{e}-85,1]$} & 0.083 \\
\hline 136 & G & e.41 & {$[6.9 \mathrm{e}-85,1]$} & 0.083 \\
\hline 137 & E & 8.41 & {$[6.9 \mathrm{e}-85,1]$} & $\theta .083$ \\
\hline 138 & k & 0.41 & {$[6.9 \mathrm{e}-85,1]$} & 0.083 \\
\hline 139 & $\vec{T}$ & 0.41 & {$[6.9 \mathrm{e}-85,1]$} & 0.083 \\
\hline $14 \theta$ & 5 & 0.41 & {$[6.9 \mathrm{e}-85,1]$} & 6.083 \\
\hline 141 & $\gamma$ & 0.41 & {$[6.9 \mathrm{e}-85,1]$} & 0.083 \\
\hline 142 & G & 0.41 & {$[6.9 \mathrm{e}-65,1]$} & 0.683 \\
\hline 143 & G & 0.41 & {$[6.9 \mathrm{e}-05,1]$} & 0.083 \\
\hline 144 & G & 0.41 & {$[6.9 \mathrm{e}-85,1]$} & 0.083 \\
\hline 145 & D & 0.99 & {$[8.47,1]$} & $6.4 e-11$ \\
\hline 146 & E & 0.85 & {$[0.11,1]$} & $2 e-05$ \\
\hline 147 & N & 0.97 & {$[0.47,1]$} & $3.5 e-13$ \\
\hline 148 & k & 0.91 & {$[0.21,1]$} & $6.4 \mathrm{e}-69$ \\
\hline 149 & $\mathrm{r}$ & 0.96 & {$[0.47,1]$} & $9.8 \mathrm{e}-13$ \\
\hline 150 & G & 8.67 & {$[0.851,1]$} & $4.8 \mathrm{e}-65$ \\
\hline 151 & E & 0.099 & {$[6.9 \mathrm{e}-05,1]$} & 0.16 \\
\hline 152 & $\mathrm{k}$ & 0.7 & {$[0.021,1]$} & $6.2 \mathrm{e}-65$ \\
\hline 153 & T & 0.82 & {$[0.051,1]$} & $2.1 \mathrm{e}-05$ \\
\hline 154 & s & 0.9 & {$[8.21,1]$} & $7 e-69$ \\
\hline 155 & $\mathrm{Y}$ & $\theta .57$ & {$[0.021,1]$} & 0.00011 \\
\hline 156 & G & 0.4 & {$[6.9 \mathrm{e}-85,1]$} & 0.085 \\
\hline 157 & E & 6.39 & {$[6.9 \mathrm{e}-85,1]$} & 0.086 \\
\hline 158 & $\mathrm{k}$ & 0.39 & {$[6.9 \mathrm{e}-85,1]$} & 0.086 \\
\hline 159 & A & $\theta .4$ & {$[6,9 \mathrm{e}-85,1]$} & 0.085 \\
\hline 160 & s & 0.4 & {$[6.9 \mathrm{e}-05,1]$} & 0.085 \\
\hline 161 & r & 0.4 & {$[6.9 \mathrm{e}-\theta 5,1]$} & 0.085 \\
\hline 162 & G & 8.39 & {$[6.9 \mathrm{e}-85,1]$} & 0.086 \\
\hline 163 & G & 0.89 & {$[0.11,1]$} & $1.4 \mathrm{e}-65$ \\
\hline 164 & G & $\theta .4$ & {$[6.9 \mathrm{e}-\theta 5,1]$} & 0.085 \\
\hline 165 & D & 0.39 & {$[6.9 \mathrm{e}-85,1]$} & 0.087 \\
\hline 166 & D & 0.4 & {$[6.9 \mathrm{e}-85,1]$} & 0.086 \\
\hline 167 & $\mathrm{~N}$ & 0.4 & {$[6.9 \mathrm{e}-85,1]$} & 0.085 \\
\hline 168 & k & 0.39 & {$[6.9 \mathrm{e}-85,1]$} & 0.086 \\
\hline 169 & $\mathrm{r}$ & $\theta .4$ & {$[6.9 \mathrm{e}-85,1]$} & 0.085 \\
\hline $17 \theta$ & G & 0.88 & {$[0.11,1]$} & $1.5 e-05$ \\
\hline 171 & E & 0.39 & {$[6.9 \mathrm{e}-05,1]$} & 0.086 \\
\hline 172 & k & 0.39 & {$[6.9 \mathrm{e}-85,1]$} & 0.086 \\
\hline 173 & $\mathrm{~T}$ & 0.4 & {$[6.9 \mathrm{e}-\theta 5,1]$} & 6.084 \\
\hline 174 & s & 0.4 & {$[6.9 \mathrm{e}-85,1]$} & 0.085 \\
\hline 175 & $\mathrm{r}$ & 0.4 & {$[6.9 \mathrm{e}-85,1]$} & 0.085 \\
\hline 176 & G & 0.39 & {$[6.9 \mathrm{e}-05,1]$} & 0.086 \\
\hline 177 & N & 0.39 & {$[6.9 \mathrm{e}-05,1]$} & 0.087 \\
\hline 178 & $\mathrm{E}$ & 0.39 & {$[6.9 \mathrm{e}-85,1]$} & 0.086 \\
\hline 179 & E & 0.39 & {$[6.9 \mathrm{e}-85,1]$} & 0.086 \\
\hline 180 & G & 0.39 & {$[6.9 \mathrm{e}-85,1]$} & 0.086 \\
\hline 181 & G & 0.4 & {$[6.9 \mathrm{e}-05,1]$} & 0.084 \\
\hline 182 & $\gamma$ & 0.4 & {$[6.9 \mathrm{e}-05,1]$} & 0.085 \\
\hline
\end{tabular}




\begin{tabular}{|c|c|c|c|c|}
\hline 183 & G & 0.39 & {$[6.9 \mathrm{e}-65,1]$} & 0.086 \\
\hline 184 & G & $\theta .4$ & {$[6.9 \mathrm{e}-85,1]$} & $\theta .085$ \\
\hline 185 & $G$ & 0.4 & {$[6.9 \mathrm{e}-85,1]$} & 0.685 \\
\hline 186 & v & 0.4 & {$[6.9 \mathrm{e}-85,1]$} & 0.085 \\
\hline 187 & G & 0.39 & {$[6.9 \mathrm{e}-85,1]$} & 0.086 \\
\hline 188 & A & 0.41 & {$[6.9 \mathrm{e}-85,1]$} & $\theta .084$ \\
\hline 189 & $\gamma$ & 0.41 & {$[6.9 \mathrm{e}-05,1]$} & 0.084 \\
\hline 190 & $s$ & 0.41 & {$[6.9 \mathrm{e}-05,1]$} & 0.083 \\
\hline 191 & s & 8.41 & {$[6.9 \mathrm{e}-85,1]$} & 0.684 \\
\hline 192 & E & 0.39 & {$[6.9 \mathrm{e}-05,1]$} & 0.086 \\
\hline 193 & T & 0.4 & {$[6.9 \mathrm{e}-65,1]$} & 0.085 \\
\hline 194 & $\mathrm{~T}$ & 0.9 & {$[0.21,1]$} & $6.4 \mathrm{e}-89$ \\
\hline 195 & $T$ & 0.9 & {$[0.21,1]$} & $6.4 \mathrm{e}-69$ \\
\hline 196 & $\mathrm{~N}$ & 0.99 & {$[0.47,1]$} & 2. $5 e-17$ \\
\hline 197 & $\gamma$ & 0.67 & {$[0.021,1]$} & $6.7 \mathrm{e}-05$ \\
\hline 198 & E & 0.83 & {$[0.11,1]$} & $1.7 \mathrm{e}-68$ \\
\hline 199 & $\mathrm{E}$ & 0.95 & {$[0.47,1]$} & $1 e-12$ \\
\hline 200 & $\mathrm{~N}$ & 0.58 & {$[0.021,1]$} & ө. 00011 \\
\hline 201 & D & 0.93 & {$[0.21,1]$} & $1.6 \mathrm{e}-69$ \\
\hline 202 & D & 0.7 & {$[0.021,1]$} & $7.4 e-05$ \\
\hline 203 & s & 0.9 & {$[0.21,1]$} & $1.5 \mathrm{e}-09$ \\
\hline 204 & G & 0.61 & {$[0.021,1]$} & 8.00012 \\
\hline 205 & T & 0.76 & {$[0.051,1]$} & $4 e-85$ \\
\hline 206 & K & 0.95 & {$[0.47,1]$} & $1.7 \mathrm{e}-69$ \\
\hline 207 & $\mathrm{~T}$ & 0.74 & {$[0.051,1]$} & $4.7 e-05$ \\
\hline 208 & s & 0.95 & {$[0.47,1]$} & $1.2 \mathrm{e}-89$ \\
\hline 209 & E & 0.75 & {$[0.051,1]$} & $2.4 \mathrm{e}-05$ \\
\hline 210 & D & $\theta .091$ & {$[6.9 \mathrm{e}-65,1]$} & 0.17 \\
\hline 211 & $\gamma$ & 0.92 & {$[0.21,1]$} & $4,3 e-69$ \\
\hline 212 & k & 0.889 & {$[6.9 \mathrm{e}-05,1]$} & 0.16 \\
\hline 213 & $\mathrm{E}$ & 0.51 & {$[0.021,1]$} & 0.00015 \\
\hline 214 & $\mathrm{E}$ & 0.899 & {$[6.9 \mathrm{e}-65,1]$} & 0.16 \\
\hline 215 & k & 0.52 & {$[0.021,1]$} & $\theta .00014$ \\
\hline 216 & $\mathrm{~K}$ & 0.089 & {$[6.9 \mathrm{e}-85,1]$} & e.16 \\
\hline 217 & H & $\theta .12$ & {$[6.9 \mathrm{e}-85,1]$} & 0.15 \\
\hline 218 & H & 0.13 & {$[6.9 \mathrm{e}-65,1]$} & 0.14 \\
\hline 219 & $\mathrm{~K}$ & 0.089 & {$[6.9 \mathrm{e}-85,1]$} & 0.16 \\
\hline 220 & H & 0.091 & {$[6.9 \mathrm{e}-65,1]$} & 0.16 \\
\hline 221 & L & 0.96 & {$[0.47,1]$} & $2.3 e-10$ \\
\hline 222 & $\mathrm{E}$ & 0.695 & {$[6.9 \mathrm{e}-65,1]$} & $\theta .16$ \\
\hline 223 & $\mathrm{E}$ & 0.83 & {$[8.11,1]$} & $1.7 \mathrm{e}-68$ \\
\hline 224 & L & 0.78 & {$[0.051,1]$} & $3.7 \mathrm{e}-05$ \\
\hline 225 & G & 0.11 & {$[6.9 \mathrm{e}-65,1]$} & 0.15 \\
\hline 226 & G & 0.59 & {$[0.021,1]$} & $\theta .00011$ \\
\hline 227 & L & 0.25 & {$[6.9 \mathrm{e}-65,1]$} & $\theta .11$ \\
\hline 228 & G & $\theta .1$ & {$[6.9 \mathrm{e}-85,1]$} & 0.16 \\
\hline 229 & A & 0.12 & {$[6.9 \mathrm{e}-05,1]$} & 0.15 \\
\hline 230 & v & $\theta .64$ & {$[0.021,1]$} & $7.9 e-65$ \\
\hline 231 & A & 0.1 & {$[6.9 \mathrm{e}-65,1]$} & $\theta .16$ \\
\hline 232 & A & $\theta .12$ & {$[6.9 \mathrm{e}-65,1]$} & e.15 \\
\hline 233 & G & 8.876 & {$[6.9 \mathrm{e}-65,1]$} & 8.17 \\
\hline 234 & A & 0.14 & {$[6.9 \mathrm{e}-65,1]$} & $\theta .14$ \\
\hline 235 & $F$ & 0.67 & {$[0.021,1]$} & $6.8 \mathrm{e}-05$ \\
\hline 236 & A & 0.12 & {$[6.9 \mathrm{e}-65,1]$} & 0.15 \\
\hline 237 & L & 0.29 & {$[6.9 \mathrm{e}-85,1]$} & $\theta .11$ \\
\hline 238 & H & 0.091 & {$[6.9 \mathrm{e}-05,1]$} & $\theta .16$ \\
\hline 239 & E & 0.899 & {$[6.9 \mathrm{e}-85,1]$} & 0.16 \\
\hline 240 & K & 0.089 & {$[6.9 \mathrm{e}-85,1]$} & 0.16 \\
\hline 241 & $\mathrm{H}$ & 0.13 & {$[6.9 \mathrm{e}-05,1]$} & 0.14 \\
\hline 242 & k & $\theta .6$ & {$[0.021,1]$} & $9.1 \mathrm{e}-05$ \\
\hline 243 & A & $\theta .14$ & {$[6.9 \mathrm{e}-05,1]$} & $\theta .14$ \\
\hline 244 & $\mathrm{E}$ & 0.51 & {$[0.021,1]$} & 0.00014 \\
\hline 245 & $\mathrm{k}$ & 0.089 & {$[6.9 \mathrm{e}-65,1]$} & 8.16 \\
\hline 246 & D & 0.097 & {$[6.9 \mathrm{e}-85,1]$} & $\theta .17$ \\
\hline 247 & $P$ & 0.21 & {$[6.9 \mathrm{e}-05,1]$} & 0.12 \\
\hline 248 & E & 0.699 & {$[6.9 \mathrm{e}-65,1]$} & 8.16 \\
\hline 249 & H & 0.67 & {$[0.021,1]$} & $8.8 \mathrm{e}-05$ \\
\hline 250 & A & $\theta .14$ & {$[6.9 \mathrm{e}-85,1]$} & e.14 \\
\hline 251 & H & 0.13 & {$[6.9 \mathrm{e}-85,1]$} & 0.14 \\
\hline 252 & K & 0.089 & {$[6.9 \mathrm{e}-85,1]$} & e.16 \\
\hline 253 & H & 0.13 & {$[6.9 \mathrm{e}-05,1]$} & 0.14 \\
\hline 254 & $\mathrm{~K}$ & 0.089 & {$[6.9 \mathrm{e}-05,1]$} & $\theta .16$ \\
\hline 255 & I & 0.7 & {$[0.021,1]$} & $6.2 \mathrm{e}-05$ \\
\hline 256 & $\mathrm{E}$ & 0.74 & {$[0.051,1]$} & $4 e-65$ \\
\hline 257 & E & 0.68 & {$[0.021,1]$} & $7.3 e-05$ \\
\hline 258 & $\mathrm{E}$ & 0.71 & {$[0.021,1]$} & $7.2 e-65$ \\
\hline 259 & I & 0.18 & {$[6.9 \mathrm{e}-85,1]$} & 0.13 \\
\hline 260 & A & 0.13 & {$[6.9 \mathrm{e}-85,1]$} & e.15 \\
\hline 261 & A & 0.15 & {$[6.9 \mathrm{e}-85,1]$} & $\theta .14$ \\
\hline 262 & v & 0.9 & {$[0.21,1]$} & $7.1 \mathrm{e}-69$ \\
\hline 263 & A & 0.56 & {$[0.021,1]$} & 6. 00011 \\
\hline 264 & A & 0.14 & {$[6.9 \mathrm{e}-85,1]$} & 0.14 \\
\hline 265 & v & 0.68 & {$[0.021,1]$} & $7.2 \mathrm{e}-65$ \\
\hline 266 & G & 0.096 & {$[6.9 \mathrm{e}-85,1]$} & 0.16 \\
\hline 267 & A & 0.9 & {$[8.21,1]$} & $5.4 \mathrm{e}-09$ \\
\hline 268 & G & 0.59 & {$[0.021,1]$} & $9.5 e-65$ \\
\hline 269 & 6 & 0.12 & {$[6.9 \mathrm{e}-85,1]$} & 0.15 \\
\hline $27 \theta$ & $\mathbf{F}$ & 0.18 & {$[6.9 \mathrm{e}-05,1]$} & $\theta .13$ \\
\hline 271 & A & 0.14 & {$[6.9 \mathrm{e}-05,1]$} & 8.14 \\
\hline 272 & $F$ & 0.27 & {$[6.9 \mathrm{e}-85,1]$} & $\theta .11$ \\
\hline 273 & H & $\theta .091$ & {$[6.9 \mathrm{e}-85,1]$} & $\theta .16$ \\
\hline 274 & $\mathrm{E}$ & $\theta .1$ & {$[6.9 \mathrm{e}-85,1]$} & $\theta .16$ \\
\hline 275 & H & 0.891 & {$[6.9 \mathrm{e}-85,1]$} & 0.16 \\
\hline 276 & H & $\theta .071$ & {$[6.9 \mathrm{e}-05,0.47]$} & 0.17 \\
\hline
\end{tabular}




\begin{tabular}{|c|c|c|c|}
\hline 277 & Q & 0.93 & {$[0.21,1]$} \\
\hline 278 & $\mathrm{~K}$ & 0.089 & {$[6.9 \mathrm{e}-05,1]$} \\
\hline 279 & K & 8.089 & {$[6.9 \mathrm{e}-85,1]$} \\
\hline 280 & E & 0.095 & {$[6.9 \mathrm{e}-85,1]$} \\
\hline 281 & A & 0.14 & {$[6.9 \mathrm{e}-85,1]$} \\
\hline 282 & $\mathrm{k}$ & 0.7 & {$[0.021,1]$} \\
\hline 283 & E & 0.52 & {$[0.021,1]$} \\
\hline 284 & E & 0.95 & {$[0.47,1]$} \\
\hline 285 & E & 0.98 & {$[0.47,1]$} \\
\hline 286 & E & 0.98 & {$[0.47,1]$} \\
\hline 287 & E & 0.7 & {$[0.021,1]$} \\
\hline 288 & A & 0.3 & {$[6.9 \mathrm{e}-65,1]$} \\
\hline 289 & E & 0.93 & {$[0.21,1]$} \\
\hline 290 & G & 0.84 & {$[0.851,1]$} \\
\hline 291 & k & 0.83 & {$[0.051,1]$} \\
\hline 292 & k & 0.29 & {$[6.9 \mathrm{e}-65,1]$} \\
\hline 293 & k & 0.3 & {$[6.9 \mathrm{e}-85,1]$} \\
\hline 294 & H & 0.28 & {$[6.9 \mathrm{e}-\theta 5,1]$} \\
\hline 295 & H & 0.31 & {$[6.9 \mathrm{e}-85,1]$} \\
\hline 296 & $\mathrm{~F}$ & 0.38 & {$[6.9 \mathrm{e}-65,1]$} \\
\hline 297 & $\mathrm{~F}$ & 0.39 & {$[6.9 \mathrm{e}-65,1]$} \\
\hline
\end{tabular}

\begin{tabular}{|c|c|c|c|c|c|c|c|c|}
\hline & $1.7 \mathrm{e}$ & $4.5 e-65$ & & & & 0.025 & & 88 \\
\hline 16 & $\theta .16$ & 0.16 & e.15 & $\theta .13$ & 0.1 & 0.07 & .03 & 0.038 \\
\hline & & & & & 0.1 & 0.869 & & \\
\hline 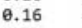 & 0.16 & 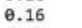 & & 0.13 & .098 & & & \\
\hline & $\theta$ & & & & 11 & & 8 & \\
\hline & 69. & 96 & & & & 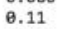 & 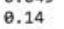 & 59 \\
\hline & $\theta .00$ & & & & & & & \\
\hline & & & & & & & & \\
\hline & 1.2 & $1.6 \mathrm{e}$ & 4.8 & 6.4 & 0.8 & & & \\
\hline & & & & & & & & \\
\hline $6 \mathrm{e}$ & $\theta .80$ & $\theta . \theta$ & $\theta . \theta$ & $0 . e^{2}$ & $\theta . \theta$ & $\theta$. & . & .5 \\
\hline & & & & & & & & \\
\hline $9 e-$ & & & & & & & & \\
\hline & 0.8 & & & & & & & \\
\hline & & & & & & & & \\
\hline 1 & & & & & & & & \\
\hline & & & & & & & & \\
\hline & & & & & & & & \\
\hline & & & & & & & & \\
\hline & & & & & & & & \\
\hline 08 & 68 & . & .001 & .6 & 0.086 & 0.085 & 0.082 & .31 \\
\hline
\end{tabular}

Supplementary Table 10: Ka/Ks values per ASR4 amino acid. First are represented amino acid position, then amino acid, w-score, confidence interval and Bayesian posterior probabilities. 